\title{
Anthropology, Tourism and Protecting One's Own: The Ethics of Representing Polynesian Cultural Identity
}

by

Marianne E. MacKinnon, B.A. Hons.

\author{
A thesis submitted to \\ the Faculty of Graduate Studies and Research \\ in partial fulfillment of \\ the requirements for the degree of \\ Master of Arts \\ Anthropology \\ Department of Sociology and Anthropology
Carleton University
Ottawa, Ontario \\ January, 2005
}

(C) 2005, Marianne E. MacKinnon 


$\begin{array}{ll}\begin{array}{l}\text { Library and } \\ \text { Archives Canada }\end{array} & \begin{array}{l}\text { Bibliothèque et } \\ \text { Archives Canada }\end{array} \\ \begin{array}{l}\text { Published Heritage } \\ \text { Branch }\end{array} & \begin{array}{l}\text { Direction du } \\ \text { Patrimoine de l'édition }\end{array} \\ \begin{array}{l}\text { 395 Wellington Street } \\ \text { Ottawa ON K1A ON4 }\end{array} & \begin{array}{l}\text { 395, rue Wellington } \\ \text { Ottawa ON K1A ON4 } \\ \text { Canada }\end{array}\end{array}$

Your file Votre référence

ISBN: 0-494-00723-0

Our file Notre référence

ISBN: 0-494-00723-0

NOTICE:

The author has granted a nonexclusive license allowing Library and Archives Canada to reproduce, publish, archive, preserve, conserve, communicate to the public by telecommunication or on the Internet, loan, distribute and sell theses worldwide, for commercial or noncommercial purposes, in microform, paper, electronic and/or any other formats.

The author retains copyright ownership and moral rights in this thesis. Neither the thesis nor substantial extracts from it may be printed or otherwise reproduced without the author's permission.
AVIS:

L'auteur a accordé une licence non exclusive permettant à la Bibliothèque et Archives Canada de reproduire, publier, archiver, sauvegarder, conserver, transmettre au public par télécommunication ou par l'Internet, prêter, distribuer et vendre des thèses partout dans le monde, à des fins commerciales ou autres, sur support microforme, papier, électronique et/ou autres formats.

L'auteur conserve la propriété du droit d'auteur et des droits moraux qui protège cette thèse. $\mathrm{Ni}$ la thèse ni des extraits substantiels de celle-ci ne doivent être imprimés ou autrement reproduits sans son autorisation.
In compliance with the Canadian

Privacy Act some supporting forms may have been removed from this thesis.

While these forms may be included in the document page count, their removal does not represent any loss of content from the thesis.
Conformément à la loi canadienne sur la protection de la vie privée, quelques formulaires secondaires ont été enlevés de cette thèse.

Bien que ces formulaires aient inclus dans la pagination, il n'y aura aucun contenu manquant.

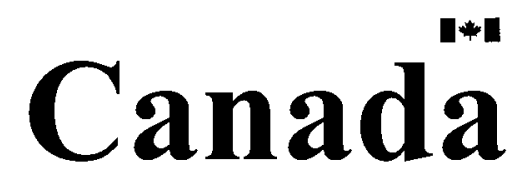




\begin{abstract}
:
Many Polynesian cultures have "persisted with few, or no, native-language speakers, as fervent Christians, and with 'modern' family structures, involvement in capitalist economies, and new social roles for women and men" (Clifford 2001:478). Can Polynesians protect themselves in power charged, unequal situations, created from the colonial carving up of the Polynesian cultural area into many individual nation-states? If so, how? And how do differently positioned authorities represent living cultures? The academic debates about cultural 'inventions' and 'authenticity,' 'insiders' and 'outsiders,' and the organic analogies implying death requiring re-discovery, revival or salvage processes, are highly contested in the Pacific, simply because these are the very analytical categories that obscure substantive issues that bind and constrain processes of social and cultural change. It is these binding processes, designed at the local, regional, and international levels of the multinational tourism and economic development aid industries, that are the fundamental components of this thesis.
\end{abstract}




\section{Table of Contents:}

1. You can't get there from here 1

2. The clash of worldviews 7

3. Through Euronesian eyes 25

4. Are tourists really guests? 35

5. Cultures on the move 50

6. Tonga and Sāmoa $\quad 68$

a. The Kingdom of Tonga 73

b. The Independent State of Sāmoa 79

7. Redefining human rights 84

8. Towards sustainability 101

9. Protecting one's own 109

10. Bibliography 116 


\section{List of Illustrations:}

Illustration 1 - Ocean Routes map $\quad 51$

Illustration $2-$ Polynesian Triangle map $\quad 54$

Illustration 3 - Settlement Timelines map $\quad 66$

Illustration 4 - The Kingdom of Tonga map $\quad 74$

Illustration 5 - The Independent State of Sāmoa map $\quad 80$ 


\section{You can't get there from here}

Emile Durkheim presented a fundamental question: How do we determine the degree of well-being, comfort or luxury that is appropriate for a human being? According to Durkheim, as a moral question, it is one that cannot be answered strictly from an economic point of view. It has to be addressed in terms of moral authority, or, as John Stuart Mill and Harriet Taylor Mill call it, the emotional realm of the superiority “custom" (Mill and Mill 1970[1832, 1851:98, 1869]), in order to understand the processes and institutions that structure the relationships between "equal beings, or between a superior and an inferior, between a protector and a dependent" (Mill and Mill $1970[1832: 73,1851,1869])$. Durkheim asserts that social change is evolutionary and ordered so that as mechanical solidarity (group consciousness) decreases, organic solidarity (individual consciousness) increases, meaning that the "substance of social life must enter into entirely new combinations in order to organise itself upon completely different foundations. But the old structure, so far as it persists, is opposed to this. That is why it must disappear" (Durkheim reproduced in Abdo 1996:122; Urry 1995:8). The state apparatus required to manage and control individual behaviour ultimately replaces mechanical/collective forms of organizing society, and institutes the new form expressed as the institutionalization of personal life, leading him to conclude that governance involved conflict at its core, especially in terms of social inclusion and/or exclusionary practices, such as the granting of certain freedoms, access to resources, and rights of political representation that can be automatically translated into legitimacy, status and authority. 
It is clear that the form of governance as implemented during the colonial era throughout the Pacific is being replicated today, but on a much larger global scale. The previous process of "colonial exploitation... varied widely, according to the resources of each area and the interests of the colonizers... to make profits from different peoples and their lands, whether through extracting wealth, using native labour, or decimating indigenous populations in order to establish settlements in their territories" (Etienne and Leacock 1980:16). Once dependence upon "goods [had] replaced goods they no longer produced or which had become new necessities... colonizers addressed their demands and their technical innovations to men, thus favoring men's access to cash, the economic dependency of women and, as a result, the emergence of the patriarchal nuclear family" (Etienne and Leacock 1980:19; see also Leacock 1980:27; Bourgeault 1983). The imposition of the colonial state to manage all this followed shortly thereafter. Capitalism has ultimately become a global exploitation system, where multinational corporations move about the globe operating freely outside their home countries in order to avoid the limitations of trade union demands for living wages, social benefits or stringent health, safety and environmental standards. The question is whether the entire globe can sustain the same level of consumption of non-renewable resources as the industrially developed 'North.'

Today, indigenous groups are up against corporate wealth and power and the state combined, highlighting the relevance of Durkheim's work once again. Durkheim's attention to conflict of social forces out of which "individual freedoms are born" (Durkheim reproduced in Abdo 1996:152) means that the state should not be viewed as merely a regulator and administrator but an entity that should be required to establish the 
conditions for conflict resolution in order to address the main question of determining the degree of well-being a society should experience. Herein lies the problem today: "public agents... social workers, health care practitioners and police... trained in 'multicultural awareness" (Vertovec 1997:58) provide a management and service delivery role, not a political one that would allow for the inclusion of previously silenced voices in the decision-making frameworks of society. The management function performed by individual governments cannot guarantee that the needs of all citizens in the world will be met or even take into account the needs of citizens outside their own borders, simply because the management function is significantly constrained by fiscal dimensions, compounded by both data collection and measurement problems as they relate to the institutional response systems and the organizational functions of policy implementation and conflict resolution procedures (see Keller 1996:18). This management function of government is quite different from the political function of determining the degree of individual well-being a society or a group of societies wish.

Zincone and Agnew (2000) argue, using a Marxist 'forces of production' framework, that there are short-term distinctive global incentives to retaining political regulation at the level of nation states and long-term global 'taming' processes that transfer political regulation beyond the state. They expect that, due to the demographic character of rich countries, they will require significant immigration in the near future (Zincone and Agnew 2000:14-15); hence they have a vested interest in implementing globally their own ideas of democratization of political rights, expressed solely in terms of electoral democracy in the developing world. The implication is that the developed world will eventually close their borders to the economically poor countries to protect 
jobs, etc., in rich countries. The economic globalization framework, as an attempt to equalize politics and economics of individual nation states, prevents the redefinition of both politics and economics along human rights lines. Political challenges, then, to the international bodies established to mediate conflicts between militarized individual states do not actually threaten the structure of the bodies themselves, just their daily functions. The historical ideological and structural distinctions drawn between the national and international, and the economic and the political, continue today, and these management forms of analysis comprise significant barriers to social change. The economic and political distinction is clear within the framework of the Universal Declaration of Human Rights of 1948 that expressly separates rights related to “...markets [versus] economic and social rights... [and] electoral democracy [versus] civil and political rights" (Donnelly 1998:159). But it is also clear that all classes of human rights need to be enforced globally rather than managed locally.

Indigenous languages, traditional religious beliefs, kinship arrangements, etc., may appear to be critical 'organic' elements of a culture that has been lost, transformed, and/or combined in novel ways, but Polynesian indigenous cultures have "persisted with few, or no, native-language speakers, as fervent Christians, and with 'modern' family structures, involvement in capitalist economies, and new social roles for women and men" (Clifford 2001:478). In this thesis the relevant question is whether, and how, Polynesians can protect themselves in power charged, unequal situations, created from the colonial carving up of the Polynesian cultural area into many individual nation states, and how differently positioned authorities represent living cultures. As such the academic debates about cultural 'inventions' and hence 'authenticity', 'insiders' and 
'outsiders,' and the organic analogies implying death requiring re-discovery, revival or salvage processes (see Grünewald 2002:1005) are highly contested in the Pacific, simply because they are the very analytical categories that obscure substantive issues that bind and constrain processes of social change. Hence the binding and constraining processes designed at the local, regional, and international levels of the tourism and economic development aid industries are the fundamental components of my analysis (see Wilbanks and Kates 1999).

Tonga and Sāmoa provide a best case scenario to evaluate the effects of 'others' defining and shaping Polynesian cultural identity. Until very recently Tonga and Sāmoa were well off the beaten travel track in the South Pacific; visits involved an expensive side trip from either Fiji or New Zealand. The recent expansion of the largely foreignowned tourism industry into budget tourism is the latest incursion into Tongan and Sāmoan local communities, bringing guests and hosts into close proximity. If basic human rights removed during the colonial era are to be restored, it has nothing to do with ensuring Tongans and Sāmoans have the space to negotiate their cultural identities. They should not have to answer to anyone in the first place. Rather, it is a matter of those who have built the constraints around the construction of cultural identity abandoning the myths about who and what Polynesians are and their assumed right to decide their future for them. This raises three important questions:

1. How will the indigenous majority populations respond to the new incursion into their local communities that places the guest and host in much closer proximity? 
2. Are the contemporary tourism representations any different from the historical conclusions drawn about Polynesian peoples by the explorers, traders, colonial administrators, missionaries and other visitors of old?

3. Is there an opportunity now for significant indigenous input into the tourism industry that could ensure the future protection of their environments, cultural values, indigenous knowledge and cultural identities as they wish them to be?

The following three chapters, 'The clash of worldviews,' 'Through Euronesian eyes' and 'Are tourists really guests?' emphasize that there are two fundamentally different ways of seeing the world that also shape possible responses to the 'other' and structure the processes for social change. These two distinct ways of seeing the world cannot be confused with empirical or anthropological knowledge or the history of social, economic, political, or other types of events. 'Cultures on the move' provides examples of how the historical record has been manipulated in support of the dominant worldview or way of seeing the world. 'Tonga and Sāmoa' illustrates how the dominant worldview is expressed today in the tourism literature supporting economic expansion. The unique set of presuppositions, beliefs, and values are indeed partial, inconsistent and perhaps held unconsciously, but nevertheless they are the very sets of moral beliefs and value systems used to interpret and represent the 'other.' More importantly, awareness of them, allows us to strategize to achieve our own future aspirations. As such, the three final chapters, 'Redefining human rights,' 'Towards sustainability' and 'Protecting one's own' offer an indigenous view of those interpretations and representations as constraints placed upon Polynesian peoples, Tongans and Sāmoans in particular, that prevent the activation of positive political, social and legal changes in their countries. 


\section{The clash of worldviews}

A worldview, then, is a moral judgement, an overall personal evaluation, about the quality of your life and those around you. But this individual evaluation is significantly influenced by culture hence there are two distinct levels of analysis, the individual and the cultural. This means the process of analysis is not just a simple matter of picking a theoretical perspective, defining the scope and level of analysis, and then describing it. "One cannot successfully counter a myth [as in moral judgement] with a scientific theorizing... The disinterested scholar, who may also possess moral preferences... has a serious problem in devising alternative categories of explanation" (Peter Berger 1987:viii). A discipline tends to be dominated by a theoretical perspective and way of doing research and preparing documentary evidence, and therefore can be seen as conventional and consisting of answers to questions deemed appropriate to ask at a particular point in time and place. History, as such, forms an integral part of the total fund of knowledge available to any discipline and "is not what has actually been preserved in popular memory, but... [that which] has been selected, written, pictured, popularized and institutionalized" (Hobsbawn and Ranger 1983:13; Karp 1991:378; see also Zinn 1990). Ideologies are constructed systems of ideas that reflect and perpetuate specific interests that, when taken for granted, or are unquestioned, come to be seen as 'natural.' The knowledge accumulated or the ideology at this stage becomes the dominant perspective or worldview. Accordingly "usage and conventions which are at last being questioned but have by no means been overcome, [forces one to acknowledge that] the social presence of a woman is different... from that of a man" (Berger 1972:45), 
as is the case for indigenous peoples in general. In this context the word 'discipline' implies a process of becoming enculturated, defined by Spiro as internalizing or automating cultural propositions as personal beliefs that are thought to be true, proper, or right (Spiro 1984:326). And they are different for men and women, and for European or western and indigenous peoples (Agrawal 1995:432; see also Hviding 2003:52-59).

Practitioners within disciplines do change their theoretical perspectives, research approaches and ways of writing about their subject matter. But they remain within a kind of binary, "a fundamental human experience... [an] aesthetic masculinity" (Rose 1993:99), often being forced to choose between sometimes two incompatible theoretical perspectives. The binary is a competitive social process revolving around what is important to look at and how one goes about looking, highlighting "that the claims to knowledge we can defend by our impressive scientific successes do not argue for a unified world or universal order, but rather for a dappled world of mottled objects" (Cartwright 1999:10; Agrawal 1995). In this case the roles of those excluded from the creation of recorded history and their status as victims and silent witnesses, cannot be changed very easily. History, that is, the historical record, can only serve as a guide to the context in which usually men have spoken and to highlight the necessity for a quest "to uncover the history of 'the people without history" (Wolf 1982:xvi; Thaman 2003:12; see also Zinn 1990:4). The task of improving the relationship between the dominant perspectives and the silenced perspectives points in the direction of a different kind of frame of reference - i.e., a more cooperative partnership. Without a cooperative venture between men and women and vastly different cultures, there are only two possible outcomes. 
The first is retaliation, by matching or exceeding the levels of violence directed at those deemed to be inferior and hence silenced throughout history. The second is to “acknowledge authority [and seek] equality of service” (Evans-Pritchard 1965:56), which simply means coping with inequality and violence, which oppressed groups have done extremely well throughout history and continue to do so today — some better than others. The structural competitive system we work within implies resistance at every level to the dominant ideology, and it is a masculine world. We can challenge it, but we nevertheless have been restricted to individual battles or small incremental political and legal battles that ensure we never get to resolve the real issue of whether people are entitled to human or environmental rights in the first place.

The power imbalances implied by competition are often understood in terms of physical coercion only, defined specifically in terms of one individual or a nation state (as an independent political entity) compelling others to do what s/he/they want them to do. Correspondingly, indigenous or minority groups subject to coercive attempts such as:

1. acculturation, or the process of a subordinate culture borrowing ideas and practices in order to modify or replace traditional ideas and practices of their own choosing,

2. syncretism, or the process of mixing elements from multiple cultures, and

3. assimilation, where distinctive cultural features of one culture are expected to disappear over time, are generally automatically considered to be in a position to resist and demand that their individual human rights or their cultural rights be upheld and protected. The argument generally goes that those seeking rights have a responsibility to present their case and 
then to defend their own rights, whether they are specific to individual rights versus group cultural rights, political and civil rights versus socio-economic rights (e.g., jobs, food, housing etc.), or nation state rights versus indigenous self-determination, or not. However, understanding the relationship between the state and its cultures is not just about engagement in the negotiation process, establishing the existence of coercion or proving a breach to peoples' rights - it is a question of the process of seeing and who has the right to decide what view will be seen by others.

"It is seeing which establishes our place in the surrounding world; we explain that world with words, but words can never undo the fact that we are surrounded by it. The relation between what we see and what we know is never settled" (Berger 1972:front cover). One learns the correct language of communication, but this does not make it neutral. And herein lies the problem: the structures of communication also define how resistance to the dominant ideology, expressed in either the written or verbal form as the language in common use, will be expressed in response to it. "Since those in positions of power are, by definition, the very people who create and define the 'up-to-date' expertise, their access to the latest information, skills, and techniques makes it a self fulfilling prophecy" (Crewe and Harrison 1998:97). Berger notes, in relationships between men and women that the woman is viewed quite differently, the "essential way of seeing women, the essential use to which their images are put, has not changed.... the 'ideal' spectator is always assumed to be male" (Berger 1972:64). Hence Berger suggests that one only needs to transform the woman in any drawing into a man to "notice the violence which that transformation does. Not to the image, but to the assumptions of a likely viewer" (Berger 1972:64). It follows then that no description can be treated as though it 
were an objective representation "disassociated from considerations of power" (Osborne 1998:432). Thus it is possible to use the same categorical analysis to deconstruct the place of indigenous peoples in general, as that used to deconstruct the place of women.

The encounters between Europeans and the inhabitants of the Pacific and other lands "was in reality an exercise in extreme power... an event in which the Europeans assumed power over the native inhabitants, over their lands and their persons" (Rivera 1992[1990]:8, emphasis in original; see also Garland 1999:78). But the feminine is not always ignored - it is a matter of strategy: "European women were essential to the colonial enterprise and the solidification of racial boundaries that repeatedly tied their supportive and subordinate posture to community cohesion and colonial peace" (Stoler 2000 [1989]:454). Violence, then, is implied and written into history by how men talk and write about what women think and feel (see also Mill and Mill 1970 [1832, 1851, 1869]). The historical value of women and an indigenous culture, therefore, relates to what is reflected by the underlying system of ideas about the world that is seen to be 'natural.' The classification of being 'natural' points directly to the "feminization of what is looked at" (Rose 1993:88) and it becomes important to recognize that there are two specific dimensions: the association to nature and the association to the feminine (see Zweers 2000:23-55).

These two dimensions are critical because they characterize the dominant ideology leading to women's, as the feminine, and indigenous peoples' human rights being completely denied or significantly controlled by implementing one-dimensional concepts of liberty, equality and human rights involving the emotional realm of the superiority “custom" (Mill and Mill 1970 [1832, 1851:98, 1869]). Women and feminized 
cultures are confined and controlled in another important way, by mechanisms of permitted 'resistance' and 'ways of expressing dissent' as defined by others. The various approaches to studying resistance movements are indeed "motivated by quests to understand, to appreciate, and to manipulate... [but] the context and background... [often remains] passive... [rather than an environment where] human, natural, and spirit worlds are blended in ways not conceptualized in the scientific" (Norwood and Monk 1987:3; see also Bowman 1997:46). This leads to the subject of study becoming abstracted, blamed, and controlled in the name of science. Therefore, the question becomes whether reconstructing the writings about the inhabitants of other lands, embedded in the historical, academic and governance records, changes the dynamic of removing peoples human rights and taking their lands, increases our knowledge by adding new explanations, or just opens the way to justify conquered peoples' continued exclusion by sharing the blame with them.

The quest to understand is actually independent of specific/isolated and individual historical accounts; rather, it is dependent upon the potential to abandon myths about the relationship between men and women and between Europeans and Polynesians, and the ability to determine or to define who has the right to decide what is important about the specific relationship. Looking specifically at the scientific endeavour, the idea that science itself is constrained by the failure to recognize that "our beliefs about the structure of the world go hand-in-hand with the methodologies we adopt to study it" (Cartwright 1999:12) becomes critical. Hence, the reaction and counter-reactions to the myths help explain the structural (or institutional) changes over time but these explanations do very little to assist or encourage the development of new and innovative 
methods, techniques and procedures for studying the relationships between nature and humanity. To determine why women and indigenous peoples are excluded from academia and governance practice, subsumed in the concept of a nature that can be conquered, requires that an attempt be made to highlight the underlying ideas used to describe women and indigenous peoples. By doing so, the way indigenous peoples have been viewed, judged, processed and controlled in the past is exposed, providing a comparative baseline upon which contemporary descriptions, such as those produced by the tourism industry, can be compared, thereby highlighting potential avenues or opportunities for Polynesians to gain benefits more directly.

As such the efforts made to reconstruct the history of women that depict women positively forces one immediately to confront two major assumptions: why women scholars and writers were considered to be rare, unique, eccentric, and exceptional, and at the same time why their writings were considered to be merely fine 'stories' that did not represent an accurate, or true account of their observations. From "the fourteenth century onwards, western women... [wrote] accounts of their travels... ignored by... critics and publishers alike" (Mills 1991:27) but their writing was also "problematic because, although... widely read at the time of... publication... [they were] not considered within critical studies of colonial discourse... [nor] analysed as textual artefacts, but rather as simple autobiographies" (Mills 1991:4; see also Gardner and Lewis 2000).

Therefore women's writing, production, and reception had to be negotiated in very different ways from that of males. Mills contends that the ideas of resistance and silence within this discursive framework defined what could be said and by whom, as a necessary aspect of the power relationships between men and women that significantly 
influenced the subject position of the writer, indicating that gender concerns cannot simply be added as an ingredient to current disciplinary and theoretical frameworks. When looking at women's contributions to science, one has to make a concerted effort to ignore the 'automatic' or 'natural' dominant ideological position that assumes women are rare, exotic, unique, etc., placing their accounts in an inferior position. But these very constraints surrounding women's writing make it extremely difficult, if not impossible, to evaluate the past, simply because in the end the record that was produced was a judgement based upon either the negotiated writing of the woman and her publisher, or her publisher's own opinion and practice.

Thus history speaks more to the position of women and indigenous people as seen by men and European scholars and the social structures as a whole (Evans-Pritchard 1965). The problem is accentuated by emphasizing structural forms of analysis. For example, Ortner (2000[1974]), using Levi-Strauss' proposition that humans conceptualize the world in binary opposites (e.g., mind/body, nature/culture, men/women, etc.), argues that women are universally devalued because every culture "is engaged in the process of generating and sustaining systems of meaningful forms (symbols, artifacts, etc.) by means of which humanity transcends the givens of natural existence, bends them to its purposes, controls them in its interest" (Ortner 2000[1974]:359), thus placing women who are "naturally" (Ortner 2000[1974]:361) closer to nature, having inherent knowledge of nature, in a mediating position in the culture-nature binary. Hence "the result is a (sadly) efficient feedback system... [where] aspects of woman's situation (physical, social, psychological) contribute to... institutional forms that reproduce her situation" (Ortner 2000[1974]:367). But because 
this argument begins and ends with a cultural universal idea of subordination, the irony is that one cannot be a mediator outside the competitive system so described, and a participant inside it, at the same time. Women are compared to other women, leading to accusations of women creating their own subordination, rather than viewing women's accounts as another dimension of a total description, highlighting that there is a "complex transcoding of femininity and nature in the field of vision" (Rose 1993:94). The visual power of fusing beauty, sexuality, fertility, and landscape, has the effect of making people "vulnerable to the desires of men... the imagined and desired... is offered to the (implicitly masculine) spectator" (Rose 1993:96-97). The dilemma confronted by the feminized 'other,' within such a binary opposite pattern of human interaction, is how one goes about changing a universal pattern of thought, i.e., male superiority, and the violent expression of it. The specific, or particular, historical reconstruction is insufficient to explain such a universal pattern of human thought, especially since the new meanings constructed are time and place dependent.

The New Zealand movie, 'Whale Rider,' (Ihimaera 2002) is an attempt to counter the contemporary argument that Polynesians had a significant amount of agency, perhaps not exactly equal to Europeans, but that Polynesians in general welcomed the cultural changes introduced by Europeans by virtue of their voluntary participation in New Zealand's treaty processes. 'Whale Rider' is based on a best-selling book published in Māori in 1987, titled Te Kaieke Tohorā, by Witi Ihimaera, the first Māori novelist ever to be published in New Zealand. In this contemporary re-telling of a Māori legend, a young girl must challenge both her grandfather and a thousand years of tradition to fulfill her destiny. Although based upon one Māori origin myth, the basic story line has been 
modified to fit the contemporary world: thus the critical Christian category of a male heir to the throne stands in stark contrast to the Polynesian worldview with regard to the transfer of power ('mana') from a Chief to 'his' successor and the valuation of women and children in general. The movie also challenges many other contemporary understandings of what Māori culture is, but here, the contemporary valuation of women and their ability to hold 'mana' is of particular interest. How this dimension is understood also structures the representations that can be made in the tourism industry that affect indigenous people's ability to participate equally in social and political life.

The basic movie story line is that in a small New Zealand east coast village, in every generation, a male heir born to the Chief succeeds to the title of Chief. Koro (this is actually a title of respect translated as Sir, old man (elder), but used as a name throughout the movie) is the Chief. His eldest son, Porourangi, fathers twins - a boy and a girl. But the boy and his mother die in childbirth. The surviving girl is named Pai or Pikea after the original whale rider ancestor (according to the origin myth, their first ancestor arrived on the back of a whale). The grief-stricken father leaves her with her grandparents and leaves the country, refusing to accept the succession to Chief. The problem is that Koro believes that a male heir is required, and that his son has abandoned his birthright by refusing to produce another male heir, leaving him without a successor. He blames Pai for the death of her brother (the firstborn male heir) and believes that she is a curse upon the whānau (an extended family). He hopes to reverse the curse and provide for the next Chief by gathering all the young first-born males of the whānau together for training and the selection of the next Chief. Pai is denied the right to this training because she is a girl, and is denied a place of honour on the marae (meeting area 
including the land and buildings). But all the young males fail the test set for them and Koro loses his 'mana' (a chief's power, symbolized by a whale tooth necklace in the movie). Things become so bad that both Koro and Pai call upon the whales that subsequently come to shore and beach themselves. Koro is sure that their predicament is as a result of the curse of Pai and that the presence of the beached whales signals an apocalyptic end to the whānau.

The contemporary European/western understanding of Polynesian gender relations and the concept of mana, in particular, as it pertains to chieftainship, are used here to contrast the cultural differences with regard to positioning and distribution of power and control of women in the two cultures of the Pacific. Koro claims that chiefly succession is by birth of a first-born male and that mana can only be transmitted between a male Chief and his successor. The historical record supports a reading that women were devalued in relation to men excluding them from becoming a chief and at the same time acknowledges that seniority determined by position (first-born descent), outweighed the gender distinction (see Firth 1957:7). This contradiction in the historical record cannot actually be clarified much further, other than to perhaps argue that seniority did not include the most senior position in society, i.e., the position of chief. Claudia Orange (1987) points out, that it is impossible to tell exactly what the status of women really was, because, even in the Treaty of Waitangi, only two negotiators (Henry Williams and the missionary team of Taylor and Puckey) allowed high-ranking women to actually sign the treaty. Where women were denied the right to sign, their 'husbands' also refused to sign, even on the woman's behalf (Orange 1987:90). The word husband is in quotes because 
negotiators often selected a female chief's representative without regard for the social position of the chief or the selected representative (husband).

Seniority by descent (i.e., from a ranking family and first-born) is also described as being ritually honoured. All firstborn, male and female, were considered 'tapu' (a condition of mana, see below) and those of the ranking family were titled and held considerable political power or played important behind-the-scenes political roles (Best (1924) and Goldman (1970) cited in Shore 1989:173). And there are descriptions of social status in general being determined by descent through the female line, (i.e., a matrilineal descent pattern) especially among high-ranking families e.g., a chiefly line or large land holdings, in which case the mother was far more important than her husband. Women were described as being important for another reason: it was the only way of distinguishing the relative status of half-siblings, a family pattern common throughout Polynesia (Shore 1989:173). In the movie, Pai's mother dies and she is raised by her fathers' parents. But this living arrangement did not formally change her social status as it does under European adoption procedures.

Ignoring the imposition of the European patriarchal family and adoption procedures throughout Polynesia, a possible explanation of European confusion of both traditional gender roles and chieftainship systems probably stems from the fact that 'mana' has multiple meanings. As one of those foundational ideas, it is applied to numerous and differing objects, institutions, actions, and symbolic productions, and in any combination of ways, throughout Polynesia, and, as Firth (1970[1940]) argued, throughout Oceania (Firth 1970[1940]:318). For example, Sahlins in his comparative analysis of Hawaii and New Zealand highlights a principal difference between the 
cultures of Hawaii and New Zealand. The difference relates not to the overall foundational idea of what constitutes knowledge and power, but to the forms of institutional hierarchy; in Hawaiian mythology and practice this is expressed through chiefs, and in Māori mythology it is expressed through "corporate tribal groups" (Schrempp, cited in Sahlins 1985:195). Western analysts may view mana as some kind of general and abstract force, but as Shore (1989) points out, Polynesians "seem to emphasize a variety of particular powers, or at the very least specific manifestations of a general concept" (Shore 1989:138) that remains a central idea in the Polynesian worldview, despite the lack of literature on the topic, incorrect and detrimental conclusions, and the impossibility of reconstructing the past (see also Keesing 1987:168). As such, any institution, event or object is highly susceptible to misinterpretation, particularly if the European universalizing tendency expressed in terms of "the 'insider' perspective coupled with the extreme relativist position" (Lawson 1997:162) is applied, making it inevitable that the foundational idea will be ignored.

Therefore in relation to the possession of spiritual power and/or specialized skill and/or knowledge expressed through social and political institutions, such as chieftainship, 'mana' establishes the boundaries of how spiritual power and knowledge will be used and transmitted. Firth (1970[1940]:318), Keesing (1987:168), and Shore (1989:138) all note that there is a general lack of adequate or accurate literature about the concept of 'mana' simply because early original research records the European meanings and understandings of terms, such as 'mana,' 'tapu' and 'noa,' rather than exact translations. They also note that it is relatively easy to pick up the difference between translations if one considers "whether a native would really have thought out and 
performed an experiment in the way... [described]" (Firth 1970[1940]:319), thus raising doubts and suggesting fabrication occurred in order to prove an accepted colonial understanding.

Tapu and noa are, in fact, the alternatives of mana rather than being binary oppositional forms of mana as most of the literature suggests. Stripping the binary oppositional understanding from the descriptions identifies that the tapu state is consistently described as the condition of being contained and bound: a condition that controls mana, a state in which mana (formal power such as chieftainship) is ritually tiedup through the imposition of sacred forms and symbols. Thus tapu is characterized and expressed by immobility, inactivity, passivity, binding, and the divine. Likewise, noa is consistently described as the condition of being free, unmarked, unconstrained, unguided, open and clean. The state of being noa characterizes everyday life in that it is considered to be informal, casual, haphazard, not having a formal purpose, and includes states where there is an element of an imperative to action e.g., food and sex. Confusion is evident by the colonial binding of women especially in relation to sexuality, allowing for incorrect conclusions to be drawn about the present and the future. For example, Ortner $1981: 376$ cited in Shore 1989:173) suggests that the effect of belief systems such as 'mana' has been extremely detrimental to women by turning women into symbolic objects, or sexual bait to attract men. However, this understanding is significantly flawed and detrimental to Polynesians, Polynesian women in particular, because the descriptions upon which this statement is based are comprised of European understandings of the concept. Nevertheless all descriptions, whether they are original or constructed, true or false, identify something important anyway. 
The representations of unique cultural identity, such as those noted in 'Whale Rider,' have normally been addressed in the Pacific as a battle between external nation states and internal independence movements (see Linnekin 1990:158; de Rota Monter 1998:125). Since independence struggles have not occurred in Tonga or Sāmoa, the concepts of 'cultural identity' and 'tradition' have vastly different meanings, in that they are "deployed not so much in defence of highly prized aspects of unique cultural identities, but in defence of elite power and privilege against growing demands for accountability in government as well as more extensive opportunities for participation by those without traditionally derived political or social status" (Lawson 1996:5). The question then is whether the codification or institutionalization of specific 'traditions' within the western notion of a nation state alters the dynamic nature of those institutions and practices that comprise a 'tradition.' Hence, the claim to indigenous traditions on behalf of the nation state revolves around whether mixing actually occurs or whether there is a specific selection of cultural traditions in accordance with predetermined criteria. As Thomas (1991:36) notes, these kinds of issues directly involve positioning and control of peoples and their cultures. One side (usually the subordinate culture) sees outcomes of the relationship as being imposed from the 'outside,' and the other (usually the dominant) seeing the process as having been negotiated fairly.

The 'Whale Rider' specifically highlights the problem created when there is a clash between cultural traditions and the composite or selected 'traditions' designed are accepted as true 'traditions.' This basic problem is then compounded by representations, such as those made in the tourism industry, that are said to benefit the whole country in terms of various economic benefits. And an identical representational problem exists 
between researchers and their subject(s). As such, an investigation of these constructed 'traditions' and their impact upon cultural identity within the tourism industry and the research project raises specific kinds of methodological problems. The investigation itself involves deciding between privileging either the 'insider' or 'outsider' perspective as the central component of the description and the projection. In addition, the Boasian notion of cultural relativism (i.e., that there are no universal standards of analysis so that cultures need to be evaluated on their own terms), certainly valuable in countering racist and sexist ideas, also poses an essentialist problem (i.e., that positions and concerns are conceptualized and described in terms of existing accepted theoretical methodological ways of doing things) in the contemporary analytical context.

Marvin Harris (1979; see also Headland et al., 1990 for the debate) argues strongly for the outsider perspective and an essentialist framework: a scientific and 'objective' analysis, interpretation and projection of cultural identity by a trained researcher, constrained only by ethical guidelines designed to protect the subject. Elizabeth Garland (1999:74), Elizabeth Harrison (2002:587-588) and many others note that, even with an increased ethical concern for the protection of the subject, there is rarely any corresponding overt acknowledgement of the role of the researcher who seeks “the soul" (Shore 1989:137; see also Firth 1970[1940]; Sahlins 1985) of indigenous peoples in order to understand, represent and project their worldview. Therefore traditional associations such as 'the people,' 'specimen,' 'informant,' or 'subject' remain problematic, "because these associations involve relations perceived as unequal or hierarchical" (Ames 1992:81). Thus an investigation and projection of cultural identity, especially one that is not one's own, has serious implications for the subject culture. 
Rather than concentrating on whether academics, researchers or governments have honourable intentions toward their subjects, and practice self-reflexivity (self assessment) and positionality (recognizing one's own position), the investigation from the subject position emphasizes that it is not the fact that a researcher practices these techniques that matters (see Hoggart et al., (2002), Limb and Dwyer (2001), and Moss (2002) for good examples), but what one does or does not do with this information. It is the end effect or result of the research or representation that identifies how and whose authority has ultimately been maintained. If the traditional associations are maintained, then clearly the meanings that are negotiated, determined, controlled and disguised within the practice of interpretation nullify the voice of the subject and privilege the trained academic voice, as Harris (1979) and others argue should be the case.

Not even the suggestion of Hoggart et al., (2002) to establish an "intersubjective dialogue" (Hoggart et al., 2002:26) in order to establish mutual understanding really changes anything unless the researcher chooses. Unless one writes down exactly what another says, one can only claim to have written down what he or she believes was said by another. As tourism develops, the ethical concern for the subject, if it is to have any practical meaning, will have to change to involve more than a simple revival or reinterpretation of the ethnographic record in an effort to provide an 'authentic' Tongan or Sāmoan; the ethical concern will have to be expressed in terms of whether the subjects' human right to decide their own destinies has been breached or not. That kind of change "will certainly create some disturbances" (Ames 1992:86) because there is a general reluctance to be, or perhaps it could be described as a fear of being, branded "eurocentic at best, or racist at worst" (Lawson 1997:162), if non-indigenous persons were to attempt 
a critique of contemporary traditions and cultural practices that are on the whole their own - especially in situations where people are seeking redress for very real grievances of the imperial past and/or because of their present marginal socio-economic position. But as 'Whale Rider' highlights, the contemporary 'traditions,' enforced either formally or informally, may not actually be worth salvaging and reproducing. And herein lies the significant threat to the dominant culture. 


\section{Through Euronesian" eyes}

I did my undergraduate work in Anthropology and Geography, and was struck not only by how different the two disciplines are in terms of epistemologies and methodology, but in how removed both of them can be from an indigenous or native perspective or worldview. The indigenous perspective is too often missing from academia as it is from governance practice. It is frequently assumed that seeing the world from an indigenous perspective is just a matter of being able to describe and translate a specific cultural group's traditional discourses, ways of thinking and creating knowledge, into contemporary Western vocabularies; or worse, just a matter of inserting a representative or two of the selected group(s) to provide information to governance bodies. As a result, decolonisation processes throughout the Pacific have repeatedly meant just that, "replacing white faces with brown faces" (Gegeo 2001:492), the point being that highly educated brown faces are actually no different from "or maybe even worse than their colonial counterparts. Their worldviews are colonial" (Gegeo 2001:493; see also MacCannell 1992:129-146). The same can be said of many contemporary disciplinary practices and discussions. This thesis, then, is not about the gaps or missing voices within recorded history, but about how and why the indigenous perspective or worldview is viewed as one best presented by non-indigenous peoples and about what opportunities exist for indigenous peoples to gain back the right to present their own perspective using their own vocabularies.

* Euronesian is a Sāmoan ethnic category meaning Polynesian and European mix. 
Being indigenous can be understood in a variety of ways, but here the term is used to conceptualize and discuss the construction, and in particular, the constraints placed upon the construction of a Polynesian identity in a rapidly globalizing world. First and foremost, and perhaps most problematically, as Ihimaera (1998:11-16) notes, the term 'indigenous' connotes subjective experience that structures the written and spoken word. Because the translated 'word' supersedes the subjective, the notion of indigenous identity as a subjective category is highly contested - there is no hard and fast definition possible (see also Cheater and Hopa 1997:208;" Turner 2002:83). Nor is there any continuity over time. Identity construction, therefore, revolves around the specific human rights issue relating to who has the right to construct one's individual identity, and who has the right to make representations on behalf of another individual, an entire culture or a group of cultures. For me, this thesis is a specific response, prompted by the particular memories of a Polynesian Māori person raised in Aotearoa (New Zealand), of what I see in the world and how I interact with it in the construction of my own identity. My hope is that this discussion will provide other individuals like me some insight into alternative self-protective measures other than those designed for them in the historical record and the strongly defended contemporary understanding of who 'you' are. Thus it is, in a sense, a story of my own identity struggles, one that calls for a short introduction to guide the reader.

In July 2000 , I was called back for the first time in 22 years to New Zealand, to say goodbye to my mother, who passed away shortly thereafter. My mother was the firstborn of a wahine rangatira (woman of rank) and a tangata rangatira (man of rank). As the firstborn of five children, she was expected to assume her position on the marae 
council upon her mother's death. A marae is the meeting area (land and buildings) of a whānau, or a hapū (lineage grouping or several extended families) or iwi (clan, tribe, nation). She did for a little while - when an elder tells you to "Get in the car. Now!" you do. She was a fluent Māori speaker — her first language was Māori — but she taught her children only English. She believed and tried very hard to ensure that we did not identify ourselves as Māori. My father, is a first generation New Zealand born pākehā (i.e., non-Māori) and the youngest of seven children. My parents' union produced three children and they legally adopted a fourth. By the time I, as the eldest, was 13 years of age we had no contact with our whānau, let alone Māori in general. We children were raised in-between the two cultures of New Zealand, not being welcome in either. At home we were pākehā most of the time, outside the home we were Māori to the pākehā and pākehā to the Māori. Only one brother chose to remain and raise his children in New Zealand. My younger brother and my sister are raising their children in Australia, and my children were born and raised in Canada. All our children, despite being raised in vastly different places, express the same sense of loss and not belonging anywhere. My daughter's heritage is constantly challenged "no... you look... white..., Indian..., Mexican..., Spanish...," etc. Needless to say, we were ill prepared to assume the responsibilities of being Māori upon our mother's/grandmother's death. In fact, I would say that there is active resistance to the very idea of being described as Māori simply because this evokes such pain.

What we (pākehā, Māori, and indigenous peoples in general) all have in common is the unspoken understanding that to be indigenous is not a good thing. This intensely negative understanding is deepened further if you are also female. In retrospect, going 
through the legal transfer of treaty land rights provided me with an important way to understand why so many painful choices were made, and why the problems my mother endured being Māori have not been, nor can they be, addressed. Each problem she personally confronted went through a visible surface change between her generation and mine, but the underlying ideas creating the problem for both of us in the first place has been reinforced and strengthened — not abandoned. As a result, we children ultimately know little about our Māori cultural heritage, and because my mother's brother, suffering from something akin to Alzheimer's, is the last living relative of their generation, I have been left with constructing our past as best I can from the Māori Land Court probate records. In our particular case, the first partition order for our whānau land claims was dated July 28, 1920, with 18 listed shareholders or descendents of Mikeara Rini, Hemo Rini, Wira Rini, Hei Rini, Repe Rini (the only female sibling), and Runga Rini. Our written genealogical record begins here. The mother of the six original Rini children and the mothers of their children (with the exception of Repe Rini) are not recorded at all. From this extremely truncated reconstruction, two specific cultural elements relevant to this thesis are worthy of highlighting.

The first relates specifically to the difference between Polynesian and European worldview in terms of the transmission of economic (e.g., land, food, shelter) and political rights (e.g., administrative and management functions of the land) from one generation to another. Firth (1957:7) devised a new Polynesian descent category (ambilateral) in the attempt to reverse what was understood to be Polynesian descent patterns at the time of European settlement. This new category is not commonly acknowledged today simply because the idea of establishing land-rights by descent-group 
membership and transferred mostly through women and residence does not exist anymore and there is no way of verifying his suggestion in the historical literature. Similarly and anecdotally, in our case, as told to me by my relatives, land rights should have been transferred only to descent-group females who remained on the land. This is also discernable as a past practice in that of the original 18 shareholders, females were allocated the greater number of individual land shares, e.g., on one of the three blocks of land, my grandfathers' sister was allocated 1108 shares to his 178 shares. Unfortunately, proving the previous descent-group pattern is as problematic for us as it was for Firth, given that the female line was completely struck from the record in every other respect and transferred to the male line in the first instance.

The actual dispersal of land rights by the British beyond that which was traditional (Firth 1957:7) required changes in both the political and legal (social) systems as well. It is impossible to identify who held and should hold marae council positions vis-à-vis share allocations because land rights were distributed based upon other criteria. For example, my grandfather's first wife was also allocated shares giving her title to holding a marae council position, even though she did not reside on the land and did not come from the same descent-group. Indeed, we now number 85 shareholders, even though several of my first cousins have not yet transferred their treaty land rights, as they are entitled to do. As my sister argues, being a shareholder does not give you anything. You cannot live on or sell the land. You can only compete for a lease, along with everyone else, to use the land. As such this form of ownership has no actual contemporary value to the individual. Today our marae council and the corporation shareholder positions (to administer and manage the land and resources) are filled by 
election among those who bother to show up at the marae or the corporation shareholder meetings.

The second cultural change relates to the difference in the organization of descent-groupings and naming protocols. The difference between Polynesian (first name carried) and European (last name carried) naming protocols is much easier to identify compared to attempts to reconstruct the traditionally fixed nature of a ranking descentgroup's connection to a specific piece of land as noted above. For example, my grandfather, a descendent of Wira Rini, and the eldest of two children, is recorded as both Hooro Wira Rini (European naming protocol) and Hooro Wira (Polynesian naming protocol). My grandmother, the seventh of eight children, Ira or Mareireira Hoani (Polynesian naming protocol) or Marerira Hoani Tatana (European naming protocol) is a descendent of Repe Rini and her husband Hoani Hapeta Tatana. The probate records document share allocations to surviving spouses and the denial of share allocations to children under the age of 5 at the time of death. Hence my grandmother and her younger sibling received no actual share allocation, the equivalent being transferred to their father (Hoani Hapeta Tatana my great-grandfather) and subsequently distributed to his children by his second wife. Given the lack of records, the first-cousin marriage of my grandparents was explained by my mother as the reason why grandmother 'lost' her allocation. I suggest that the probate records actually point to the disconnection from the Polynesian descent rules. Either way the end result was that the 'Rini' descent-group was expanded to include a portion of the Tatana descent-group for the purposes of land rights, and our treaty land rights flow from our grandfather only. He, as the firstborn of Wira Rini, belongs to his mothers' marae and hence replaced her on that marae council. In any 
event, my mother and her siblings carried forward the Wira surname rather than the Rini (European protocol) or the Hooro (Polynesian protocol) surname.

These may appear to be very simple changes in social organization, but they have profound impacts upon one's sense of belonging. The Māori Land Court probate documents only hint at the difficulties experienced in the transition from Polynesian cultural values to European ones. In effect, the European patriarchal family was instituted for the transmission of all rights (economic, political and legal/social) from one generation to another. It is, in fact, the merging of the three elements of Polynesian identity that has come to be falsely acknowledged as the traditional Polynesian 'collective' with land ownership rights held in 'common.' This European understanding has been particularly problematic for most Polynesian peoples resulting in the ultimate removal of individual human rights, especially women's human rights, and general property rights over time. In our case, the mandatory equal division of the land to all subsequent offspring and spouses has meant that our generation has to confront the legislated minimum share split. In an environment of scarce land resources this has proven to be an effective method of nullifying indigenous human and property rights. Either way the office of the Māori Trustee is the practical political and legal expression of the historically imposed 'common' ownership designed to ultimately extinguish both individual and 'common' Māori property rights. Similarly, the contemporary New Zealand government is in the process of passing legislation that will result in the annulment of Māori 'customary' treaty rights to the foreshore and seabed (see Young and NZPA 2004; Collins 2004). The British introduction of 'common' ownership ultimately 
has meant that in all practical terms, Māori are restricted to arguing for veto or approval rights on proposed future uses of such property.

Similarly the fixing of European family surnames effectively disconnected many Māori from their past (i.e., the ability to name those before you) and truncated the formation of individual identities under either culture. We children are certainly no exception. My adopted sister is actually my niece (my cousins daughter), so I imagine our experienced disconnection from Maori culture as being something similar to what happens to those who are adopted and separated from both their biological parents and their cultural origin. Originally, Polynesian names were passed through the male line, as they are in European protocols, but as noted above, in a significantly different way and with a significantly different meaning. The cultural identity difficulties encountered today all relate to the fact that Polynesian names and one's placement within a descentgroup (e.g., naming protocols, generational categories, the privileging of firstborn children, the ownership of land by women, etc.) are all important characteristics, expressions, or elements of 'mana' (see Firth 1970[1940]:317; Sahlins 1985:215; Shore 1989:137-144, 173) that cannot automatically be passed from one generation to another. A father's first name was transmitted to his children only. Correspondingly women did not forfeit their birth names or their place within their birth descent-group. Everyone, male and female, was required to build and maintain his or her own identity - you could not claim, nor could you be assigned, your father's or your grandfather's deeds. That is, until the European arrived and 'mana' was defined as something similar to 'spirituality' only. The selected substitute — 'Christianity' — remains the acceptable understanding, 
contrary to significant evidence otherwise (see Firth 1970[1940]:318 citing Benedict, Malinowski and others; Keesing 1987:168; Shore 1989:139).

The point that needs to be made here is that, when the pākehā arrived in Aotearoa, as in every other island in the Pacific, the original patterns of traditions, histories, and genealogies that frame the construction of 'mana,' and hence one's identity, could not be maintained. The difficulty, then, as the probate records that I have reviewed for my immediate family indicate, is that they do not provide, and in fact are incapable of providing, proof of how things were before the 1920 Māori Land Court shareholder allocation was made. They merely provide anecdotal evidence that, in the colonial context, important cultural forms were changed without much forethought as to the repercussions. Following what I consider to be such fundamental cultural changes (economic, political and legal/social), the European study of Polynesian cultures has ultimately rendered Polynesian peoples "people without history" (Wolf 1997[1982]:xvi). As such, the historical records of the explorers, traders, colonial administrators, missionaries, tourists of old, and even the indigenous peoples who studied and performed in Europe, record what European peoples perceived Polynesian peoples to be. In other words, Polynesian conquest, or the removal of Polynesian history, occurred at the point the new colonial story was written down and repeated. This new story was not and is not a Polynesian one. Nor does it imply that Polynesian history was a result of a merger of European and Polynesian cultural values, as is often argued in the literature today. Given my subjective perspective, the question of how and why the indigenous perspective or worldview remains one that is viewed as being one best presented by non-indigenous peoples, is the subject of this thesis. 
Constructing an identity, individually and/or culturally, in the contemporary European/western cultural context, means that Polynesian choices are structured by someone else's conception of one's history, culture and future aspirations. Hence I accept in the writing of this thesis the risk inherent in suggesting that opportunities do indeed exist for indigenous peoples to gain back the right to present their own perspective and to create their own identities, but that these opportunities are extremely limited and remain always subject to acceptance. The risk is of losing faith that things can change, of being accused of not taking responsibility for ones own situation, or of 'inventiveness' or perhaps of being 'inauthentic' in the cold light of a recorded authoritative history and an authoritative contemporary presentation of who I am. However, this is exactly the point of this thesis. If positive change is to occur, it has nothing to do with participation or negotiating future protections of island environments, cultural values, indigenous knowledge and cultural identities, but a matter of those who have built constraints around the construction of these same elements, abandoning the myths about who and what Polynesians are and their assumed right to decide their future for them. 


\section{Are tourists really guests?}

Capitalism has become a global exploitation system where multinational corporations move about the globe operating freely outside their home countries. As such, a distinction has to be drawn not only between where tourists come from and where they go when they are on holiday, but also between the sending and receiving countries and between the industry and the receiving or host countries. The tourism industry itself, is embedded within the global political economy hence, "the nature of impacts depends on facts such as the number of tourists to residents; the amount of contact between locals and tourists; whether tourism is the main industry or one of a number; the kind of tourism (e.g., elite; explorer or drifter; mass; charter); the demographic make-up of the local community; [and] the degree of involvement in the industry" (Craik 1991:89). Given these practical business and marketing aspects combined with the functional characteristics of tourists, the nature of impacts underlies the political necessity for host populations to "orchestrate their own emergence from behind immense veils of misunderstanding and... prejudicial practices..." (Hollinshead 1996:309; see also Hardy et al., 2002; Hunter and Green 1995) raising the question, are tourists really guests? Shifting the onus from the host to take self-protective steps, Brown (1998:99) wonders why such a multi-national industry does not implement a more cooperative approach on its own, as a practical way of doing business, noting that to do so formally would automatically require a shift in analysis as well.

The shift in analysis, then, corresponds to the more general changes brought about by the "globalization of development" (Hunter and Green 1995:36; Edwards et al., 2000) 
that has occurred simultaneously between various interrelated groups in various ways depending upon the form of development in any one location. Thus it is clear that tourism impacts can be defined either positively or negatively depending upon many internal and/or external circumstances and interests. The problem of evaluation occurs because much of the past and current research is travel industry sponsored and heavily concentrated upon producing favourable results and maintaining economic growth in particular locations. To counterbalance this history, a number of writers have opted for describing negative local impacts only, stripped of the larger context of tourism development. And yet others, (see Hardy et al., 2002:488; Holden 2003) note that the historical context of sustainable development and the shift to sustainable tourism signifies a change in perception indicative of more fundamental changes to the nature of tourism rather than to changes in decision-making, i.e., identifying stakeholders versus including the local voice in decisions.

It is argued that the tourism industry "constitutes one of these major contemporary forces of change by providing the most significant means of direct large-scale physical contact and cultural exchange" (Terkenli 2002:227). Setting aside the problematic concept of cultural exchange, tourism is actually highly vulnerable to internal and external shocks not only directly from economic downturns, natural disasters, disease, socio-political turmoil, crime, terrorism, etc., but also from secondary effects such as a decline in tourist volumes due to perceived risks to personal safety and/or peaceful conditions that can generate significant income losses (Sönmez 2002:164-165). Host destinations are not only burdened by these 'normal' concerns, they must also be concerned with their political relationship with the tourist-generating countries. But "it is 
best not to view sustainability in just management terms involving many stakeholders but also to realize that for tourism, the global and the local is a dyad acting as a dialectical process" (Teo 2002:471, emphasis in original). The 'other' as always being a part of the "leisure and tourism activity of dominant cultures" (Wearing and Wearing 2001:152), is a part of a relationship that revolves around control not cooperation, hence reinforcing dominant culture superiority. At the same time it allows the formal exclusion of the 'other' from theoretical analysis.

Tourism, as a specific focus of study in the social sciences, is relatively new, and most of the current themes in the literature, such as globalization, technological change, entrepreneurship, trans-national corporations, less developed countries, organizational structures (i.e., small versus large firms), the labour process in general, welfare state restructuring, knowledge production (e.g., research, educational systems) etc., overlap several disciplines that also use ethnographic and cross-cultural approaches. As a result, the extensive tourism literature, whether the evaluations are based upon dependency, modernization, life cycle, local agency etc., theoretical models, is overwhelmingly onesided, highlighting a significant gap between indigenous knowledge (Hviding 2002: 52) about their communities and western economic development goals in host destinations. This calls for a rethinking of conventional approaches to cultural identity.

Following WWII tourism grew rapidly, and is now the largest global industry in terms of revenue generation. Indigenous owned and controlled tourism operations are a very small part of the tourism industry in all Polynesian countries, thus structuring the analytical host destination in a specific way. The trouble with tourism studies is that the staggering expansion of the industry around the world has produced "an enormous record 
of instances, case studies and variations.... dominated by policy led and industry sponsored work so the analysis tends to internalize industry led priorities and perspectives" (Franklin and Crang 2001:5; see also Brown 1998; Rojek and Urry 1997). In addition, work, travel and leisure are assumed to be universal human 'needs.' This understanding is then applied equally to both 'guests' and 'hosts.' Diagnostic tools such as the four Hs: 1) Habitat (geography), 2) Heritage (ethnographic traditions), 3) History (the effects of acculturation), and 4) marketable Handicrafts, contrasted to the four Ss (sun, sea, sand and sex) of the classic tourism literature designed for the mass drifter types of tourism, (Smith 1996) are developed without considering what Milne and Ateljevic (2001:376) call a 'top-down' theoretical and methodological process or the political nature of the tourism industry itself (Mosse 2001:159). In such a way, theory and ethnography are effectively separated, a process that is unique to both anthropology and tourism studies. This unique analytical feature reflects the influence of the master ethnographic texts and is a consequence of abstraction, including concepts such as "structure, ritual, myth, descent, hierarchy, and the like" ((Marcus 1988:69) that take on a life of their own, often retaining their original meanings but in a disguised or modified form.

It is this ethnographic feature that structures the complexity and nuances of the tourism industry and anthropology as a whole at the local, regional, national and international levels. Combining this feature with cultural commoditization, also an economic development process that has "historical and conceptual origins that considerably predate the rise of tourism" (Linnekin 1997:217) also identifies the problematic aspects of core concepts such as the exotic and the primitive in western 
constructs of ethnicity, tradition, authenticity, and identity used to promote and endorse certain types of cultural representations. These processes are described by Bowman (1997:46-47) as a specific kind of latent western cultural construction upon which the discipline was founded (i.e., having the "prerogative to identify all others," see also Gupta and Ferguson 1992:7) and ascribe western social and economic values to tourism providing the tools for the management of both hosts and guests. As a result statements such as, "by 1991 tourism... had become the world's largest employer" (P. Quick 1991 cited in Smith and Brent 2001:9) are made without raising the additional questions about the kinds of jobs being created or questions about who (i.e., foreign workers or locals) will fill those jobs. Also hidden is the fact that indigenous enterprises in host destinations are insignificantly small, compared to the hundred plus room hotel complexes built by international and often multinational corporations, and it is arguable as to whether this is likely to remain so precisely because of the required trade-off between cultural values (e.g., the assumption that indigenous people have 'collective' cultural histories and therefore 'collective' future aspirations) and individual western economic performance.

The 'ethnographic present,' especially with respect to the issues of time, authenticity and ethnicity as significant variables of study for both anthropology and the tourism industry, are important because the descriptions provided about indigenous cultures fix a specific time frame that then becomes static within the ethnographic research project and/or the representations made in the tourism literature and travel brochures (Urry 1995:17; see Smith and Brent 2001; Bowman 1997; Crew and Sims 1991). The ethnographic interpretation process critical to this thesis is one that is assumed to be an authentic description rather than an intentionally designed text that 
hides or disguises ongoing internal processes of change producing negative impacts upon host destinations. Within the ethnographic interpretation process, the texts and sub-texts produced as a whole reflect 'outsider' perspectives (i.e., the tourist economy, their age, gender, motivations, attitudes, etc.) rather than those of the 'insider' host destination. Berno (1996) suggests that the confrontation between indigenous and western conceptual frameworks can be viewed through the lens of etic and emic approaches to cross-cultural research but that "it is imperative than one does not make the assumption that one's own etic-emic concepts are necessarily true for any other given culture" (Berno 1996:378). Hence understanding this dimension of the ethnographic record is critical to the evaluation of contemporary cultural conditions and to the definition of adequate strategies for the future protection of cultural identity.

The academic study of tourism in anthropology was conceived at the 1974 American Association meeting and the subsequent publication of the conference papers compiled by Valene Smith in Hosts and Guests: The Anthropology of Tourism in 1977. This publication is recognized as being representative of research focused on the impacts upon host cultures, using the tourism discourse of production and consumption of destinations and attractions. The second edition, published in 1989, at a time when "tourism research was considered frivolous" (Smith and Brent 2001:8), comprised a reevaluation of research in the first edition that subsequently created a database of various kinds of tourism impacts. Smith and Brent suggest that this second volume combined with Emanuel de Kadt's Tourism: Passport to Development? Perspectives on the Social and Cultural Effects of Tourism in Developing Countries published in 1976 and Dean 
MacCannell's The Tourist: A New Theory of the Leisure Class also published in 1976, form the foundational documents for the anthropology of tourism.

The research category 'tourist experience' was initially based upon criticism of traditional management orientations specific to environmental, regional, spatial, evolutionary and/or socio-cultural impact studies. Early tourism studies emphasized over-dependence of indigenous cultures upon western lifestyles and economic structures that supposedly created the situation of chronic underdevelopment (Craik 1991:106; Rajotte 1980:3; see also Ayres 2002; Hunter 1995). Hunter and Green (1995) note that cultural and environmental tourism studies tended to be focused upon specific areas of study, e.g., remote regions, unique physical features, tourist commons, land tenure systems etc., unfortunately ensuring that the research completed reflected a very narrow view of indigenous cultures and their environments, and reinforcing stereotypes of the 'native' as 'natural,' i.e., authentic primitive peoples are closely connected to pristine nature (see also Briassoulis 2002:1067; Smith 1990; Hall 1994). Impact analysis also expanded the discussions of existing ideas such as MacCannell's concern with authenticity correlated to years of tourist education levels (cited in Graburn 2001:49-50; see also MacCannell 1989), Urry's (2002:141-161) globalizing the tourist gaze, Suvantola's (2002:2; see also Strain 2003:3) "meaningful recreational experience" of tourists, Deem's (1999:161) tourist ghettoization based upon consumption differences between women, men, and women and men, Edensor's (2000) staged tourism spaces where tourists themselves perform to reinforce "social norms and conventions" (Edensor's 2000:323), and many others. 
Since tourist desire is unlikely to diminish given the strong associations drawn in the literature between tourism and personal enrichment and social enlargement, Rojek and Urry (1997) suggest that it is important to consider the effects upon western society itself (i.e., tourist origins) and the possibility that travel "may demystify our notions of 'the other' in all of its manifold forms" (Rojek and Urry 1997:19) thus increasing the possibility of changing the negative impacts of tourism upon host destinations. Cohen (1995:18-20) on the other hand, suggests that a shift in ethnographic descriptions of tourist perceptions based upon the natural and authentic, to descriptions based upon the artificial and contrived (e.g., the preservation of a historic heritage monument) would be more effective in reducing the negative impacts of tourism upon indigenous host destinations. Coinciding with the notion of self-study or tourist self-education by travelling there, is the recognition that the tourism industry reflects a significant modern population movement control problem that is discussed in terms of package tours, organized visits, orderly travel plans, arranging insurance, and implementing security measures to avoid kidnapping, murder, bombings, disease etc., just to name a few aspects. As a control problem, comes the recognition that tourist volumes can be manipulated quite easily: for example, by changing or cancelling airline routes with or without notice, where host destinations can be made or destroyed over-night.

Contemporary analytical models offer various frameworks by incorporating combinations of research categories and themes such as definition, motivation, and authenticity of the traditional demand and/or supply-side theoretical paradigms (e.g. Apostolakis 2003:801; see also Smith 1996; Wood 1997). The concern with authenticity, combining descriptive product definition approaches and conceptual consumer 
motivational approaches, is closely followed by the recognition that the growing economic dependency of many nations upon tourism "necessitates... [a] reexamination of the anthropology of tourism" (Smith and Brent 2001:11). The extreme of such a tourist monologue emphasizes results in studies that do "not include indigenous workers, environmental destruction, distorted development, or multinational corporations removing financial resources from countries" (Bell and Lyall 2002:144). Although tourism depends on the desires of the middle classes for whom global travel is accessible, the ever-accelerating range of experiences required by these global 'consumers' also situates some cultures as theme parks and picturesque sites for consumption.

The analytical merging of 'guest' and 'host' perspectives creates additional problems of analysis as well (Agarwal et al., 2000:246; Ayres 202:154). For example, sub-issues such as shifting boundaries between direct and indirect production (e.g., employment) has specific implications for class, gender, and age-based social division of labour that are dependent upon the broader context (e.g., tourist origins or destination) within which they are situated. Following from this, tourism understood only as a product of the individual decisions made by tourists and their desires to visit specific locations implies that the terms 'consumers' and 'producers' rather than 'guests' and 'hosts' more aptly describes the socioeconomic relationship under study. Within this view, even though tourist actions are significantly constrained and managed by the tourism industry, the influences exerted by the tourist and the tourism industry, sometimes separately, are also responsible for the creation of the negative perceptions about tourism and tourists generally in host destinations. Indigenous peoples are usually 
not owners of tourism operations, nor are they tourists, but workers. As workers they do not gain benefits to the same extent or in the same way as owners and/or tourists do.

Krippendorf (1999) reminds us that there is a significant down side to affluence in our relationships with others. Higher wages and shorter working hours for the tourist at home structure the selection of their leisure activities and hence their interactions with host peoples. This simple fact establishes a dynamic where the 'tourist' and the 'native' are diametrically opposed. What is freedom and pleasure to one, amounts to constraint, burden and work, for the other. Leisure clashes with work and recreational needs are not the same as existential needs. "Natives in continuous contact with tourists soon discover their weaknesses and uncertainties in a strange environment. Some of them exploit it, others develop feelings of contempt.... One thing is certain: tourists and natives come nowhere near a meaningful contact - far from it, in fact" (Krippendorf 1999:61). Tourism and ethnography may occur at different historical periods but they arise from the same social formation even if experienced quite differently. Tourists are foreigners with great wealth and power, with their own idiosyncratic requirements and demands. "In effect, after the primitive culture has been conquered, it may be reconstituted in tourism, for the tourist world is one of the reconstruction and the simulacra" (Bruner 1989:439; Rosaldo 1989: 31). The very culture that was intentionally altered or destroyed but presented as accidentally altered or destroyed is precisely that which the tourist longs to see.

The question then is why we need a reminder of this difference between tourist and host. Josephides (1997:17; see also Pearce 1990:138-139) suggests that the shape of the ethnographies produced has a lot to do with it. By extending Marilyn Strathern's 
ideas of partial anthropological knowledge Lisette Josephides deconstructs three specific ethnographic writing styles: 1) the kind of deconstructive interpretation that covers the full spectrum of global connections encompassing marginality, agency and selfdefinition; 2) the reflexive-authorial attitude that inserts the ethnographer into the text (i.e., auto-biographical); and 3) the 'culture in action,' account that is a type of discourse where the ethnographer is usually outside the text (i.e., let the locals speak for themselves). These styles highlight two very different strategies of ethnographic writing, the self-reflexive/interpretive one and the deconstructive approach producing very different end products. Because this is not a one-way relationship, the subject having been also shaped by their situation, perception and expectations, the caution is that this does not imply equality or unity between the ethnographer and the studied, either.

Phillips and Steiner (1999) identify that "to be represented... objects of nonWestern peoples had to be transposed into the Western system of classification..." (Phillips and Steiner 1999:7). Thus, representation "may be fatally prone to reduction, in as much as concepts replace complex processes of interpretation and singular texts stand for plural exchanges" (Rapport 1997:179; Rosaldo 1989:38-39). In the same way, the research classification process also reinforces existing western hierarchies of gender, class and race that construct an illusion of a universalist inclusiveness. For example, in identifying an 'ethnic' object, three major assumptions or meanings are evident: 1) that 'ethnic' is closer to nature and therefore less artificial (see critiques by Cohen 1995:1820; Graburn 2001), 2) that 'ethnic' is interchangeable across regions (see critiques by Bell and Lyall 2002:144; Gupta and Ferguson 1992), and 3) that 'ethnic' refers to evidence of a vanishing world (see critiques by Garland 1999:78; Lawson 1997; Orange 
1987; Walker 1990). The same can be applied to the use of concepts or markers such as 'authenticity,' 'purity,' 'pristine nature,' or 'hybridity.' Placing the tourism development debate in which the proponents point to economic benefits and critics point to social costs within this analytical framework highlights the basic problem. Who benefits? But it is not only about who benefits, it is also about costs: not only economic costs, or even determining who pays, but about social, cultural and environmental costs, all of which should be weighed against any possible benefit (Rajotte 1980:8-13; see also Braissoulis 2002).

"The crux of the [tourism development] argument is that the relationship between tourism and culture is a complex and nuanced one in that it is mediated even while it is resisted rhetorically" (Joseph 2001:999). 'Mediated resistance' or culturally derived rhetorical strategies function to empower those subject to negative impacts. For example, this strategy may take the form of a joke often used to emphasize local people's awareness of the touristic images of themselves, their ability to play with those images, and their enjoyment of subtly disposing of them. Jokes can also highlight the conceit of tourists who assign local people only the role of object of the "tourist gaze" (Urry cited in MacDonald 1997:155). This strategy is an effective way for indigenous host cultures to assess tourism opportunities, potentials, and impacts, both positive and negative, in terms of policy decisions and management. They use the same ethnographic, cross-cultural approaches and classic literature as everyone else. The problem is that there is little or no literature that emphasizes their own unique perspective, so that the end results of actions taken as a result of their analysis is likely to reflect the tourism perspective and needs. 
Relative to the significant literature focused upon the practical business and marketing aspects of tourism (that also includes extensive cost benefit analysis), very little work addresses the political nature of the tourism industry itself. Cheong and Miller (2000:371; Bell and Lyall 2002:145; see also Briassoulis 2002; Scheyvens 2002) identify two contemporary political dimensions that involve the incorporation of local activism into tourism studies. The first, public policy and planning analysis, "is often entangled with, or subordinate to, other policies, which may well hinder policy intervention in development and weaken the representation of the stakeholders in such places" (Cheong and Miller 2000:373). Acknowledging that the term 'stakeholder' is itself problematic, contemporary studies attempt to address the problem of selective exclusion by advocating local host community involvement in the identification of problems, opportunities and possible solutions. Unfortunately, most studies do not address the issues of representation and vested interests, either culturally or economically at the decisionmaking level; hence the question of whether a multinational company really should be at the negotiating table affecting a local community, in the first place, is never actually addressed. The second dimension is studied mostly within the disciplines of political economy and development studies, which tend to be more critical of the problem of dependency, inequality and hierarchical relationships between nation states and/or multinational corporations and local citizens. These particular studies emphasize local resistance as a challenge to continual oppression (Cheong and Miller 2000:374) and the lack of human agency within existing decision-making models at all levels.

It is recognized throughout the critical literature, and in particular in the anthropology of tourism literature, that because the 'ethnographic present' is framed by 
static interpretation combined with the universality of work and leisure in tourism debates, the issues of time, authenticity, and ethnicity are increasingly synonymous with identity. Nevertheless, the only relevant tourism questions that can be asked remain focused upon: What was the 'real' culture? And, when did it exist? In an effort to circumvent this, Scheyvens (2002) suggests that a far greater emphasis needs to be placed upon local development in order to ensure that economic, political, and social benefits accrue to a local community. The caution is that this requires "full participation of communities in tourism" (Scheyvens 2002:146, emphasis in original). But there are a number of challenges that need to be addressed to enable communities to maximize the benefits of participating in the tourism industry. Scheyvens offers budget backpacker tourism as a viable option. However, in the Pacific, the indigenous tourism industry is virtually nonexistent, travel is extremely expensive, environments are fragile, and significant adjustments would have to be made to allow for budget tourism (e.g., campgrounds, hostels, etc.). Backpackers, for example, may stay longer, but their needs ultimately place a much greater strain on the host destination in terms of the protection of cultural identity.

Others suggest that tourist and host person-centered approaches that ensure the voice of the 'other' is heard despite the focus upon economics, marketing and management, is required in order to reduce the negative impact of just 'being viewed' (Wearing and Wearing 2001:157). White and Tengan (2001) note that even though there are "anthropologists who wish to reproduce a vision of committed, honest work in faraway places, or native voices may speak of finally guarding and purifying indigenous communities, these possibilities remain contingent on specific historical and political 
conditions, caught up in wider forces of economic and cultural production," (White and Tengan 2001:404) and it is these very same unsettled conditions that offer a way out of the current discourses of disabling generalizations. The other point to stress is that the granting of respect "rather than sightseeing, curiosity, objectification, inferiorization and exploitation" (Wearing and Wearing 2001:156) requires a significant shift in power. Leaving this up to individual choice (e.g., ethical practice), in a context where the tourism industry is actually controlled by powerful multinational corporations, does not seem to offer anything new for the people of host destinations. 


\section{Cultures on the move}

Much has been written about the Pacific Ocean. The caution is that the "way of seeing the world' as described in the written record cannot be confused with the empirical knowledge compiled about the Pacific Ocean. The Pacific Ocean is the world's largest body of water extending from the Bering Sea in the Arctic north to the Antarctica's Ross Sea in the south, and stretching at the widest east-west point a distance of some 19,800 $\mathrm{km}$ between Indonesia and Colombia. The lowest point on the earth's surface is also in the Pacific Ocean - the Marianas Trench. The Pacific contains about 25,000 islands and the majority of them are located south of the equator. Important migrations had obviously occurred throughout the Pacific for hundreds of years before the Spanish conquistador and explorer Vasco Núñez de Balboa (in 1513) and the Portuguese explorer Ferdinand Magellan (in 1519) first crossed the Pacific, followed by the Spanish and the Dutch (definition.com 2004).

Human settlement of the Pacific was a major event in pre-European world history despite the vastness of the Pacific Ocean. In 1521, Ferdinand Magellan named the Pacific (Pacífico meaning peaceful) and in 1756, the French, Charles de Brosses coined the term Australasia (Latin for south of Asia) grouping together Australia, New Zealand, New Guinea and most of the eastern islands of Indonesia. All the remaining islands in the Pacific he named Polynesia derived from the Greek words poly (many) and nesos (islands). We have the British navigator and explorer Captain James Cook, in 1769, to thank for the earliest formulation of what has come to be known as the 'Polynesian Problem' (i.e., categorizing languages, cultures, ethnicity, appearance, dispersion and 
origins) that first challenged Charles de Brosses' two Pacific culture area categories:

Australasia and Polynesia. Captain James Cook (1728-1778), like his contemporaries, Captain George Vancouver (1758-1798) and Captain George Dixon (1755-1800), on voyages in the Pacific all documented the similarities of physical features and cultural characteristics between Polynesians and Northwest American coastal peoples (e.g., as they were called at this time: Haida, Bella Coola, Kwakiutl, Nootka, Salish and others) beginning the 'Polynesian problem' debates in earnest.

[I]t was a common presumption that the Polynesian tribes on the isolated islands in the East Pacific were American Indians carried there, like all the early Europeans, by the prevailing easterly winds and currents.... All the voyages in the Polynesian part of the ocean, without exception, followed a course from America towards Asia, and to return from Asia it was necessary to sail from Indonesian waters along Japan to the high latitudes between the Aleutian Islands and Hawaii (Heyerdahl 1979:154; see illustration 1 below).

Illustration 1

\section{Ocean Routes}

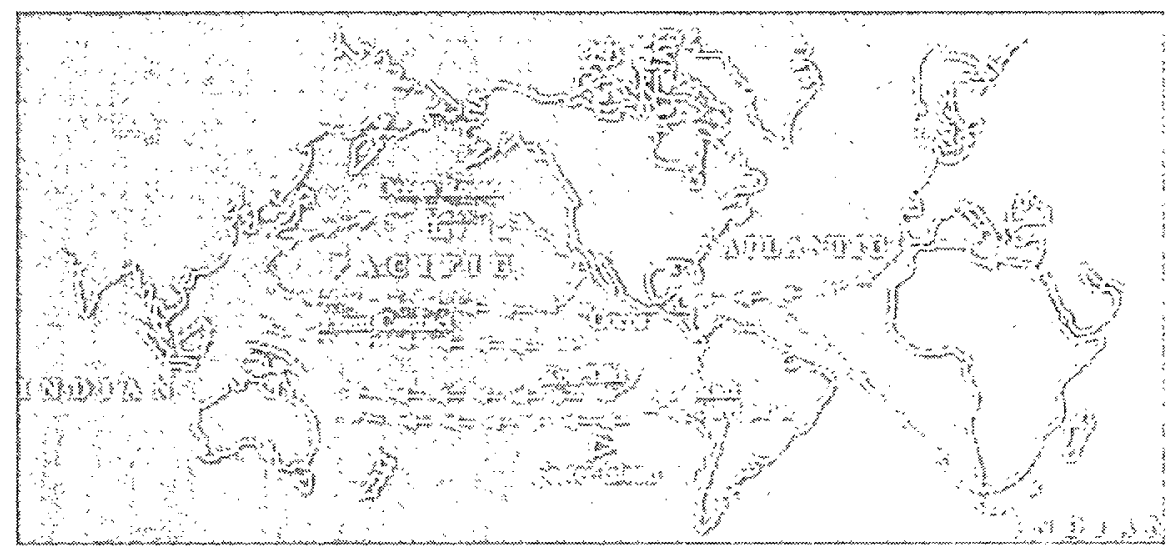

Map Source: http://www.bradshawfoundation.com/thor/ 
Travelling during what is now referred to as Europe's second age of geographic exploration, (the scientific information gathering phase as opposed to the earlier goal of searching for new routes to Asia) Captain Cook is credited with documenting the contemporary Polynesian cultural area and presenting the first so-called serious suggestion that the Pacific was intentionally explored and settled prior to European discovery. Whether his representations were negative or positive, and for whom, is a matter of interpretation, but he met his end in Hawaii on his third and last voyage in 1778 , which indicates that there was in fact a significant difference between European and Polynesian perceptions even back then.

Eighteenth-century observers began to speculate about oversea connections between these three island people [i.e., Indonesian, Polynesian, and North American] living in separate areas of the same ocean. The nineteenth-century ethnologists noted that more than vague linguistic evidence linked Polynesia to the Old World: the Polynesian islanders possessed pigs, chickens, breadfruit, bananas, sugar cane, yams, taro, as well as the custom of lashing an outrigger to the side of their canoes - all of which were unquestionably Asiatic culture elements (Heyerdahl 1979:155).

It was not until 1831, when the French seafarer Dumon d'Urville having mapped and explored a significant part of the Pacific producing an equally detailed geographic and material cultural record of the scattered islands of the Pacific Ocean, as those of Captain James Cook, that Charles de Brosses' two Pacific culture area categories were amended (definition.com 2004) to the present, three distinct ethnic regions: Melanesia -

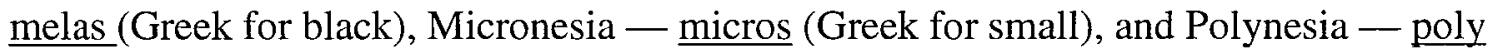
(Greek for many). Polynesian remains the largest of the three culture areas (see illustration 2). Australasia has since been replaced by the term Oceania, to describe the 
smallest and youngest terrestrial (earth/land) ecozone in the world comprising a total land area of less than 50,000 square miles. Oceania refers to all the islands of the Pacific Ocean belonging to Melanesia (including New Guinea previously classified as Australasia), Micronesia, and Polynesia (including New Zealand also previously classified as Australasia) and excludes Australia and the Malay Archipelago.

The people of Polynesia live on Pacific islands within what is called the Polynesian triangle (see illustration 2) and a band of isolated islands and individual island communities, called the Polynesian Outliers. The triangle has corners over 4,000 miles apart between New Zealand and Easter Island and over 5,000 miles to Hawaii, and includes the Islands of Futuna, East Uvea (renamed Wallis Island), and the Ellice Islands (renamed Tuvalu). Within the triangle, the Phoenix and Christmas Islands (belonging to the Micronesian Gilbert Islands chain, renamed Kiribati in 1979) are excluded. The longestablished communities defined linguistically and culturally as Polynesian that exist on several small islands and atolls within the Caroline Islands of Micronesia and several islands within Melanesia, e.g., Firth's Tikopia, form the Polynesian Outliers. Fiji, including Rotuma, located between the Polynesian Outliers and the west arm of the triangle originally classified as Melanesian, is self-described as Polynesian and is thus formally accepted today as forming a part of the Polynesian triangle proper. Some of these islands are remarkably isolated; for example, the Hawaiian chain is more than 2,000 miles and Easter Island is more than 1,000 miles away from the nearest land. Given this island geography, exploration in the Pacific has historically been time-consuming and expensive. 
Illustration 2

\section{The Polynesian Triangle}

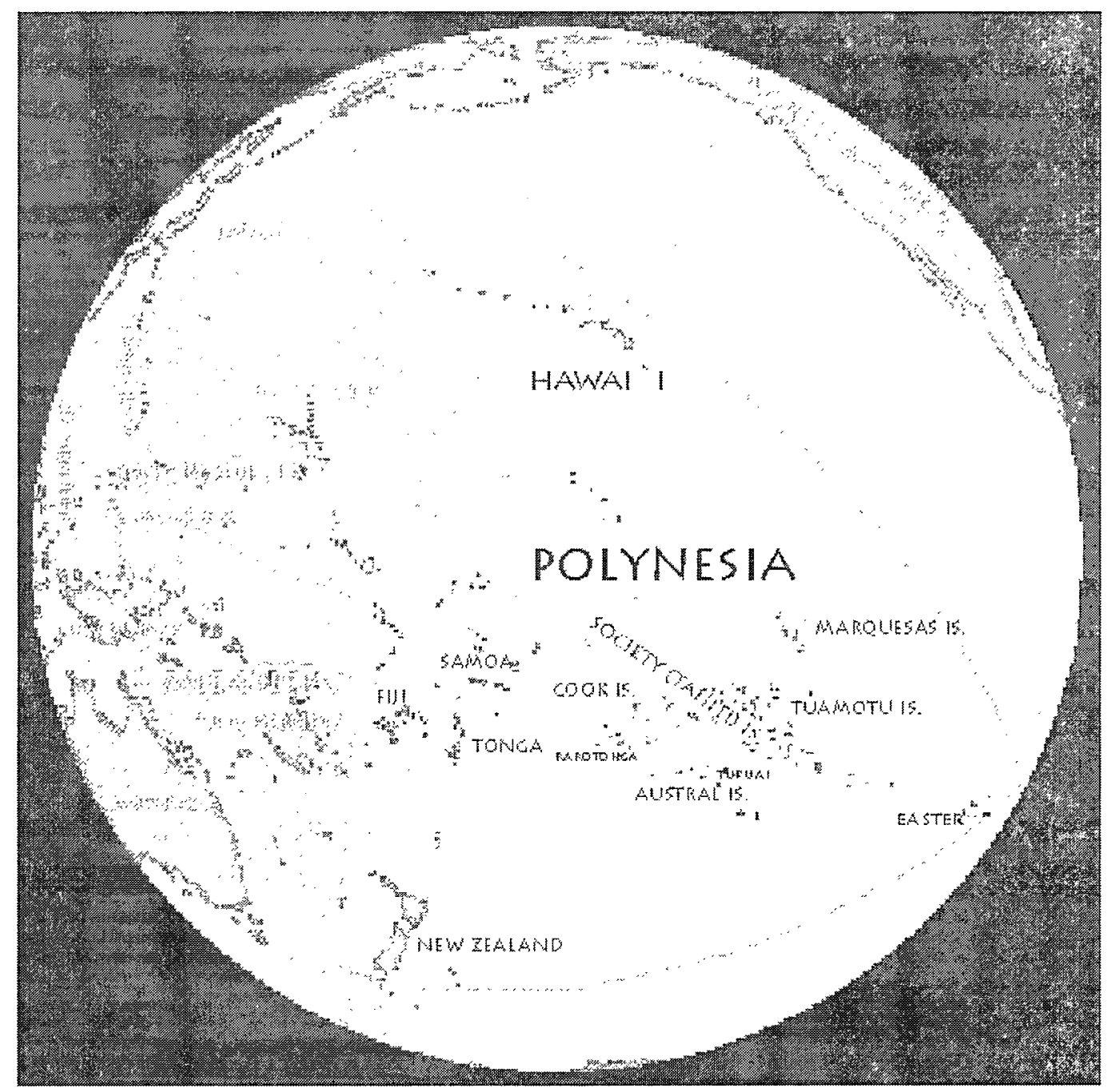

Map Source: http://leahi.kcc.hawaii.edu/org/pvs/polynesia.html 
The popular perceptions of Pacific exploration are said to reflect the worldview of the early European cartographers and geographers, rather than archaeological and genetic sciences. The original European explorers describe their surprise at finding island after island occupied, even though they lacked metal, 'ships' and navigational instruments. But interestingly enough, they also record the exploits of the legendary voyages of Kupe (New Zealand), Hotu Matu'a (Easter Island), or Mo'ikeha (Hawaii), just to name a few, as they learned the languages of the islanders and heard their stories. This explains the traditional explorer heroes including Abel Janszoon Tasman from Holland travelling in the Pacific between 1603 and 1659, Jean Francois de Surville and Marion du Fresne, both from France travelling in the Pacific between 1717 and 1772, and Captain James Cook from Great Britain travelling in the Pacific between 1728 and 1779 , being remembered and repeated. Four centuries later, the Pacific has seen an incredible number of linguists, archaeologists, anthropologists, folklorists, historians, ethno-botanists, oceanographers, and many other amateur and professional scholars adding their worldviews to the historical record. But the picture of who Polynesians are remains very much a negative one. As a result, Polynesians themselves have joined in the quest, but with a significant difference - they are not 'outsiders.'

European exploration and occupation of the Pacific has indeed resulted in the creation of seventeen independent nation states: Australia, Fiji, Japan, Kiribati, the Marshall Islands, the Federated States of Micronesia, Nauru, New Zealand, Palau, Papua New Guinea, the Philippines, Sāmoa, Solomon Islands, Taiwan (i.e., the Republic of China), Tonga, Tuvalu, and Vanuatu. They are all relatively young states, eleven achieving their independence from their colonial nation after 1960: Sāmoa in 1962, 
Nauru in 1968, Fiji in 1970, Papua New Guinea in 1975, Solomon Islands and Tuvalu in 1978, Kiribati in 1979, Vanuatu in 1980, the Marshall Islands and the Federated States of Micronesia in 1986, and, Palau in 1994 (definition.com 2004). The Northern Mariana Islands (territories of United States), Cook Islands and Niue (both territories of New Zealand) are referred to as being self-governing or independent by association. However, a large number of islands in the Pacific remain territories and possessions of Australia, Chile, France, Japan, New Zealand, the United Kingdom (the British Commonwealth) and the United States.

In many respects, the exploitation of the Pacific's mineral resources has been naturally limited by the Pacific Ocean's great size and depth. However today, around the coasts of Australia and New Zealand fossil fuels and natural gas are being extracted and pearls are harvested along the coasts of Australia, Papua New Guinea, the Philippines, Japan, Nicaragua, and Panama. As a direct result of colonial control, colonized peoples became familiar with European economic, political, legal and social practices, adopting or rather, coming to terms with many of the newly required and mandatory 'ways of doing things.' It has been argued that cultural imperialism, or the imposition of ideas and practices upon one or more cultures, eventually displacing old ideas and practices of indigenous cultures, is not always negative. Accordingly, a significant amount of literature has been written about such strategies as cultural assimilation, syncretism and/or acculturation. Underlying this spectrum of possible strategies to deal with cultural imperialism is the claim that these processes are mutually achieved because they involve an equal unconstrained interaction of giving and taking. 
However, cultural change, migration, and tourism in general expose the contemporary problems of understanding identity politics in such ways. Inherent in those kinds of representations or arguments about colonized peoples is the assumption that the original classification by European occupation into nation states established a homogenous and harmonious group of cultures within those boundaries. Contrary to this understanding, identity politics actually makes it impossible to acknowledge homogeneity because every culture, whether a dominant one or not, is made up of a multiplicity of groups that have vastly different understandings, ways of thinking, and interests that do not automatically lead to cooperation - cooperation itself has to be constructed. Acknowledging multiplicity, then, allows one to see that where coercive strategies are preferred, such as those noted above, they will be designed and structured to appear as though they are the result of mutual agreement, but they merely evoke coping strategies in the 'other' due to the lack of discursive spaces to voice their individual and cultural needs in their own vocabularies.

It was not until the development of modern archaeological research programs, particularly in Hawaii and New Zealand during the 1950s, that the most prominent lines of inquiry into Polynesian settlement patterns, all revolving around the study of languages and voyaging myths of Polynesian ancestors, actually changed. While language studies supported the dominant theories of migration patterns and an eastern Polynesian migration path, these studies did not actually shed much light on the original homeland of Polynesian peoples, or the actual migration routes they followed throughout the Pacific. Nor could this work provide evidence of how Polynesians were able to sail so far around the Pacific. Hence the major focus of anthropological study, in the attempt 
to fill in some of these gaps in knowledge, has been historical reconstruction or reinterpretation based upon archaeological and linguistic materials. The majority of ethnographic work was produced between the two world wars, i.e., 1918 to 1939 approximately. The major anthropologists working and publishing their findings in Polynesia during this period were: Margaret Mead, Robert Wood Williamson, Raymond Firth, Herbert Ian Hogbin, Felix Maxwell Keesing, Edwin Grant Burrows, Ernest Beaglehole, Sir Peter H. Buck (Te Rangi Hiroa), and there were many others providing valuable contributions to the study of continuity and change. This work essentially established an extensive somewhat disconnected catalogue of material culture, languages, artifacts, myths, legends, social and political practices, and more importantly, European opinions of what they observed and passed on as fact.

The Bishop Museum of Honolulu, Hawaii, was the first institution in the Pacific to conduct specific and systematic cultural studies beginning in the 1920 s, by establishing scientific formats for the collection and the organization of data for publication. Sir Peter H. Buck, New Zealand's own indigenous ethnologist (1927 - 1936) published his findings along with all of those noted above, and served as a Director between 1936 and 1951 for the museum. But even the work by this institution was not able to provide information on actual routes, migration sequences, chronologies of settlement, or the means of navigation. It could be argued that the works of Sir Peter H. Buck (1959[1938]) and Hohepa Te Rake (Rout 1926, the 'reporter' for Hohepa) are examples showing that the critical problem of language and representation still permeates the discipline of anthropology today. The European representations of the 'savages' were not readily accepted by either Maori writer, but their own attempts to change European perceptions 
of Polynesians led to descriptions and justifications that claimed Polynesian peoples were just like Europeans originating from the same biological ancestors. Hohepa's account is very much concerned with establishing a Caucasian (or Mediterranean) origin and overturning the popularly labelled 'savage' category and is equally racist in its description of other ethnic groups e.g., the stories of the 'savage' Moriori.

The 'Polynesian problem' and its impact can be illustrated by the debate between the Norwegian explorer and archaeologist Thor Heyerdahl and the New Zealand historian Andrew Sharp. Expert opinion was and remains to a large extent almost universally against Heyerdahl, but not because of what he studied or wrote. Everyone has gauged his work upon an erroneous belief that Heyerdahl was claiming that Polynesians descended from South American peoples (Inca, Aztec, Maya) who in turn descended from the great pyramid builders of ancient Egypt (Heyerdahl 1979:v). As such, the response to Heyerdahl was usually that South American Indians had neither the vessels nor the navigating ability to cross the ocean thus leading them to disregard his extensive set of work. Similarly, Andrew Sharp wrote the book entitled Ancient Voyagers in the Pacific in 1956, arguing that the 'vision' of Polynesians as great voyagers was nothing more that a romantic story since the canoes they used weren't seaworthy and Polynesian navigational abilities and methods were limited (Sharp 1970[1961]:14-15) leading him to draw the conclusion that Polynesians were incapable of intentionally exploring let alone colonizing the Pacific. McCall's (1994[1980]:26) response was that they must have had an incredible degree of good luck then.

Interestingly, Heyerdahl's research remains largely ignored even though most of his theories were in fact tested successfully e.g., paths across the oceans (Heyerdahl 
1979: 27-55) that inadvertently uncovered a major weakness in academic thinking — i.e., there was no solid evidence proving the theories of a Southeast Asian origin of migration and settlement either. Thus the image of Northwest American coastal Indians, South American Indians, and Polynesians blindly drifting around the ocean hoping to find land largely stands unchallenged. And despite a visibly different Polynesian approach to the open ocean, Polynesian history remains subsumed in an understanding of the ocean as a dangerous and menacing part of the world requiring subjugation and control (Clark 2000).

For the first few decades after first contact, Polynesians went about their affairs as if the coming of Europeans did not represent a turning point in their history. Their self-perception and explanations of their changing circumstances affirmed their own cultural understandings; but in their actual dealings with Europeans, their behaviour was directed by the novelty of the occasion, giving rise to a new cultural form for culture contact (Campbell 2003:80).

From this perspective, the removal of Polynesian human rights, and the destruction of distinctive ways of life, belief systems, values and whole cultures was and continues to be described and accomplished by relatively peaceful means. In this case, the presentation of a separate and third 'culture of contact' at the time of European contact is used as the backdrop for describing Polynesian responses to the European as a 'novelty,' implying complete and utter Polynesian ignorance. The problem is that the very claim to knowing Polynesian self-perceptions and cultural understandings at the time of first contact is identical to the language used and recorded by European explorers, traders, missionaries and settlers. Suggesting, contrary to the historical record, that "Europeans dealt with Polynesians as rational creatures... rather than as noble savage 
objects of admiration" (Campbell 2003:79) does not change the negative image already portrayed. Polynesians did not, as explained, live "in a world of immanent supernaturalism" (Campbell 2003:80) but rather reacted to Europeans as though they were enemies. European management and control strategies may have been designed "to protect and maintain what they believed to be traditional political practices and institutions" (Lawson 1996:161; see also Etienne 1980:222) but this does not mean the indigenous peoples encountered were unaware of the dangers inherent in the relationship with a conqueror. A more appropriate analysis would have accounted for why European demands over time have come to be viewed by both sides as involving a significant degree of 'accommodation' that has ultimately lessened European responsibility for the many negative outcomes experienced by those encountered.

Unfortunately for Polynesian indigenous peoples, 'accommodations' are acknowledged as having been 'negotiated fairly and justly' either formally, as in New Zealand's Treaty of Waitangi signed in 1840 between the British and 500 Māori chiefs, or informally via relocating peoples from places such as India, also a British colony at the time, in numbers that became larger than the indigenous peoples, as in Fiji, or using numerous other management techniques that had the appearance of being beneficial to them. For example, in New Zealand it was said that the intention of the British acquisition of sovereignty of New Zealand as 'negotiated' and outlined in the Treaty of Waitangi was to benefit both Māori and Europeans. But there were massive discrepancies in translation and misunderstood meanings of core cultural ideas such as 'sovereignty' and 'ownership' rights, culminating in what are referred to as 'the Māori Wars' during the 1860s. As a result of war "it became clear that the treaty contained the 
seeds of continuing conflict, particularly over land, power and authority" (Orange 1987:1; see also PGS 1986). By 1900 the Māori population had dwindled by $75 \%$ to an estimated 45,000 (Walker 1990:81).

Why the popular negative perceptions of Polynesians have remained can also be illustrated by the curious story of Easter Island. Easter Island provides one of the world's most riveting mysteries of a 'vanished' civilization stemming from the remains of numerous abandoned gigantic stone statues, the remains of a written script (Rongorongo), an impoverished island landscape rather than the expected romantic tropical paradise and a population that has little or no knowledge of or links to the romanticized past associated with sexual freedoms. Alongside the anthropological work by the British Museum (Routledge 1998[1919]), explanations such as Erich von Daniken (Switzerland) offered the theory that extraterrestrials constructed the statues rather than Polynesians, and less fancifully, many others have advanced hypotheses that suggest the statues were placed by mana or spiritual force as described by VanDerhaegen (2001:3). What is curious about the story of Easter Island, despite the numerous disciplinary approaches to study in the Pacific, is the persistence over time of historical inaccuracies, falsified timelines, and the imposition of European cultural concepts upon the past.

The popular cultural presentation of Easter Island in the film Rapa Nui (Reynolds and Price 1994) is a case in point. As a love story set on Rapanui prior to 1722 and in the context of technological (building statues) and cultural institutions such as the Orongo ceremony (or Bird Man Cult), this version of history is dominated by environmental determinist, diffusionist, biological (race and gender), and evolutionary ideas. The Little Ice Age coinciding with a smaller migration period is represented in the film by an 
iceberg. But the iceberg is the long awaited 'big white canoe' sent by the gods to rescue them and it is used to suggest that over-harvesting their most valuable natural resource their forest — not natural climatic change induced disaster, led to the destruction of plant and animal habitat and their potential and only means of leaving the island. As the story goes, land birds and animals disappeared with the forests. Soil erosion increased and agriculture became impossible. As food became scarcer and canoes could no longer be constructed, the complex centralized society was replaced by feuding and chaos. Warrior societies formed, the huge stone statues were toppled by rival gangs, and the human population of the island fell to between one-quarter and one-tenth of its prior size. Only one couple escapes with a baby. The baby having been conceived prior to the woman's entrance into the 'cave of the white virgin,' to ensure the baby is born to a 'white' mother and they escape 'according to archaeological evidence (smaller statues)' to Pitcairn Island. Thus it is that by the time Europeans arrived the landscape stood barren and the stone statues became "the strange proof that a great civilization" (Krystek 1997:2 see also Hamblin and Christiansen 2001:696-698) had died. Given this scenario, the only question that can be asked in such circumstances, is what on earth "were they thinking when they cut down the last palm tree?" (Diamond 1995:7). The implications of the images of the big 'white' canoe, the cave of the 'white' virgin, and the 'white' mother, is obvious: the formal European occupation of the Pacific is being surreptitiously presented as though it was the best thing that could have happened to the people of the Pacific.

The implications of falsified historical timelines are less obvious, but nevertheless hide significant ecological and social patterns that contradict the positive images presented in support of European occupation. The records actually show that throughout 
the Pacific, the weather had turned cool and rain diminished. This period, generally referred to as the Little Ice Age, occurred in the Pacific between AD 500 and AD 1000 (McCall 1980:24 \&36). This period was also a smaller migration period in the Pacific, when New Zealand and a few other islands, on existing migration routes, were populated. By AD 1000, Rapanui technological history took a dramatic turn, watercraft, agricultural, and fishing tool innovation were abandoned. The implication of such a weather change meant that regeneration of vegetation on several islands in the Pacific had been significantly altered; thus it is hard to attribute the decline of an already fragile Rapanui environment to human abuse alone. Occurring 100 years after their arrival and lasting for 500 years would have been a sufficient time span to establish a tradition of survival - dependent upon an adequate rainfall. It can be argued that the technological shifts from statue construction to the annual Orongo ceremony were logical religious sequences of a highly civilized people within a closed ecological unit dependent entirely upon their environment. So-called cross-cultural analysis highlights that Pitcairn Island (also a Polynesian island), where similar but smaller statues were built, also abandoned statue construction at about the same time period that Rapanui was experiencing arable land, food and other resource shortages (McCall 1980:36). The European descriptions of these technological shifts, all carry negative connotations e.g., as ancestor worship and then cult worship. The current anthropological view suggests that the technological and social shifts have been in response to ecological disaster. 
Archaeology has given us the time sequence of Polynesian island settlement through radiocarbon dating and the Lapita pottery findings and migrations. Savai'i, Samoa 2000-500BC... $\rightarrow$ Marquesas... 100AD and Tahiti 300AD $\rightarrow$ Hawaii 500AD. Return voyages from East into West Polynesia lead to the settlement of Aotearoa, New Zealand 800-1000AD from the Cook Islands. These are around about periods of the Polynesian (Tanata mao'i from Savai'i, Samoa) settlements... (AhChing 2003).

McCall also suggests that because there are no recorded Dutch observations about fallen figures or signs of warfare during their visits, an important distinction can be drawn between environmental and cultural causes. “[By 1722] trees were virtually absent.... [By] 1774 many of the statues had been toppled from their pedestals [and by] 1863 it seems that all the statues were prostrate" (Bellwood 1987[1978]:112). Between 1805 and 1862, the year that marks the peak of the Peruvian slave raids in which Rapanui was significantly depopulated of both men and women, for service first, on whaling ships, then on plantations. In 1866, a mere 15 islanders were repatriated by the French introducing smallpox, respiratory diseases, measles and other diseases caught in Peru, leaving just over one thousand people still alive. In 1868 Jean-Baptiste Bornier purchased a tract of land near Hanga Roa and systematically induced the remaining inhabitants to leave, including the missionaries. He transported 200 to Tahiti, and 150 to the Gambier archipelago to work on plantations, so that by 1871 only 175 people remained on Rapanui. The legal ownership of land, animals, and the people remained in dispute between the French, British, Tahitian entrepreneurs, the Catholic mission and the Rapanui (Porteous 1981:8-21). By 1877 only 110 people remained alive on the island (McCall 1980:59). Ten years later, Rapanui was annexed by Chile. 
Illustration 3

\section{Settlement Timelines}

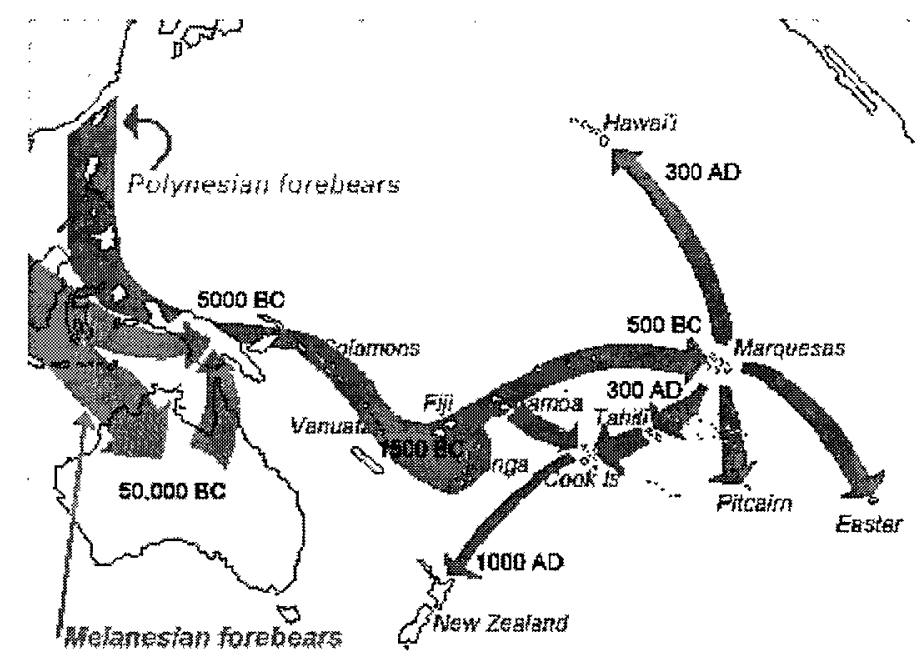

Map source: http://maaori.com/people/migration.htm

Genetic studies... [(e.g. Hurles et al., 2002)] ruled out Taiwan as a progenitor of the Polynesians, yet genetic Y-chromosome studies conclude a definite similarity between ancient South East Asian Migrants and the pure Polynesians of the Samoa and Tonga realm.... Fijians and Tongans have Melanesian genes as they are at the border of Polynesia. It is the similar culture of Fijians which tie them to Polynesia as seen in Samoa and Tonga (Anthropology).... Despite scientific evidence, we as Polynesians know from our similarities that Tonga is a part of the Polynesian family, Malo lelei Tama si'i... (AhChing 2003).

Other genetic research indicates that prehistoric Polynesian (as in Charles de Brosses' classifications) populations had continued interactions for extended periods of time in some regions of the Pacific with low-level genetic variation prior to European contact. Following European contact, there was indeed genetic mixing (admixture) and significant population crashes on many islands as a result of European disease strains having been introduced (Matisoo-Smith et al., 1998:15145). Even so, the 'Polynesian 
problem' as coined by Captain James Cook in 1769 has persisted, the negative connotations reproduced over time actually encouraging the expansion of genetic studies beyond human genetics to include other species in the attempt to trace and/or confirm Polynesian migration patterns in the Pacific. For example, the genetic studies of the Pacific rat (R. exulans), the third most widely dispersed rat species in the Pacific occurs in large numbers in archaeological middens (household rubbish or food dump sites) that suggests that they accompanied Polynesians on their voyages perhaps being deliberately transported as a food item since this specific species of rat cannot swim (Matisoo-Smith and Robins 2004:9168).

Further three isolated populations corresponding to three migration and settlement periods were revealed (Pickrell 2004) suggesting that the Polynesian migration and settlement pattern was slow and complex rather than the 'express train' directly from Taiwan. The other unique aspect of the Pacific rat genetic studies is that European travellers (explorers, traders, settlers etc.) introduced two additional rat species (Rattus rattus and Rattus norvegicus) and hybridization between the three rat species did not occur (Matisoo-Smith et al., 1998:15146) unlike the transportation and hybridization of the same species of dogs, pigs, and jungle fowl. 


\section{Tonga and Sāmoa}

Tourism is the fastest growing industry in the Pacific based upon natural island beauty, and for most small island countries, tourism is the largest earner of foreign exchange. "The money that offshore citizens send back home to their relatives accounts for Sāmoa and Tonga's largest foreign exchange earnings" (Naidu 2002:3) but even so, tourism holds the most promise in terms of long-term economic stability. The analytical problem relates to whose long-term economic stability. Australia, New Zealand, Fiji, Guam, Saipan, New Caledonia, French Polynesia and Hawaii are the major tourist destinations in the Pacific, and they all highlight significant concerns with regard to the increased local pollution in the form of un-scenic household litter and garbage, and solid and liquid wastes from tourism activities, the lack of clean water, both fresh and sea affecting both coral reefs and forest biodiversity, the emergence of worker shanty towns and the high costs of feeding, housing, and transporting tourists.

"Recent studies on global tourism trends predict visitor volumes to the Pacific region as a whole will double over this decade with corresponding benefits for Pacific Island countries" (UNESCAP 2000 (b)). But the benefits are offset by some major problems. The largest is money leakage, because tourist resorts and hotels are often selfcontained, the cruise ship being the ultimate form of self-containment. Governments provide extremely attractive investment inducements, such as no duties or taxes on profits, and allow the importation of their own staff needs. Hence tourism operators can operate a resort and either export all the profits or collect all holiday package payments prior to a visitor's arrival on the island. The problem for the island is that without 
adequate tax revenues, infrastructure such as roads, water and sewage treatment, electricity, and recreational areas cannot be constructed and education and training cannot be provided. Either way, tourists place a considerable amount of stress upon the local ecosystem. Tourists are more likely to use more water, demand imported foods and consume large amounts of sea foods. And they add significantly to solid and liquid wastes (UNESCAP 2000 (a) and (b)).

The Kingdom of Tonga, the two Sāmoas (the Independent State of Sāmoa (formerly Western Sāmoa) and American Sāmoa), Niue, Tuvalu and Tokelau comprise what is known as Western or 'old' Polynesia. Tonga and Sāmoa, including American Sāmoa, lie east of the $180^{\text {th }}$ meridian, and are therefore in the same time zone, but because the international dateline was drawn east of Tonga and west of the two Sāmoas, they have different dates, i.e., if it is Saturday in Sāmoa, it is Sunday in Tonga. The designation of Western or 'old' Polynesia refers to the archaeological records that indicate settlement between 2000-500BC (AhChing 2003; see also illustration \#1 ocean routes and illustration \#3 settlement timelines). Eastern or 'new' Polynesia refers to the later, Hawaiian, the Marquesas, Tahitian, Cook Island and New Zealand settlement periods. Western Polynesia, with the exception of American Sāmoa, has been far less impacted by the colonial enterprise and the tourism industry. Until very recently Tonga and Sāmoa, were well off the beaten travel track in the South Pacific. Getting there involved an expensive side trip from either Fiji or New Zealand. Tonga has a population comprised of Tongans and about 300 Europeans, the official languages are Tongan and English, and they have a hereditary constitutional monarchy. Sāmoa has a population comprised of 93\% Sāmoan and 7\% Euronesians or 'mixed Polynesian and European.' 
Their official languages are Sāmoan and English, and their government consists of customary chiefs or 'matai' from among which national parliament representatives are elected. American Sāmoa, on the other hand, is exactly that, American. Their government operates by the grace of Washington (Stanley 1999).

Although politics is as old as the island communities, it is interesting that the association between the social and the political is largely disconnected. Part of this disconnection in the Pacific relates to the fact that the "most powerful or progressive group in any given island was usually granted a political role by the colonists or formalized as the ruling party in perpetuity" (Helu 1994:320). The political hierarchies established by the colonial powers to govern the newly formed nation state did little to ensure the survival of indigenous ways of life (see Howard 1990:268). Hence the indigenous cultural struggle remains one of survival. As Helu notes, it is important to understand what the political thought was, and what those thoughts actually mean in practice in terms of shaping people's perceptions that created the current political system today. Of course, when the colonial masters went home, as they did in most Polynesian countries, the governments they left behind were actually bits and pieces of various European parliamentary systems stuck together, with lots of 'odd' local customs thrown in, 'odd' meaning selected acceptable elements of a tradition rather than the whole of a social organizational structure including its foundational ideas and traditions. Since that time, the political systems established by the colonial administrators and missionaries have remained very much as they were originally designed, changes here and there having occurred in concert with wider international political requirements, rather than as a result of local activism. "The peculiar combination of inherited traditional structures, 
processes and values with modern institutions of the state and business enterprises has resulted in opportunities for widespread graft and corruption" (Naidu 2002:1). Both Tonga and Sāmoa have had to deal with scandals over the sale of passports, and Tonga has had to explain the disappearance of US\$20 million, by government officials (Naidu 2002:2).

In missionary-dominated islands, like Tonga and Sāmoa, the colonial 'masters' never went back home. The Churches' political power devolved very, very slowly to local ranking families that offered the most comprehensive protection to the missionaries in exchange for securing high status within the church. What emerged "were quaint mixtures of medieval feudalism, $17^{\text {th }}$ century absolutism, and local rigid elitism" (Helu 1994:320). Tongans are predominantly Protestant (61\%) and 16\% are Roman Catholic. $47 \%$ of Sāmoans belong to the Congregational Christian Church and 20\% each belong to the Roman Catholic or the Methodist Church. The high literacy rates (15 years of age or over) can be attributed to their contributions to the educational systems in both countries. Tonga has a literacy rate of 92.8\% (1976) and Sāmoa virtually 100\% in 1990 (Atlapedia 2003). For example, the Church of Jesus Christ of Latter-day Saints (the Mormons) is dedicated to helping provide educational opportunities for students at the Brigham Young University in Hawaii to which the Polynesian Cultural Center (PCC 2004) is attached. Since opening in 1963 over 30 million tourists have visited this world class theme park of Polynesian cultures, and over 13,000 Polynesian students have worked there to finance their studies at Brigham Young University.

Because island communities are "generally small and their cultures have strong affinities... [it is important to attempt to design] a common, basic [political] structure" 
(Helu 1994:321) that is capable of providing the essential elements that can reactivate democratic and human rights values. By extension, politics also provides the means by which one's social, political and economic status can be raised. The implications, then, are far-reaching. Helu suggests, given the small population size of Polynesian nation states, that several contemporary ideals and principles such as public participation, the rule of law, civil liberties, the right of association, and the right of dissent, are worthy of consideration, as they offer some form of 'direct' democracy capable of transferring control of their lives over to themselves.

The other option to gain control has been underway since 1982 via environmental issues in the Pacific. The South Pacific Regional Environment Programme (UNESCAP 2000 (b)) for example, assists small Pacific island countries to create environmental management strategies, facilitates the negotiation of international and regional environmental agreements related to the management of conservation areas, and assists in educational programs designed to provide choices about sustainability and to develop a common vision for the future using new technologies for communications and energy use, funding and hardware. But despite these accomplishments, the environmental problems that existed in 1994 continue to worsen, meaning that there will be another major shift towards environmental 'responsibility.' The question is who will be held responsible for environmental degradation? 


\section{The Kingdom of Tonga}

Tonga is an archipelago located in the South West Pacific Ocean. Tonga's nearest neighbours are Sāmoa to the north, Fiji to the northwest and New Caledonia, more than $1000 \mathrm{~km}$ away to the west. The territory comprises 169 islands, of which 30 are inhabited, and where most of the land has been converted to plantations or towns. Large areas of rainforest and bush remain on the Niuas, 'Eua and many of the uninhabited volcanic islands. The archipelago consists of two parallel island chains: the western chain which is of volcanic origin with limestone formations, and the eastern chain of uplifted coral formations. The four main island groups are Tongatapu, Ha'apai, Vava'u and the Niuas.

Tonga has seven officially protected areas, including five national marine parks and reserves, one national historic park, and the 'Eua National Park. Except for creeks on 'Eua and a stream on Niuatoputapu, there is no running water on any of the islands. Winter (July to September) temperatures are cool between $17^{\circ} \mathrm{C}$ to $22^{\circ} \mathrm{C}$ and summer (December to April) temperatures rise to $25^{\circ} \mathrm{C}$ to $33^{\circ} \mathrm{C}$. The islands receive abundant rainfall year round with the maximum amounts falling during the late summer months (November to April). The archipelago lies squarely in the South Pacific's cyclone/typhoon belt, with the greatest risk occurring from January to March of each year. 
Illustration 4

The Kingdom of Tonga

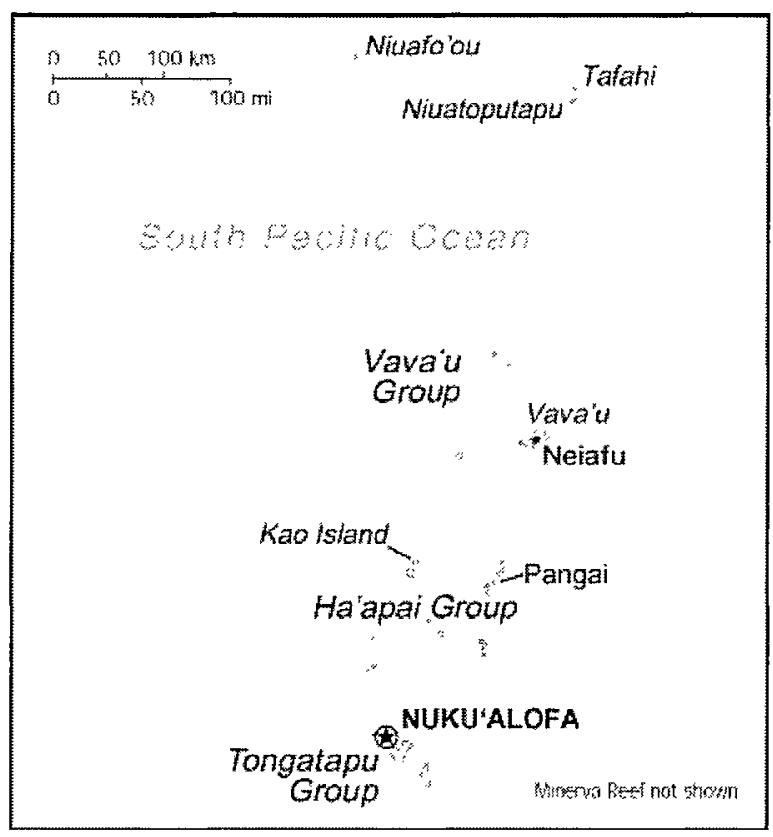

Map Source: http://www.cia.gov/cia/publications/factbook/print/tn.html

The acceptable popular tourism description of the historical story of Tonga, listed

on the Lonely Planet tourist guide web site (condensed version), goes as follows:

The royal title Tu'i Tonga was passed from father to son, and during the mid- $17^{\text {th }}$ century the most powerful royal title to emerge was the Tu' $i$ Kanokupolu. By the time of the first European contact the Tu'i Kanokupolu was the most powerful figure in Tonga. The first Europeans known to reach the islands were the Dutch, who got inter-racial relations off to a classy starl by killing one islander and taking several captive en route to the East Indies. Abel Tasman, another Dutchman, passed through the southernmost islands in 1643, taking on supplies and trading with the people of 'Ata, 'Eua and Tongatapu. Needless to say, the Tongans were relatively indifferent to the European place names of Rotterdam, Amersterdam, Pylstaart and Middleburgh that the Dutch magnanimously bestowed on their islands (Lonely Planet 2004). 
The British turned up next imposing their own set of place names. Captain Cook was among them, calling Tonga the 'Friendly Islands.' Then came the Spanish, followed by the French, but none of them managed to establish a colonial administration until the missionaries arrived in 1822. This is when the historical account above, particularly in relation to royalty and the passage of titles, is actually contradicted. The Wesleyans were the most successful in infiltrating Tongan societies, followed closely by the French Catholic missionaries. The Wesleyans converted Taufa'ahau, ruler of Ha'apai, baptizing him George, who then became King George Tupou I after he successfully 'united' all the islands of the Tongan archipelago. George's great-grandson took the throne in 1896 but Tonga was placed under British protection (status changed from a nation state to a protectorate), particularly in relation to foreign affairs. His daughter, Queen Salote, and not his son, assumed the throne. She was a popular queen and it is her son, Taufa'ahau Tupou IV, ascending to the throne in 1945, who successfully restored Tongan sovereignty in 1970 . He did so by establishing diplomatic relations with the Soviet Union, thus forcing Tonga's readmission to the British Commonwealth as its own nation state. Tonga gained membership in the United Nations in 1999. Since this time his reign has been marked by an emphasis upon economic development.

The Tongan economy is primarily based on agriculture, $90 \%$ of which is pumpkin exports to Japan (UNIFEM 2004). Although economic development has not been smooth, Tonga now has a fairly large and well-established cottage industry for the manufacture of tourism handicrafts, and a small light industrial sector. Currently tourism operations are specifically being targeted as important aspects of economic development. The early 1990s saw public protests against government corruption and money 
laundering and concerns about the increase in foreign influence in Tongan life, ultimately resulting in Tonga being removed from the economic development funding allocation listing by the Organization for Economic Cooperation and Development. This normally would not have been a problem except that the "demand for imported goods and products led to a substantial trade deficit, which was offset largely by remittances from overseas citizens, foreign aid, and, to a lesser degree, tourism" (PolitInfo 2004).

Tonga's human rights record is poor, and made worse by the fact that Tongans don't have much of a chance to change their government. At times, government authorities have infringed human rights and freedoms quite significantly; e.g., the independent newspaper, Taimi 'o Tonga, now published in New Zealand, was banned for criticizing the King. Following a ruling by the judiciary that this ban was illegal, the government simply seized the paper and changed the law, sparking the largest political demonstration in the country's history. The law was passed anyway. The reason the Tongan government could do this is because of an automatic royal majority in parliament (PolitInfo 2004; see also James 2003). In this 30-seat parliament that serves a three-year term, 12 ministers from the privy council or cabinet, and 9 nobles, are selected by and from Tonga's 33 aristocratic families, and 9 Peoples Representatives are elected by universal suffrage (Freedom 2004). The judiciary is independent but is often subject to royal assent, Taimi 'o Tonga being a case in point. It is expected that, when the present King dies, constitutional reform pressure will likely accelerate (Latukefu 1992).

In terms of social organization, the extended family is understood to be the basic social unit on Tonga, serving as the mini welfare state, with land, food and shelter being shared equally among its members. The traditional extended family is said to explain 
why Tongan women cannot (as in they do not need to) purchase or own land and why Tongans lack the sense of 'possessing' children, hence their being frequently "shifted from one household to another," (Lonely Planet 2004) calling several places 'home.' Societal violence against women is seldom publicized, and most incidents are generally dealt with in so-called 'traditional' ways. The difficulty, as noted in the literature, is that support networks, such as shelters, advice lines, etc., are church-affiliated rather than government supported (PolitInfo 2004); thus it is impossible to dispute the claimed Tongan tradition and the enforced religious adherence that discourages and prevents women from seeking protection (Freedom 2004; Taufe'ulungaki 1992).

Tonga's inheritance laws, especially those related to land, are a primary example of the extent and magnitude of discriminatory practices against women. 'Traditionally,' women could only lease but not own land, raising significant problems should a woman and her children survive her husband. Similarly, and 'traditionally,' foreign interests could only purchase a very limited amount of freehold land (a maximum of $4 \%$ of a village communal land holdings) by entering into a business partnership with an existing village or Tongan individual, i.e., they could only secure a maximum of 50\% ownership of a maximum of $4 \%$ of Tongan land. Recent legal changes allowing women and foreign interests to purchase freehold land without the current partnership conditions ultimately means that women and Tongans in general are unlikely to ever be in a position to compete with foreign interests in terms of purchasing power. It is likely that the continuing urbanization as a result of the move from subsistence to cash economies made easier by corporate purchases of land, will have a significantly negative impact upon traditional forms of food production. 
The rising poverty levels linked to urbanization and economic trade reforms have left many islands in trade deficits in foodstuffs and therefore dependent on food imports. Along with urbanization, there has been an increase in household garbage and litter that is explained in terms of the newly found wealth to buy luxury items and to provide for customary gifts. For example, tins of corned beef, a highly prized luxury item, secured originally from the explorers and colonial administrators, is also one of the more common waste items. As a luxury item, corned beef is described as a custom "deeply ingrained by the time the missionaries arrived" (Lonely Planet 2004). Further, because corned beef is a desired, luxury item, the consumption of canned food is also considered to be a form of self imposition of all the contemporary medical problems associated with high fat foods, e.g., diabetes, overweight, etc. And little is said with regard to the massive amounts of mutton flaps and turkey tails imported by the ton from New Zealand, Australia, and the United States, or the lack of infrastructure providing healthy alternatives, or the disposal facilities to handle wastes such as cans. 


\section{The Independent State of Sāmoa}

The volcanic islands of Sāmoa lie halfway between Hawaii and New Zealand. The two major islands are Upolu and Savai'i and both have extensive coral reefs. The only other inhabited islands, Manono and Apolima, are located between Upolu and Savai'i. All the islands are dominated by rugged and mountainous terrain covered with tropical vegetation and bear the scars of extinct volcanoes (lots of lava fields) and hence there are many rivers and streams. Sāmoa is located next to the equator and therefore has a tropical climate with two seasons. It is hot and humid most of the year, modified only slightly by the southeasterly trade winds blowing mostly from April to October. The average temperature ranges between $22^{\circ} \mathrm{C}$ and $30^{\circ} \mathrm{C}$ all year round. The summer, wet season is between November and April, and the winter dry season falls between May and October. The hottest month is December and the coolest is July with most rainfall (113 inches) occurring during the summer, wet season. Sāmoa also lies in the Pacific cyclone/typhoon belt, experiencing the occasional hurricane as well, especially during the summer, wet season (November to April).

Sāmoa faces major environmental threats from deforestation and over-fishing as a result of agricultural change, logging, and the use of marine 'fishing' explosives, creating significant vegetation and species imbalances (e.g., an increase in the 'crown-of-thorns' starfish that threatens the coral reefs). International funding bodies over the last few years have made concerted efforts to develop eco-friendly industries and conservation areas. Because of the islands' remoteness and therefore the limited colonial influence (i.e., the limited importation of foreign species) international interest has also increased in 
terms of 'apothecary,' or the protection and documentation of native medicinal plants and animal species.

Illustration 5

\section{The Independent State of Sāmoa}

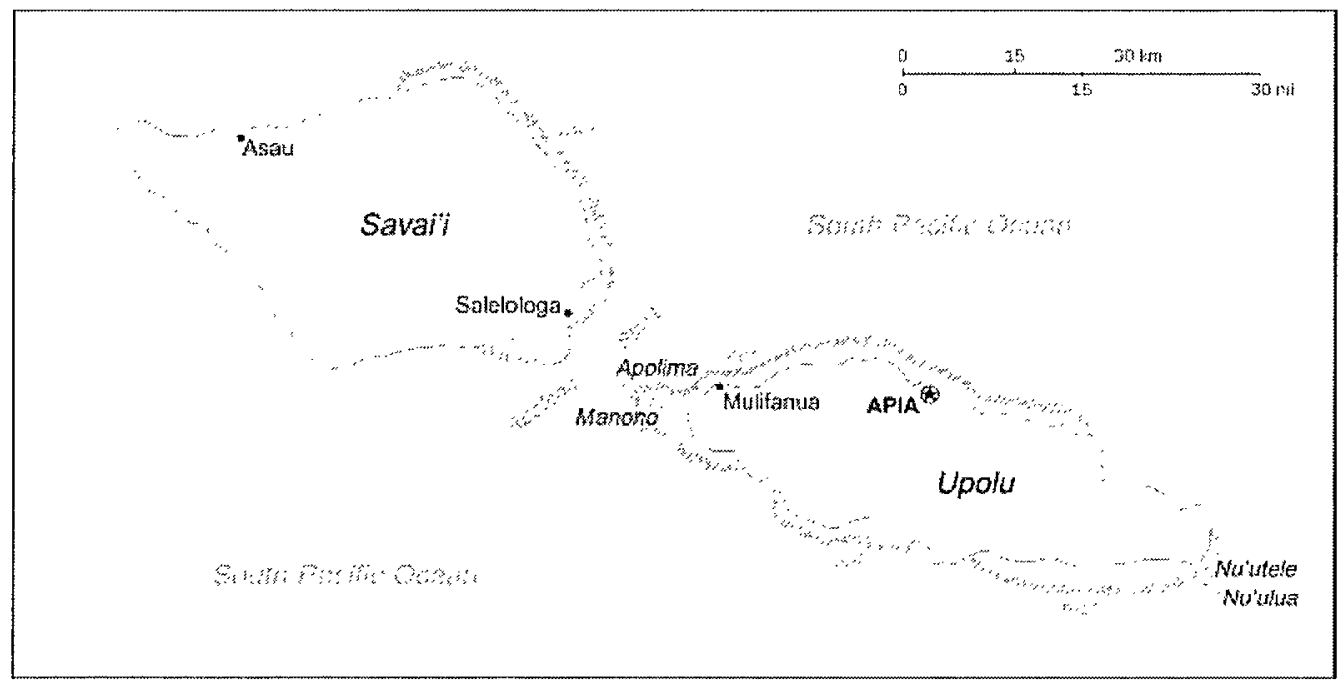

Map Source: http://www.cia.gov/cia/publications/factbook/print/ws.html

Much of the early contact and 'bloody encounters' between Sãmoans and Europeans took place in the islands that are now a part of American Sāmoa, but the islands comprising the Independent State of Sāmoa also suffered from the same diseases and acts of violence that came with the European ships. By the time the British arrived looking for Christian Fletcher and the rest of the Bounty mutineers, the Sāmoans were not in a welcoming mood, gaining themselves the reputation of being hostile and aggressive. It is actually surprising that the missionaries weren't wiped out when they arrived in the early $19^{\text {th }}$ century threatening everlasting damnation, a fact that has propped up the argument that Christianity was enthusiastically embraced, supposedly 
being a product of "religious pragmatism [rather] than blind faith" (Lonely Planet 2004). Of course, by the late $19^{\text {th }}$ century, Britain, America and Germany were engaged in a three-way tug-of-war over who owned the territory, so that in the end Sāmoa was carved up into Western Sāmoa, belonging to Germany, and Eastern Sāmoa, belonging to the United States of America. Britain was left out in the cold.

This possession agreement was short-lived, giving rise to the Mau Movement, dedicated to the preservation of Sāmoan culture and seeking independence from both of them. But the Mau Movement was also cut short, by the beginning of WWI in 1914. As part of the war effort, Britain asked New Zealand to 'liberate' Western Sāmoa from the Germans, in effect permanently fixing the division of Sāmoa into West and East. By 1961 the Mau Movement had become resigned to the division, submitting an independence proposal to the United Nations for Western Sāmoa only. Independence was duly granted in January 1962. Independence did not actually go so well due to labour disputes and an increasing dependence upon foreign aid, and things became worse following a series of cyclones that decimated their main taro export crop. The crops that survived the cyclones got fungal blight. Although Sāmoa has not yet recovered, tourism is easing the pressure a little (Lonely Planet 2004).

Western Sāmoa was renamed the Independent State of Sāmoa in 1995. Sāmoa's unicameral parliament has 49 seats, of which two are reserved for citizens of non-Sāmoan descent. In 1990 universal suffrage and five year terms were instituted. However, the right to stand for election remains restricted to the 25,000 matai, $95 \%$ of whom are men. The head of state has traditionally been selected from the four paramount chiefs, who then select the prime minister. Upon the death of the current head of state, Susuga 
Malietoa Tanumafili II, the next head of state will be elected. Each village has its own council, or fono (see Vaiao and Alailima 1994). The judiciary is supposedly independent, but there are continuing infringements at the village and the state level upon individual rights, freedom of religion, speech, assembly and association. For example, The Sāmoa Observer, an independent newspaper, has been sued several times by the government, especially with respect to allegations of corruption and abuse of power (Freedom 2004).

Sāmoans are described in the Lonely Planet tourist guide web site (condensed version), as follows:

Sāmoans are very tradition-oriented, very steeped in a complex set of social hierarchies, courtesies and customs that regulate their social, religious and political life. Sāmoan culture is based on fa'amatai, a system of government that has a chief, or matai, governing an entire 'aiga (extended family). Wealth and food are distributed on a needs basis and honour and social standing is shared or shouldered equally by all members of the 'aiga. The matai represents the family on the village council, meters out justice, and makes sure that all customs are properly observed (Lonely Planet 2004).

Although Sāmoan culture dates back thousands of years, most Sāmoans these days are indeed devout Christians. The matai often choose the religious denomination of the village, requiring financial support to the selected church leaders and their projects under the threat of banishment for non-adherence. Today religion is such a big part of Sāmoan village life that religious rules are considered to be mandatory, even for visitors. The strict observance of transplanted religion may seem odd, but the literature suggests that Christianity was actually 'Sāmoanised.' Again, like Tonga, and given that domestic violence against women, discrimination against women in the workplace, and under- 
representation of women in politics are all serious problems in Sāmoa, this is questionable. It is difficult to determine if in fact it is the 'traditional' norms as it is claimed, or enforced religious adherence that actually discourages and prevents women from stepping forward to complain or to seek protection (Freedom 2004; see also Drage 1994; Crocombe 1994). Sāmoan villages are immaculately kept and controlled by women's committees in contrast to the urban areas that are classified as the male domain. 


\section{Redefining human rights}

The significance of an 'outsider' claiming the right to determine a particular way of life for others and on behalf of all citizens of a nation state cannot be understated. Representations of unique cultural identity by nation states have normally resulted in violent battles between external occupying powers with their settler populations and internal, usually indigenous, independence movements (e.g., see Hodgson and Schroeder 2002:80). Since independence struggles against an occupying nation state did not occur in Tonga or Sāmoa, the concepts of 'cultural identity' and 'tradition' have vastly different meanings in comparison to those countries that have been involved in independence movements. An illustration of the negative impact of representations made about Polynesians is the recent sensational media story about the long arm of British law that has followed the 1790 Bounty mutiny leader, Fletcher Christian, long after his death. The criminal defence argument was raised that Pitcairn Island was a social 'experiment' gone seriously awry due to the absence of external influence (i.e., the extreme isolation in the middle of the Pacific Ocean) and inbreeding activating the claim to a unique identity and 'sexual tradition.'

The current sensational criminal trials, where seven men, including the current mayor, faced "nearly 100 charges of rape and child sex abuse dating back to the 1960 s.... [And] a second batch of six men, who now live in Australia and New Zealand, will go on trial next year, charged with similar offences" (Marks 2004; see also Wark 2004). Two girls filed a complaint to a British constable, Gail Cox, who was conducting police training two years ago, and the case has now grown to involve 13 defendants and 12 
victims, including one victim who was 5 years of age at the time. Nothing is said about the fact that the mutineers killed the male Tahitians, took their partners (wives) as their own and eventually slaughtered each other (Pitcairn government 2004). This story of the virtual slavery of Tahitian women does not make it a Polynesian 'tradition' even though it has been presented as such.

The concept of self-determination has historically described autonomous smallscale, indigenous, or tribal groups that self-identify or could be classified as belonging to a single cultural area. As noted, Polynesia could be classified as such, but is generally not, simply because of the number of colonial nation states involved in the colonial enterprise in the Pacific. Polynesia as a single cultural area was not held intact. As such, most groups activating the claim to self-determination against a colonial nation state were assumed to lack the social and political institutions of government and were subsequently brought under the formal control of newly established nation states as the enabling mechanism for self-government. As such, most indigenous groups subjected to such containment were also engaged in political independence struggles based on various strategies of ancestral cultural claims, human rights principles, or separate national governments. Despite United Nations sanction for self-determination, nation state governments and international bodies are reluctant to approve outright support for indigenous control over "land, power and authority" (Orange 1987:1). As in the case of economic development, the preference of a nation state appears to be for the appearance of 'sustainability,' 'partnerships' and 'cooperation' rather than the granting of selfdetermination outright to indigenous peoples. Further, these terms apply within 
predefined and fixed parameters, ensuring that indigenous peoples do not control anything, except what they hold a legal title (e.g., copyright) to.

Given this context, European demands in the past are often described and accepted as having been delivered in a paternalistic manner, but they are forgiven because as claimed, European demands were intended to "protect... traditional political practices and institutions" (Lawson 1997:161). A compounding factor eliminating the 'traditional' from view, is the contemporary view that a global culture (Smith 1990; see also Escobar 2001:169) is emerging, but it is emerging within a frame where a restructuring of the existing ideas about resistance, identity construction, and the adversarial relationship to the colonial form of State have not happened. The question is whether this is an appropriate starting point for an analysis of economic versus political development that ultimately allows the analysis to rest on the degree of accommodation, or, in today's terminology, the degree of participation in 'negotiation' processes, either formally, as in New Zealand's Treaty of Waitangi, or informally, via relocating peoples, as in Fiji, or using numerous other means, e.g., adding or changing laws. All had the appearance of being beneficial to indigenous peoples and their cultures.

Unlike Tonga and Sāmoa, New Zealand has an established Māori arts industry, including performance arts, and a general tourism products industry. The NZ government (TRCNZ 2001) tourism report was a compilation of findings gained from responses about the tourism industry by tourism operators in New Zealand. The report highlights that Māori-owned industries report significantly lower incomes (between $\$ 50,000$ to $\$ 350,000$ annually), than non-Māori-owned industries, largely due to a lack of financial resources, difficulties securing financing, allegedly limited available training 
and education in how to run an economically viable business, and because these industries are often considered to be high-risk investments- even though they are listed in the top 15 'must-see attractions' by international visitors. Non-Māori tourism operators sell 93\% of Māori tourism production, and complain that sales are low because of "the lack of new products, limited variety of products, variability in quality and uncompetitive pricing" (TRCNZ 2001; see also TRCNZ 2003). It is suggested by the majority of tourism operators that since earnings are low for non-Māori operations selling 93\% of Māori cultural production, then Māori operations selling only $7 \%$ of their own production are affected by the same dynamics. Thus, in the context of globalization, economic competition and the tourism industry, this belief is translated into common themes that are expressed in the New Zealand government tourism development literature: 1) that there is a need for indigenous peoples to take responsibility for their own business success or failure, 2) that there is a need for indigenous peoples to accept partnerships with governments and/or the private business sector that can provide capacity building, training and education, allowing Māori to take 'ownership' of their own businesses and culture, and be 'agents of social change,' "not victims of it" (TRCNZ 2001:21; see also Harrison 2002:589; TRCNZ 2003:63ff), and 3) that successful indigenous businesses need to accept self-sacrifice on behalf of the whole group, e.g., by employing, backing, or directly financing their own people.

Māori tourism operations representing only $7 \%$ of all tourism Māori cultural products sold, does not make their perspective (even if every single one responded to the call for information) representative enough to protect the whole of Māori culture. They remain significantly outnumbered by non-Māori operators, without adding financial 
institutions and government agencies. With this in mind, the first, eighth, and ninth recommendations for improving Māori-owned tourism industries are of particular interest: the first, (TRCNZ 2001:11) to Develop and Implement a Market Research Programme for Māori Tourism to gather market data on product branding, visitor satisfaction, business distribution and attitudes towards tourism, the eighth, (TRCNZ 2001:20) to Protect Intellectual and Cultural Property by ensuring amendments to existing legislative mechanisms e.g., the 1994 Copyright Act and to implement an authentication branding system for tourism Māori cultural products, and, the ninth, (TRCNZ 2001:21) to facilitate Māori Self-Determination. The insertion of special conditions for the protection of the production of Māori cultural products, i.e., the selection of a "well chosen mark of authenticity," (TRCNZ 2001:20) combined with selfhelp capacity building strategies even in the form of Māori Self-Determination, will not be sufficient to protect Māori culture, for the simple reason that the frame of reference is not the protection of culture.

In practical terms, due to vastly different ownership and management systems, New Zealand's copyright legislation standardizes the assumption that Māori and the New Zealand government economic development goals are exactly the same and that Māori culture actually belongs to everybody in New Zealand. Based on this assumption, the control of Māori cultural product production is assumed to be the best way to meet the tourism development goals for the benefit of everyone, including Māori. The problem is that "the western individualist notions of originality within the copyright framework... undercuts traditional systems" (Anderson 1990:10; see also Cheater and Hopa 1997:214220) and removes existing Māori control of their own cultural production. Whether the 
removal of Māori control was intended or not, the proposed authentication process, described as having the potential of allowing sellers to charge a premium price for the products produced because production quality is assured, does exactly that. And in exchange for producing the correct products, Māori will have something to be proud of. The protections offered are for those who wish to sell Māori culture, not those who wish to protect their cultural identity from ownership claims in the first place.

While the question of 'authenticity' may play an important role in a market economy, the political influence in choosing what is an 'authentic' cultural product raises the question of when this influence becomes cultural appropriation or theft (Anderson 1990:10; Marcus and Myers 1995:33; Crew and Sims 1991). Copyright legislation doesn't remove the question, because legislative controls cannot simply be mapped onto indigenous systems of regulating their cultural symbols. The choosing of what is 'authentic' within the context of institutionalizing authentication procedures for cultural production and "the ways in which different styles of representation reflect or help constitute particular theoretical stances" (James et al., 1997:3) actually supersede the need for mechanisms defining ownership, control and the right to decide what representations can be made. In such a way, the New Zealand government has assumed the authority to represent the Māori, for the benefit of everyone in New Zealand, having selected what it considers to be the most appropriate strategies for the development of Māori tourism industries. The Māori are given the choice to participate in economic development educational partnerships or not. Further it is assumed that Polynesians in general do not need representation in determining how their culture(s) should be protected either, indicating that a time will come when New Zealand tourism operators 
may challenge the tourism cultural production of shared Polynesian symbols offered, for example, in Tongan and Sāmoan craft markets.

The ethical dilemma relates to whether or not this kind of treatment of 'subject' peoples, and support for critical practices and cultural representations that are detrimental to indigenous peoples, are acknowledged at all. Indigenous peoples are held to an unequal and subordinate position — that is then used against them to limit their ability to exercise actual control over their cultural symbols and cultural representations by others. Tourism production in this context is the same as academic production in terms of "constructed domains of truth, serious fictions" (Clifford 1988:10; Pearce 1990:138-139; see also Bowman 1997). The critical question is whether a claim to authority can be accepted where there is a significant power imbalance between a researcher/government and the subject that would be sufficient to override the 'sense of one's place,' which is "at the same time a sense of the place of the others... at the root of all processes of cooptation... including legally sanctioned relationships" (Erving Goffman cited in Bourdieu 1987:5). In this context, authentication processes have a very specific meaning for indigenous people — the continued removal of their human rights (i.e., their right to decide) rather than being permitted to "determine their own future" (Agrawal 1995:432; see also Cheater and Hopa 1997). The New Zealand government's intentions may be honourable in terms of encouraging indigenous tourism industries, but demanding Māori relinquish control over their own production is not the answer. The only task left is to free "themselves from their ethnological fate" (Ames 1992:87) of being blamed for the negative outcomes that come about from the removal of individual and cultural rights. Positive outcomes, on the other hand are allocated 'for the benefit of all.' 
Economic development terms such as 'sustainability,' 'partnership,' 'cooperation,' 'community,' 'participation,' and 'empowerment,' just to name a few, all have different meanings in practice, depending upon who one is. This difference can only be measured in terms of the "effects on peoples' lives"” ( $\mathrm{Li}$ 2002:266; see also Brosius 1999:37; Rocheleau 2001:86). As such, one possible analytical lens is the concept of 'human rights,' comprised of previous concepts such as 'natural rights,' 'natural law,' 'the rights of man,' etc. (Weston 1992:14). Human rights as we know them today were originally conceived in 1945 and listed in the International Bill of Human Rights. The first set of these rights comprise the Universal Declaration of Human Rights that "went to the General Assembly in September 1948 and was adopted on 10 December of the same year without a dissenting vote" (UN 1987). The remaining instruments of the International Bill of Human Rights were opened for signature in 1966 and came into force in 1976. These remaining instruments were grouped into either the International Covenant on Civil and Political Rights, or the International Covenant on Economic, Social and Cultural Rights (Donnelly 1998:6, 165-168; UN 1987; UN 1997). The second class of rights forms the existing approved basic social protection standards that guarantee individual rights to socially provided goods and services (such as food, water, health care, education, etc.), historically provided through state-centric institutions, i.e., via the Welfare State.

The advantage in viewing human rights through the lens of the Universal Declaration as a whole is that it automatically over-rides the negative connotations of current rights discourse used to mobilize resistance and to negotiate the restoration of specific individual or group rights. The drawback is that not every state has signed onto 
both classes of rights. For example, the United States has signed the Civil and Political Rights covenant but not the Economic, Social and Cultural covenant. And it is difficult to avoid the built-in bias for allocating special rights to specific groups in that the Declaration already distinguishes between rights that are applied equally to all and those that are special rights. For example, Article 25.2 "Motherhood and childhood are entitled to special care and assistance" (Donnelly 1998:168): hence a woman's human rights are more likely to be viewed in terms of the biological functions of childbirth, or as being "secondary, or trivial in relation to other human rights" (Bunch 1992:969). Nevertheless, acknowledging that both classes of rights are contested or negotiated places the parallel process of eroding state government roles and responsibilities towards its citizens by way of downsizing government and transferring social protection service delivery to private non-profit and private for-profit sectors of society, within a very specific context that take on "different meanings in different contexts" (Cordes et al., 2001:91).

Tonga and Sāmoa have not been immune to these same processes - it has just been enacted differently via privatization of services to religious organizations rather than non-government organizations (NGOs), with exactly the same end results. Transferring social welfare to the private domain significantly controls, and in fact, determines, the way public life and public spaces are conceptualized and in the values associated with them (see Banerjee 2001:9-13; see also Esping-Andersen et al., 2001; Taylor-Gooby 2001; Visser 2000). Reversing the negative impacts of privatization, regardless of the model individual governments have used, is complicated in the Pacific, in that the very basis upon which the colonial systems of government control were constructed is vastly different from the original indigenous social systems. 
This does not mean that public action and reaction ceased, but it does mean that contemporary social protest movements are constrained by structural colonial and therefore 'Christian' categories and understandings of human rights and the construction of corresponding social protective systems. Those who recognize a "strong nation state committed... to the Western ideal of democracy and economic prosperity... [have also watched] less and less concern for the common good" (Chace 1995:130). Several strategies have in fact been tried in an attempt to implement or renew human rights for the common good, with limited success. For example, the concept of civil society has been reworked several times over, with new terms such as the 'global commons,' 'civil commons,' 'tourist commons,' etc., and various other terms being coined in an attempt to add new dimensions to the human rights debates (Briassoulis 2002:1069-1070; Garland 1999:74; see also Jasanoff 1999; Keller 1996; King and Murray 2001; McMurtry 2001; Smith 1990; Walzer 2000; de Zengotita 2003). At the international level, the Organization for Economic Cooperation and Development (OECD), monitoring the formal list of countries eligible for Development Assistance from funding donor member states in 1996, introduced in the Shaping the $21^{\text {st }}$ Century statement the idea that sustainable development actually meant development that was locally owned, highlighting the maintenance of a significant difference between donors and receivers of funding.

To bring about the transfer in 'ownership,' donor programs (multilateral agencies and non-government organizations) were expected to switch to a partnership model specifically encouraging stronger local commitment, participation, and ownership of development projects in terms of a developing country financing its own development 
programs through public expenditures (OECD 1996; see also Tsing 2000:118; Rankin 2001). This strategy was then linked directly to the United Nations Millennium Development Goals, targets and indicators that were unanimously adopted in September 2000 by the member states of the OECD, committing them to an expanded vision of development beyond the realm of economics. Goldin et al., (2002) suggest that, because a consensus emerged among OECD member states around the view that development meant increasing the control of the poor over their lives through education, health, and participation, there has been a shift in conceptual thinking. However, they also note that in practice such a shift is not always identifiable or quantifiable, drawing the same conclusion that public-private development partnerships are essential to activate desired self-help strategies.

There are eight Millennium Development Goals, 18 targets, and 48 indicators for the measurement of results of development projects in developing countries as well as for those countries and multilateral institutions that fund development programs. The Pacific Millennium Development Goals are identical to the United Nations Millennium Development Goals one to seven, although in a slightly different priority order, excluding targets 8 and 11. Target 8 is to reverse the incidence of malaria and other major diseases and Target 11 addresses the problem of slum dwellers and urbanization. The first seven goals (11 targets) are considered to be mutually reinforcing, in that any improvement in any one will help to reduce global poverty in general. The eighth goal (targets 12 to 18) is specific to creating global partnerships for development and is described as the means by which the first seven goals can be achieved. The difficulty is that the poorest countries or regions of a country, and heavily indebted countries, will need more than a 
self-help strategy designed to replace increased assistance from wealthier countries and regions. The claim that all countries (rich and poor alike) will benefit from the removal of trade barriers to facilitate the free exchange of goods and services will never actually improve the export markets of aid-receiving countries if the funding countries do not open their borders to imports. 'Partnership' does nothing to change this.

Polynesian countries are supposedly better placed to accomplish the goals of the Millennium Development Goals to reduce poverty and hunger at the same time, compared to Melanesian, Micronesian and Asian countries. The similarity of these distinct cultural areas relates more to problems such as malnutrition in women and children that also point to: 1) the overall devaluation of women and children in general, and, 2) the changes in land ownership as a result of the formal switch from a subsistence economy to the western monetary economy, displacing large numbers of people, predominantly women and children. Polynesia is also noted as a Millennium Development exception, having low rates of child mortality, maternal mortality and relatively high rates of universal primary education. But herein lies the difficulty. As an example, both Tonga and Sāmoa have more than $95 \%$ of children enrolled in primary school, thus limiting their ability to secure funds for a problem that does not appear to exist. But because the emphasis is upon enrolment, the high scholastic attrition rate beyond the age of ten and an education system that has maintained a strong religious and gender-biased curriculum cannot be addressed. Given such a European structural foundation, the existing political framework excludes the possibility for equality and also structures political discourses "within which social inclusion is deployed... [to] repress conflict" (Levitas 1998:187-88, see also Weinthal 2002:88) rather than to encourage 
different perspectives and alternatives that ultimately offer opportunities for structural change. Hence the colonial/religious social order is actually reinforced.

Today's citizens, no matter which country they belong to, are being told that they must help themselves and not turn to government for help (Wilson 1996:569). In this context, the fundamental concern becomes: how do citizens ensure that their own individual human rights are maintained, especially if the state withdraws from the role of protector? Matthew (1998:118) and others, argue that the concept of 'human security,' defined as social protection of those items that individuals require for survival e.g., fresh water, clean air, food, and shelter, qualify as a 'national security' issue that has the potential of ensuring that the state continues to retain the responsibility for the full spectrum of human rights (see also King and Murray 2001:585; Keller 1996). The down side is that this connection to the state encourages states to choose crisis management strategies that produce "counterproductive and...undesirable side-effects" (Deudney 1992:171), such as the co-opting of NGOs and resistance movements (Crewe and Harrison 1998:94; Edwards et al., 2000:5-6; Weinthal 2002:108). Deudney (1992) adds that the "most attractive feature of linking fears about environmental threats with national security mentalities is the sense of urgency engendered, and the corresponding willingness to accept great personal sacrifice (Deudney 1992:177). Hence, the real question is whether the benefits of increased state attention to environmental issues combined with concepts of security "are worth the harms caused by imprecision and negative connotation and effect" (Broda-Bahm (1999:160). In an island environment, the link between the environment and human security is very clear, but there is a significant difference between the dominant European and subordinate Polynesian worldview. 
Gardner (1995:200ff) and others note the emergence of grassroots environmental movements (GEOs) in developing countries that have begun to use the environment to expand human rights in their local communities. These are the groups confronting everything from diminishing natural resources to government corruption. The emergence of the environmental movement, labelled environmentalism, "was synonymous with a rather narrow concept of conservation - the protection of nature... driven more by strongly held values than by scientific or economic analysis" (Keller 1996:11-12). However, it is clear that most GEOs, in any given country, are a direct result of a particular nation's social, political, and economic history that ultimately structures what concerns and issues will be addressed and in what order. They do have one thing in common - they tend to be comprised of poor or indigenous populations seeking protection against local human rights abuses related to advanced environmental degradation and loss, such as deforestation, desertification, damming and flooding projects, and/or the lack of direct input or decision-making capacity within foreigncontrolled development projects. These groups also tend to have a much lower level of organization, most often due to a lack of resources in comparison to their sponsors, the internationally based environmental and/or economic development non-governmental organizations or (NGOs) in industrialized developed countries.

Women also comprise much of both the membership and the leadership of GEOs. This is explained by two major factors: 1) women tend to be held responsible for all domestic duties, such as collecting firewood and water, cultivating crops, tending livestock and rearing children. Women suffer firsthand the effects of a deteriorating environment. For example, when a forest disappears women must walk farther to collect 
firewood; and 2) women tend to establish informal social-support networks more readily than men and they are less likely to migrate than men. Unfortunately, because these factors also structure women's participation, this does not indicate gender equality or women's independent action. It is more likely indicative of the economic and ecological stresses that prevent women from fulfilling their household and caring responsibilities. Thus, women's participation in GEOs is indicative of a survival response that simultaneously reaffirms and rejects traditional gender roles. The point that needs to be emphasized is that the strategies enacted by GEOs and NGOs are political in nature and constrained by fiscal dimensions rather than social needs (Gardner 1995:200ff). The difficulty, then, is that not all environmental degradation strategies presented as threats to life and property can be considered equal threats to state security (Deudney 1992:174). Most environmental problems actually reflect economic and decision-making inequalities (Swatuk 2002:151; see also Blum 2002:174-176; Swain 2002:67) related to resource capture, extraction and competition rather than sustainable practices that would be conducive to either individual or group human rights. The majority of arguments in support of current welfare and/or human rights regimes indicate that the control of citizens remains a desired goal that is best accomplished by eliminating the very services citizens require for survival.

This is a significant threat to democracy itself, but one that can be ignored completely as soon as human rights are placed within a national security framework. From this perspective, it is understandable why the concept of social cohesion is offered up as a plausible explanation as to why existing organizational responses to current economic, political, environmental, social and cultural "faultlines" (Jeannotte 2002:5) are 
fragmented, ineffective, expensive, and exacerbate the problems identified. Further, it also explains why there is such a strong organizational reluctance to consider alternatives that would acknowledge and add human rights to current policy. The end result is that the status quo is maintained and reinforced rather than changed. In transforming social and human rights issues into questions of security, we are turned into consumers of security products (Neocleous 2000; see also Deudney 1992), and it becomes a clear indication of a trend towards permanent insecurity for the majority of citizens (McBride 2000:18-22). Rather than supporting strategies for structural change, the existing framework, as noted, is actually buttressed against change.

The primary barriers to implementing environmental and human rights protective mechanisms relate specifically to the corresponding and existing barriers that prevent cooperation: 1) historical memory of those involved in economic and political decisionmaking processes and the associated lack of trust among them, 2) the refusal to consider alternatives without the use of coercion and the associated 'othering' processes that ignore the different perceptions of value placed upon the provision of immediate social or welfare services to citizens, and 3) the inability or lack of capacity to coordinate efforts on behalf of citizens (VanDeveer 2002:49). Coordination requires the abandonment of the 'superiority custom' as a first step. Hence, the current competitive framework ensures that GEOs, NGOs, and other activist groups remain in opposition to the state and to multinational corporations, with the only option ever offered being to buy into the framework of insecurity, coding all objections to current policies and enforcement practices as "arguments against security" (Neocleous 2000:8; Matthew 1998:119). The implications are that state's interests are prioritized against and thus supersede individual 
and group human rights. Thus the doctrine of 'national security' is expanded into the realm of 'human security' with the extension of security being offered to " Commercial Property' as a whole.... and '[the] care for the particular interest as a common interest'.... [and the] securing [of] civil society; a mechanism, that is, for securing class society" (Neocleous 2000:10-11, 13, emphasis in original) allowing for the greater exercise of state power. Adding the human subject to the security mix has also significantly complicated the notions of citizenship, democracy, and environmental sustainability. "[T]he future - for human security and the environment $-\ldots$ [begins with the recognition that] 'nature' [is] both internal and external to the human subject" (Redclift 2001:298, emphasis in original).

Given this context, security refers specifically to being and feeling secure or protected. The processes of 'securing and making safe' carry strong economic and legal connotations, as in 'security-bonds' or as in "'unable to escape"” (Neocleous 2000:14). As the term 'social cohesion' implies, the "inherently political [set of] processes" (Vertovec 1997:47) comprised of defining, formulating, and gaining a consensus of meaning is governed more by identifying specific common values that are capable of binding certain people together permanently. Thus, it "will always be contested" (Beauvais and Jenson 2002:30). But within the management realm, debates tend to revolve almost exclusively around economic issues, such as the "'cost' of social spending for economic competitiveness" (Beauvais and Jenson 2002:31) that ensures that the "emphasis is on personal responsibility, not inequities in the larger society" (Wilson 1996:569). 


\section{Towards sustainability}

There are great differences among Pacific islands in terms of their characteristics and type of tourism development, but there are some common characteristics: isolation, integration, dependence upon export monocultures, and fragile environments. How these characteristics are viewed, as either positive or negative, also corresponds to the difference in worldview about Pacific islands and Polynesians and highlight that the "theoretical landscape of sustainability has changed, and is changing, almost beyond recognition" (Redclift 2001:298). For example, island societies have historically and hence traditionally been self-sufficient in food production, and human activities or patterns of living were based upon local environmental conditions and resources until fairly recently (Coccossis 2002:131). From this 'traditional' self-sufficient economic perspective, local development has historically comprised a much narrower resource base designed specifically to provide local markets. Exports were rarely if ever considered. From this 'traditional' social and cultural perspective, local island cultures are distinct in social organization and value systems because they are isolated and small. Both cultural and economic perspectives emphasized a strong relationship between society, economy and the environment, so that, overall, every island was ultimately vulnerable to external influences. Contemporary global economic restructuring and global institutional restructuring, as significant processes of the European/western worldview, directly affect tourism development (Coccossis 2002:132) and island infrastructure development funding. 
Hence the 'traditional' systems are viewed as being the major factor preventing small island countries from making a transition into the global market economy. The importance of the subsistence economy to local island communities is rarely considered within the frame of export markets, international price instabilities, high transportation costs, the lack of overseas markets, and/or changing weather patterns (e.g., Sāmoa 1999:5). Within the export frame, subsistence economies cannot be measured or included in international economic indicators. The standard linear statistical terms and environmental indicators (e.g., GNP etc., Esping-Andersen 1993:125; Huges 2002:462468) significantly affect the validity of the analysis and funding allocations. The ambiguity built into the selection process of indicators ensures that there is only a very slender chance of defending the environment against continuing global pressures to develop tourism. However, locally, when the subsistence economy is lost in the transition to the global market economy, the market being a metaphor meaning 'forprofit' (Cordes et al., 2001:92), the difficulties experienced correspond directly to an increase in poverty (Smith et al., 2000:200-202; Pinstrup-Andersen 2001). Poverty is generally referred to in terms of 'root causes' affecting access to food: 1) urbanization, 2) rising economic output, 3) high consumption/high waste lifestyle, 4) lack of access to resources for the majority, and 5) globalization of trade, investments, and debts (UNESCAP 2000(a); see also King and Murray 2001:586; Adger et al., 2000:4; Briassoulis 2002). Research themes such as globalization, technological change, entrepreneurship, labour process and restructuring etc., currently form an impressive body of literature (Agarwal et al., 2000) but still leave significant analytical gaps in terms of strategies to halt and prevent poverty. 
A common theme in much of the tourism literature during the 1980s and 1990s has been the emphasis upon sustainable development. The concept of sustainable development "and, therefore, sustainable tourism development" (Hunter 1995:52; Hunter 2002; see also Briassoulis 2002; Hardy et al, 2002; Teo 2002) involves two distinct and important elements: human needs and environmental limitations. "Ecologically sustainable tourism calls for the endorsement of forms and scales of development which do not carry the risk of irreversible outcomes, or which impose unacceptable costs on future generations. Sustainability implies ongoing concern for the maintenance of those environmental qualities which attract and give satisfaction to visitors" (Pigram 1995:208; see also UNESCAP 2000(a) and (b)). The question remains, whose interests are being talked about? It was in this sustainable development spirit that the tourism industry and governments around the world integrated tourism development procedures to assure environmental sustainability in multiple and varied ways depending upon the country. Ecotourism was and remains an important tourism industry strategy that allows for funding to community-based conservation areas and also enhances both the host environment and the long-term prospects of the tourism industry.

Highlighting the environment as a critical dimension of 'sustainable development' was intended to shift the institutional emphasis away from dealing with environmental, economic and social development in a singular fashion to a more comprehensive interconnected approach. Nevertheless a standardized research process places the Pacific fairly low on the priority list for funding and/or local projects. Even though the United Nations may recognize the overarching need for poverty reduction in state/national policies as a fundamental prerequisite for achieving sustainable development, small 
island economies are characterized by resource and market scarcity and external influences (McElroy and Albuquerque 2002:17). Policy planning, then, needs to be defined in terms of attaining a comprehensive global strategy rather than undertaking isolated local sustainable development projects (see UNESCAP 2001; see also Briassoulis 2002). The basic economic problem remains. "Local autonomy is further restricted by heavy reliance on basic and intermediate imports... [T]his dependence is so intense that the domestic cost of living — and the destination's international competitiveness - is largely set by transport and fuel prices and inflation and exchangerate movements of its foreign suppliers" (McElroy and Albuquerque 2002:17; see also Daley 2000:110). Any shift in world prices or trade practices has a tremendous impact upon financial resources, directly affecting the price of limited export products and capital investments. Hence there is considerable concern about the pace and terms of globalization, especially trade liberalization mechanisms that seriously undermine any nation state's efforts to implement sustainable development.

The environmental dimension of sustainable development has another dependency face. The Pacific islands, in particular the islands of Tuvalu, Tonga, the Federated States of Micronesia, the Marshall Islands, and the Cook Islands, are vulnerable to the adverse impacts of climate change, sea level rise and other environmental conditions induced by human economic activities external to the island environment. Coastal erosion, for example, "is already a serious problem in many of these islands and at least two low-lying islands have already eroded below sea level" (UNESCAP 2000(a)). Given the Pacific's small land area and sparse population, the Pacific people, as a whole, do not see themselves as being responsible for climatic 
change. The problem is that the Pacific is on the front line to experience the direct negative impacts of this change, forcing them to adapt to conditions largely unforeseen or created by others, or to consider abandoning their islands as a result or as Tuvalu and Greenpeace have decided to do, file a lawsuit against two major US agencies, the ExportImport Bank and the Overseas Private Investment Corporation. (THE EDGE 2002). The choices are rather grim.

As such, the Pacific peoples advocate the 'polluter-pay' principle, and urge developed countries to reduce greenhouse gas emissions by reducing fossil fuel and biomass use (UNESCAP 2000(b)). They are also seeking greater assistance to enable developing island nations to mitigate (control) damages and to implement long-term adaptation strategies. To this end the Barbados Programme of Action for the Sustainable Development of Small Island Developing States fully funded by the Global Environment Facility (GEF) at the international level was designed specifically to formulate policy, and to develop mitigation, adaptation and preventative action plans. The World Bank is not optimistic with this first attempt to coordinate numerous regional and sub-regional agencies, bilateral donors and non-government organizations (NGOs) conducting work in the Asia-Pacific region (UNESCAP 2000(b)) simply because it is extremely difficult to implement and fund your own development strategies when heavily dependent upon foreign aid and remittances. This is exacerbated by aid funding reductions by OECD donor member states engaged in welfare state retrenchment programs. Again, Sāmoa is eligible for GEF (Sāmoa 1999) funding, but Tonga is not. Hence Tonga is considerably behind Sāmoa in terms of environmental protection. 
Throughout the Pacific, rapid economic development has led to a decrease in overall environmental quality. Environmental degradation affects island populations directly, forcing people to migrate to an urban centre, contributing to population concentration that often extends onto prime agricultural and/or forest lands, ultimately contributing to increasing air and water pollution (UNESCAP 2001), or leaving the island. Although both the rural and urban populations experience environmental degradation, their experiences are nevertheless quite different, requiring vastly different policy and action strategies "in the face of global climate change" (Adger et al., 2000:24; see also Yohe and Tol 2002; Lise and Tol 2002; Wilbanks and Kates 1999: 603-604). The emphasis upon vulnerability and adaptation within contemporary western-derived sustainable development processes and the global development funding context, within which economic and social development and environmental protection programs are being encouraged and implemented throughout the Pacific, is significantly problematic. Adaptive capacity, as an organizing and research concept combined with institutional capacity-building (i.e., self-help) strategies, viewed as providing workable indicators of vulnerability and the tools to manage potential impacts of various threats, is still very much dependent upon a country's resources to respond adequately to problems. The emphasis upon state responses to poverty rather than the causal relationship between poverty and environmental degradation may actually promote large-scale multinational environmental destruction as a result of commercial timber extraction, urban settlement and/or plantation land clearing and natural resource extraction.

The global economic system is based upon the assumption that the price of all commodities reflects the full social and environmental costs of production and that the 
allocation of resources is managed efficiently. This may sound contradictory, but it is the foundational idea of the global market system. The power imbalance between the North and South is then played out in terms of management strategies such as subsidies on energy, kerosene, diesel, electricity, water, fertilizer, credit, etc., that can significantly distort global pricing practices, overriding the requirement to cost out or include all costs of production. This partial form of resource allocation leads in turn to the overuse of resources and/or commodities, and environmental degradation, which encourages further social dislocation, particularly for those who do not receive such subsidies. The beneficiaries of such globally designed management strategies are not the poor, developing nations, or island environments, simply because they are usually not the ones in a position to purchase or to consume. Increased economic activity (especially productivity gains and capital investments) may result in higher average incomes, but it does not correspond with a reduction in poverty, the implementation of equity programs, an increase in employment rates, or the implementation of environmental protection programs. Rather, higher average incomes (see King and Murray 2001:586) usually point to an increasing gap between the rich and poor. If liberalized trade promotes greater efficiency, higher productivity and investment, enabling the transfer of technology to reduce pollution, for example, the main challenge should be to implement policies that ensure that trade does not harm the environment or the culture.

Consumption alone, beyond reasonable limits, especially those established by the environment itself, and "production characterized by gross inefficiencies in the use of energy, water and materials and in the distribution of resources" (UNESCAP 2000(a); see also Agarwal et al., 2000) prevent sustainable development. Attention must be directed 
toward "the ways and potentialities of present systems of economic and social regulation, assessing how these may begin to bring about institutional and value change at the social and economic level" (Drummond and Marsden 1988:22). Hence the key feature of sustainable development remains the problem of allocation and the effectiveness of institutional governance.

Management, or control of the sustainable development framework in terms of accountability, participation, predictability and transparency as required by the OECD development funding bodies, also requires national institutional governments to: 1) focus on the Millennium Development Goals, e.g., poverty reduction etc., 2) develop and implement policies to guide established institutions to accomplish those goals, 3 ) improve administration and participation for better delivery of social services, 4) shift decisionmaking to local communities directly affected by environmental conditions, and 5) strengthen the rule of law to eliminate corruption (UNESCAP 2000(a)). Unfortunately, the 'polluter-pays' principle is not applied; it is simply passed back to the individual country to establish the action plans, fulfill the requirements of the action plans and eventually pay for all future action plans. Managing and controlling damage efficiently is frankly irrelevant. 


\section{Protecting one's own}

The management function of government is quite different from the political function of determining the degree of individual well-being that a society wishes. Therefore a distinction has to be drawn between citizen coping strategies and resistance strategies in response or reaction to the management and delivery systems of government. Citizen coping strategies are defined here as ensuring individual survival, but because these strategies are focused upon individual or minority group responses to the management system of government, they have the effect or end result of maintaining the management function status quo. Resistance strategies, on the other hand, are political in nature, designed to address broad-based conflict issues such as determining the degree of well-being of society as a whole, with the aim of ultimately inducing change in the political and/or legal frameworks and operational (management) structures (e.g., the rules of membership, rights, statuses, capacity to participate, access to and use of resources, etc.) that shape, limit and direct forms of mobilization, participation, and action, particularly beyond the borders of one state.

Given the global interconnectedness of our world today, the industrially developed 'North' is faced with the responsibility, more so than in the developing 'South,' of ensuring that "everything [remains] constantly open to question, that everything [continues to be] discussed, and that in so far as decisions have to be taken, we are not tied to the past" (Durkheim reproduced in Abdo 1996:148). Currently, the past ensures that the only strategies that can be considered are coping ones. 
To study the "symbols-and-meanings conception of culture" (Shweder 1984:2) implies understanding what something means to another, raising much controversy especially with regard to whether there is a set of shared meanings or collective representations that make it possible to speak with one voice between cultures. The argument that there is no neutral language that describes the world has major implications, not only for the practice of social science, but also in how resistance to the dominant ideology and language is expressed. This challenge not only suggests that representations and images presented in any description can be 'read' as though they were text, but also makes clear that the process of reading another is an adversarial process, your interpretation or mine.

Resistance, then, to prevailing or dominant thoughts expressed in various descriptions form numerous "other" perspectives or multiple interpretations of the same thing, ensuring that the original or first description will not be sustained or continue to be frozen in time and space. As such, any description cannot be treated as though it were the only objective truthful record of fact either. 'Facts' are reinterpreted in the context of the present. Each 'story' has its own set of exclusions, silences, or absences that serve a purpose. First, they are necessary for the story to make sense in the present, and second, they are an effective mechanism to hide or subdue other meanings at any given point in time. Following this logic, the idea that descriptions or meanings change over time raises an additional question of whether or not it is a particular story itself that is intended to transcend time or something else.

The nineteenth-century scholars used the concept of 'development' to explain human history as a function of linear movement obviously requiring universal 
mechanisms to govern that movement. "The ideological connotations involved with the term development gave it a meaning close to the term "progress"' (Galeski 1976:152), and both terms were frequently considered interchangeable. By the twentieth century, the evolutionary idea was replaced by what was considered to be a far more neutral idea 'social change' — but stripped of ideology, history, and the universal linear movement through time. This more neutral term was expected to eliminate a vast number of problems, making it possible to avoid social conflict and therefore the need for conflict resolution mechanisms.

Until very recently, "exotic features of non-western economies were simply regarded as backward and illogical... and the eradication of such characteristics was said to be indispensable for economic progress" (Takahashi 1997:33; also Agrawal 1995:413). The end result was that "development" tended to reinforce the status quo of western thought rather than to encourage the study or management of social change itself (e.g., see Cleaver 2001:38-39). The terms 'developed' and 'underdeveloped' are commonly used to include some form of change analysis through themes such those noted by Chambers 1983:28; Chambers 1995:30; Escobar 1991:659; Gardner and Lewis 2000:15; Esteva 1992:6; Rahnema 1992:159-161; Anderson and Smith 1998:142; Galeski 1967:158; Ramirez 1999; Sachs 1992; Shiva 1992, and many others.

Even so, current analytical management themes are insufficient to address issues of conflict and social change, either at the local, regional or international level, because there is not even an illusion that the European/western worldview, or the methods and procedures from the colonial past, have been changed to make it possible. The inherent politics of representation significantly constrains the peoples of the developing world in 
general, defining their reactions to continuing human rights abuses in their local communities. Global economic progress and increased electoral political freedoms, although fundamental to human development, have only limited value if the development projects are applied only to specific pre-selected groups of people (Galeski 1967:160161). "As indigenization of the learning in social sciences and humanities are prevailing in the third world... studies of development and economic ethics ought to indigenize the approach...." (Takahashi 1997:44), ensuring that all citizens experience the full extent of their individual human rights. The difficulty for the developing world is that economic globalization follows the standardization of western business and management ethics, not the standardization of human rights.

The "greatest danger with participation is that the words will be used without the reality of changed behaviour, approaches and methods.... Unless the behaviour of most outsiders changes, participation will not be more than partial" (Chambers 1995:41; see also Lise and Tol 2002). Inequality, then, is automatically built into the system of management, with a tendency to multiply inequality, in the sense that a lack of income also affects access to health care, education, employment, social assistance, power and prestige, etc. In Marxist terms, the most important source of inequality stems directly from an unequal access to the means of production, especially in societies that allocate private ownership of the means of production. The gender and/or social class that possesses the means of production also possesses power, higher prestige, better incomes, greater access to all benefits, and they also possess the means to enforce change or to maintain the status quo. The enforced social organization of Polynesia is considerably unequal with respect to both gender and class. 
The growth of imperial colonial European nations throughout the Pacific during the $19^{\text {th }}$ century had the effect of erasing much Polynesian history. To counteract the erasure of history, this thesis was structured around the representations of Polynesian 'traditions,' said to be either a composite or an amalgam of European and Polynesian worldviews, in order to imply Polynesian agency as an integral part of the continuing adversarial frame of conquest. As such, specific myths, in terms of the contemporary expression of them, uncover the actual adversarial frame of conquest, as a binary and dialectical functional structure that defines the methods of conflict resolution available.

The representational dilemmas, or the impact of the myths perpetuated, whether they be with respect to the lost civilization on Easter Island, defending rape and underage sex on Pitcairn Island, attempting to counteract the negative impacts of excluding women as in the movie the 'Whale Rider,' or attempting to deal with the repercussions of environmental disaster/degradation and copyrighting culture, have all been reviewed. They are examples of the effects of a significant clash of worldviews emphasizing the same end result — the loss of human rights and the implementation of processes to control and contain Polynesian indigenous peoples.

The foundational ideas of the dominant worldview are also operational at the international level in such institutions as academia (e.g., anthropology, geography, tourism and indigenous studies inasmuch as they rely heavily upon the ethnographic enterprise), the United Nations (with regard to the Universal Declaration of Human Rights and Millennium Development Goals), and the Organization for Economic Cooperation and Development (as a economic development donor funding monitor). Likewise, the tourism industry, also dependent upon the ethnographic enterprise, 
discovered "the environment" (Hall 1994:136; see also McElroy and Albuquerque 2002:15), forcing a shift towards the implementation of 'sustainable development,' now a common theme in the tourism literature and international economic development aid projects around the world.

Hence the myths comprising the dominant worldview continue to subsume indigenous peoples in the concept of a nature that can be conquered at the same time as they guide governance practice, particularly those practices designed to manage the 'other.' Uncovering the myths serves another purpose as well: they shed light upon the multiple meanings contained in the recorded descriptions about how and why nature, women and indigenous people in general have been viewed, judged, processed and controlled in the past. Within this adversarial frame of reference, the question of who has agency given enforced inequality provides a much clearer picture of the range of choices available to enact successful strategies for change. Since the descriptive appearance of the 'others' agency is a critical element of contemporary governance practice, this thesis review was an attempt to refocus the analysis away from the controllers' stated intent, to the hidden meanings of the ideas and myths expressed in the descriptions of the 'other.' The next logical step then, it was argued here, is to identify ways to stop the historic nullification of Polynesian history and human rights.

The three related questions concerning the expansion of the largely foreign-owned tourism industry to include budget tourism (e.g., bed-and-breakfast; village home stays, etc.) in Tonga and Sāmoa, unfortunately, emphasize that their cultural identity is significantly structured by a European/western conception of their history, culture and future aspirations. Hence the opportunities for change to ensure they gain back the right 
to present their own perspective or worldview in the creation of their own cultural identity is extremely limited and will remain subject to the acceptance of the developed world. If positive change is to occur, it has nothing to do with Tongan and Sāmoan participation in, or negotiation of the future protection of their environments, cultural values, indigenous knowledge and cultural identities, but is a matter of those who have built the constraints abandoning the myths about who and what Polynesians are and their assumed right to decide Polynesians' future for them. 


\section{Bibliography}

Abdo, Nahla (ed.)

1996 "Emile Durkheim." pp 107-152, in Sociological Thought: Beyond Eurocentric Theory. Toronto: Canadian Scholars' Press.

Adger, W. Neil, Tor A. Benjaminsen, Katrina Brown and Hanne Svarstad

2000 Advancing a Political Ecology of Global Environmental Discourses. Centre for Social and Economic Research on the Global Environment (CSERGE) Working Paper GEC 2000-10.

Agarwal, Sheela, Rick Ball, Gareth Shaw and Allan M. Williams

2000 "The geography of tourism production: uneven disciplinary development?" Tourism Geographies, 2(3): 241-263.

Agrawal, Arun

1995 "Dismantling the Divide Between Indigenous and Scientific Knowledge." Development and Change, 26(3):413-440.

AhChing, Peter Leiataua

2003 Polynesian Origins and Migrations. John A. Burns School of Medicine, University of Hawaii. http://polynesianlineage.tripod.com/polynesians/index.html

Ames, Michael M.

1992 Cannibal Tours and Glass Boxes: The Anthropology of Museums. Vancouver: UBC Press.

Anderson, Joseph S. and Dean Howard Smith

1998 "Managing Tribal Assets: Developing Long-Term Strategic Plans." American Indian Culture and Research Journal, 22(3): 139-56.

Anderson, Peter

1990 "Aboriginal imagery: influence, appropriation, or theft?" Eyeline, 12: 8-11.

Apostolakis, Alexandros

2003 "The Convergence Process in Heritage Tourism." Annals of Tourism Research, 30(4): 795-812.

Atlapedia Online

2003 School use Country section and maps. Latimer Clarke Corporation. http://www.atlapedia.com/ 
Ayres, Ron

2002 "Cultural Tourism in Small-Island States: Contradictions and Ambiguities." pp 145-160, in Yorghos Apostolopoulos and Dennis J. Gayle (eds.), Island Tourism and Sustainable Development: Caribbean, Pacific, and Mediterranean Experiences. Westport, Connecticut: Praeger.

Banerjee, Tridib

2001 "The future of Public Space: Beyond Invented Streets and Reinvented spaces." Journal of the American Planning Association, 67(1): 9-24.

Beauvais, Caroline and Jane Jenson

2002 "Social Cohesion: Updating the State of Research." Canadian Policy Research Networks, Discussion Paper No. F|22 May 2002.

Bell, Claudia and John Lyall

2002 The Accelerated Sublime: Landscape, Tourism and Identity. Westport, Connecticut: Praeger Publishers.

Bellwood, Peter

1987 [1978]. “The Polynesians: Prehistory of an island people.” in Glyn Daniel (ed.) Volume 92, Ancient Peoples and Places. London: Thames and Hudson.

Berger, John

1972 Ways of Seeing. London: British Broadcasting Corporation and Penguin Books.

Berger, Peter L.

1987 Capitalism and Equality in America: Modern Capitalism volume 1. Peter L. Berger (ed.), Institute for Educational Affairs, New York: Hamilton Press.

Berno, Tracy

1996 "Cross-cultural research methods: content or context? A Cook Islands example." pp 376-395, in Richard Butler and Thomas Hinch (eds.), Tourism and Indigenous Peoples. London: International Thomson Business Press.

Blum, Douglas W.

2002 "Beyond Reciprocity: Governance and Cooperation around the Caspian Sea." pp 161-189, in Ken Conca and Geoffrey D. Dabelko (eds.), Environmental Peacemaking. Washington: Woodrow Wilson Center Press.

Bourdieu, Pierre

1987 "What Makes a Social Class? On The Theoretical and Practical Existence of Groups." Berkley Journal of Sociology: A Critical Review, 32: 1-18. 
Bourgeault, Ron G.

1983 "The Indian, the Métis and the Fur Trade: Class, Sexism and Racism in the Transition from "Communism" to Capitalism."

Studies in Political Economy, 12: 45-79.

Bowman, Glenn

1997 "Identifying versus identifying with 'the Other': reflections on the siting of the subject in anthropological discourse." pp 34-50, in Allison James, Jenny Hockey and Andrew Dawson (eds.), After Writing Culture: Epistemology and Praxis in Contemporary Anthropology. London: Routledge.

Briassoulis, Helen

2002 "Sustainable Tourism and the Question of the Commons." Annals of Tourism Research, 29(4): 1065-1085.

Broda-Bahm, Kenneth T.

1999 "Finding Protection in Definitions: the Quest for Environmental Security." Argumentation and Advocacy, 35: 159-170.

Brosius, J. Peter

1999 "Green Dots, Pink Hearts: Displacing Politics from the Malaysian Rain Forest." American Anthropologist, 101(1): 36-57.

Brown, Frances

1998 Tourism Reassessed: Blight or blessing? Oxford: Butterworth Heinemann.

Bruner, Edward M.

1989 "Of Cannibals, Tourists, and Ethnographers." Cultural Anthropology, 4(4): 438-445.

Buck, Peter H. (Te Rangi Hiroa)

1959 [1938]. Vikings of the Pacific. The University of Chicago Press.

Bunch, Charlotte

1992 "Feminist Visions of Human Rights in the Twenty-First Century." pp 967-977, Kathleen E. Mahoney and Paul Mahoney (eds.), Human Rights in the Twenty-first Century: A Global Challenge. Dordrecht: Martinus Nijhoff Publishers.

Campbell, I. C.

2003 "The Culture of Culture Contact: Refractions from Polynesia." Journal of World History, 14(1): 63-86.

Cartwright, Nancy

1999 The Dappled World: A study of the Boundaries of Science. Cambridge University Press. 
Chace, James

1995 “The Common Good." World Policy Journal, 12: 129-32.

Chambers, Robert

1983 “Two cultures of outsiders." pp 29-46, in Rural Development. Essex: Longman Scientific \& Technical, Longman Group UK Ltd.

1995 "Paradigm shifts and the practice of participatory research and development." pp 30-42, in Nici Nelson and Susan Wright (eds.), Power and participatory development: Theory and practice. London: Intermediate Technology.

Cheater, Angela and Ngapare Hopa

1997 "Representing Identity." pp 208-223, in Allison James, Jenny Hockey and Andrew Dawson (eds.), After Writing Culture: Epistemology and Praxis in Contemporary Anthropology. London: Routledge.

Cheong, So-Min and Marc L. Miller

2000 "Power and Tourism: A Foucauldian Observation." Annals of Tourism Research, 27(2): 371-390.

Clark, Liesl

2000 NOVA Online: Secrets of Easter Island. Sections: First inhabitants, Stone Giants, Navigation. http://www.pbs.org/wgbh/nova/easter/

Cleaver, Frances

1981 "Institutions, Agency and the Limitations of Participatory Approaches to Development." pp 36-55, in Bill Cooke and Uma Kothari (eds.), Participation: The new Tyranny? New York: St Martin's Press.

Clifford, James

1988 The Predicament of Culture: Twentieth-Century Ethnography, Literature, and Art. Cambridge, Mass.: Harvard University Press.

2001 “Indigenous Articulations." The Contemporary Pacific, 13(2): 467-490.

Coccossis, Harry

2002 "Island Tourism Development and Carrying Capacity." pp 131-143, in Yorghos Apostolopoulos and Dennis J. Gayle (eds.), Island Tourism and Sustainable Development: Caribbean, Pacific, and Mediterranean Experiences. Westport, Connecticut: Praeger.

Cohen, Erik

1995 "Contemporary tourism - trends and challenges: sustainable authenticity or contrived post-modernity?" pp 12-29, in Richard Butler and Douglas Pearce (eds.), Change in tourism: People, places, processes. London: Routledge. 
Collins, Simon

2004 'Bloodshed' if seabed bill passed, professor warns. The New Zealand Herald.

New Zealand News section. September 31, 2004.

http://www.nzherald.co.nz/storyqueryprocess.cfm?kw1=coastline \&kw2=crown\&t $\underline{\text { hesection }=\& \text { period }=\text { year } \& \text { day }=\& \text { month }=\& \text { year }=\& o p=a l l \& \text { searchorder }=2 \& \text { datedr }}$ op $=$ no\&start $=1 \&$ requesttimeout $=180$

Cordes, Joseph, Jeffrey R. Henig and Eric C. Twombly

2001 "Nonprofit Human Service Providers in an era of Privatization: Toward a Theory of Economic and Political Response." Policy Studies Review, 18(4): 91-110.

Craik, Jennifer

1991 Resorting to Tourism: Cultural Policies for Tourist Development in Australia. North Sydney: Allen \& Unwin.

Crew, Spencer R. and James E. Sims

1991 "Locating Authenticity: Fragments of a Dialogue." pp 159-175, in Ivan Karp and Steven D. Lavine (eds.), Exhibiting Cultures: the poetics and politics of Museum Display. Washington: Smithsonian Institution Press.

Crewe, Emma and Elizabeth Harrison

1998 "Technology and Expertise." pp 91-112, in Whose Development? An Ethnography of Aid. New York: Zed Books.

Crocombe, Marjorie Tuainekore

1994 "Women and Politics in Polynesia." pp 185-210, in Werner vom Busch, Marjorie Tuainekore Crocombe, Ron Crocombe, Linda Crowl, Tony Deklin, Peter Larmour, and Esther Winimamaori Williams (eds.), New Politics in the South Pacific. Institute of Pacific Studies, University of the South Pacific.

Daley, William M.

2000 "Commentary: Trade and the Environment After Seattle - Perspectives from the Wilson Center." Remarks excerpted from address at a Wilson Center Director's Forum on trade and the environment, sponsored by Environmental Change and Security Project, November 22, 1999. Environmental Change and Security Project Report, Issue 6.

Deem, Rosemary

1999 "How do we get out of the ghetto? Strategies for research on gender and leisure for the twenty-first century." Leisure Studies, 18: 161-177. 
definition.com

2004 free-definition.com:

Pacific Ocean: http://www.free-definition.com/Pacific-Ocean.html

Polynesia: http://www.free-definition.com/Polynesia.html

TheFreeDictionary.com:

Australasia: http://encyclopedia.thefreedictionary.com/Australasia

Oceania: http://encyclopedia.thefreedictionary.com/Oceania

de Rota Monter, José Antonio Fernández

1998 "Difference from the People's Point of View." pp 124-141, in Carol J.

Greenhouse (ed.) with Roshanak Kheshti, Democracy and Ethnography:

Constructing Identities in Multicultural Liberal States.

State University of New York Press.

Deudney, Daniel

1992 "The Mirage of Eco-War: The Weak Relationship among Global Environmental Change, National Security and Interstate Violence." pp 169-191, in Ian H. Rowlands and Malory Greene (eds.), Global Environmental Change and International Relations. London: MacMillan.

de Zengotita, Thomas

2003 Common Ground: Finding Our Way Back to the Enlightenment. Harper's Magazine, Jan/03.

Diamond, Jared

1995 "Easter Island's End." Discover Magazine. August 1995. http://www.hartford-hwp.com/archives/24/042.html

Donnelly, Jack

1998 International Human Rights, Second Edition: Dilemmas in World Politics. Boulder, Colorado: Westview Press.

Drage, Jean

1994 “The Exception, Not the Rule: Women's Political Activity in Pacific Islands Countries." pp 157-184, in Werner vom Busch, Marjorie Tuainekore Crocombe, Ron Crocombe, Linda Crowl, Tony Deklin, Peter Larmour, and Esther Winimamaori Williams (eds.), New Politics in the South Pacific. Institute of Pacific Studies, University of the South Pacific.

Drummond, Ian and Terry Marsden

1999 The Condition of Sustainability. Global Environmental Change Programme. London: Routledge.

Edensor, Tim

2000 "Staging Tourism: Tourists as Performers."

Annals of Tourism Research, 27(2): 322-344. 
Edwards, Michael, David Hulme, and Tina Wallace

2000 "Increasing Leverage for Development: Challenges for NGOs in a Global Future." pp 1-14, in D. Lewis and T. Wallace, eds., New Roles and Relevance. Boomfield, CT: Kumarian Press.

Escobar, Arturo

1991 "Anthropology and the development encounter: the making and marketing of development anthropology." American Ethnologist, 18(4): 658-81.

2001 "Culture Sits in Places: Reflections on Globalism and Subaltern Strategies of Localization." Political Geography, 20(1): 139-174.

Esping-Andersen, Gøsta

1993 "The Comparative Macro-Sociology of Welfare States." Part 1 European and International Contexts, pp 123-138, in Luis Moreno (ed.), Social Exchange and Welfare Development. Madrid: Consejo Superior de Investigaciones Científicas.

Esping-Andersen, Gøsta, Duncan Gallie, Anton Hemerijck, and John Myles

2001 A new Welfare Architecture for Europe? A Report commissioned by the Belgian Presidency of the European Union. September 2001. Summary document at: http://www.ccsd.ca/pubs/2002/europe.pdf Revised version expected to be published by Oxford University Press.

Esteva, Gustavo

1992 "Development." pp 6-25, in Wolfgang Sachs (ed.), The Development Dictionary: A Guide to Knowledge as Power. London: Zed Books Ltd.

Etienne, Mona

1980 "Women and Men, Cloth and Colonization: The Transformation of ProductionDistribution Relations among the Baule (Ivory Coast)." pp 214- 238, in Eleanor E. Leacock and Mona Etienne (eds.), Women and Colonization: Anthropological Perspectives. New York: Praeger.

Etienne, Mona and Eleanor E. Leacock

1980 "Introduction." pp 1- 24, in Eleanor E. Leacock and Mona Etienne (eds.), Women and Colonization: Anthropological Perspectives. New York: Praeger.

Evans-Pritchard, E.E.

1965 The Position of Women in Primitive Societies and Other Essays in Social Anthropology. London: Faber and Faber Lid. 
Firth, Raymond

1957 "A note on Descent Groups in Polynesia." Man, 57: 4-8.

1970 [1940]. "The Analysis of Mana: An empirical approach."

The Polynesian Society, 40: 483-510. pp 316-333, republished in Thomas G.

Harding and Ben J. Wallace (eds.), Cultures of the Pacific: Selected Readings.

New York: The Free Press.

Franklin, Adrian and Mike Crang

2001 "The trouble with tourism and travel theory?" Tourist Studies, 1(1): 5-22.

Freedom House

2004 Freedom House, a non-profit, non-partisan democracy watch group.

Country and Territory Reports. http://www.freedomhouse.org/index.htm

Galeski, Boguslaw

1976 "Conflict and Change as Aspects of Development." pp 151-166, in David C. Pitt (ed.), Development from Below: Anthropologists and Development Situations. Mouton Publishers.

Gardner, Katy and David Lewis

2000 "Dominant Paradigms Overturned or 'Business as Usual'? Development

Discourse and the White Paper on International Development."

Critique of Anthropology, 20(1): 15-29.

Gardner, Sarah Sturges

1995 "Major Themes in the Study of Grassroots Environmentalism in Developing Countries." Journal of Third World Studies, 12: 200-44.

Garland, Elizabeth

1999 "Developing Bushmen: Building Civil(ized) Society in the Kalahari and Beyond." pp 72-103, in J.L. Comaroff and J. Comaroff (eds.), Civil Society and the Political Imagination in Africa. Chicago: University of Chicago Press.

Gegeo, David Welchman

2001 "Cultural Rupture and Indigeneity: The Challenge of (Re)visioning 'Place' in the Pacific." The Contemporary Pacific, 13(2): 491-507.

Goldin, Ian, Halsey Rogers, and Nicholas Stern

2002 The Role and Effectiveness of Development Assistance: Lessons from World Bank Experience. pp 1-27, 69-71. A research paper from the Development Economics Vice Presidency of the World Bank. http://econ.worldbank.org/files/13080 Development Effectiveness.pdf 
Graburn, Nelson H.H.

2001 "Secular Ritual: A General Theory of Tourism." pp 42-52, in Valene L. Smith and Maryann Brent (eds.), Hosts and Guests Revisited: Tourism Issues of the $21^{\text {st }}$ Century. New York: Cognizant Communication Corporation.

Grünewald, Rodrigo de Azeredo

2002 “Tourism and Cultural Revival." Annals of Tourism Research, 29(4): 1004-1021.

Gupta, Akhil and James Ferguson

1992 "Beyond 'Culture': Space, Identity, and the Politics of Difference."

Cultural Anthropology, 7(1): 6-23.

Hall, C. Michael

1994 "Ecotourism in Australia, New Zealand and the South Pacific: Appropriate Tourism or a New Form of Ecological Imperialism?" pp 137-157, in Erlet Cater and Gwen Lowman (eds.), Ecotourism: A Sustainable Option? Chichester, West Sussex: John Wiley \& Sons.

Hamblin, W. Kenneth and Eric H. Christiansen

2001 Earth's Dynamic Systems. Ninth edition. pp 696-698.

Upper Saddle River, New Jersey: Prentice-Hall, Inc.

Hardy, Anne, Robert J.S. Beeton and Leonie Pearson

2002 "Sustainable Tourism: An Overview of the Concept and its Position in Relation to Conceptualisations of Tourism." Journal of Sustainable Tourism, 10(6): 475-496.

Harris, Marvin

1979 Cultural Materialism: The Struggle for a Science of Culture.

New York: Random House.

Harrison, Elizabeth

2002 "The Problem with the Locals': Partnership and Participation in Ethiopia." Development and Change, 33(4): 587-610.

Headland, Thomas N., Kenneth L. Pike, and Marvin Harris

1990 Emics and Etics: The Insider/Outsider Debate.

Newbury Park, California: Sage Publication.

Helu, 'I Futa

1994 "Thoughts on Political Systems for the Pacific Islands." pp 319-332, in Werner vom Busch, Marjorie Tuainekore Crocombe, Ron Crocombe, Linda Crowl, Tony Deklin, Peter Larmour, and Esther Winimamaori Williams (eds.), New Politics in the South Pacific. Institute of Pacific Studies, University of the South Pacific. 
Heyerdahl, Thor

1979 Early Man and the Ocean: A search for the beginnings of navigation and seaborne civilizations. New York: Doubleday \& Company Inc.

Hobsbawn, Erik and Terrence Ranger

1983 The Invention of Tradition. Cambridge University Press.

Hodgson, Dorothy and Richard Schroeder

2002 "Dilemmas of Counter-Mapping Community Resources in Tanzania."

Development and Change, 33(1): 79-100.

Hoggart, Keith, Loretta Lees and Anna Davies (eds.)

2002 Researching Human Geography. London: Arnold.

Holden, Andrew

2003 "In Need of New Environmental Ethics for Tourism?"

Annals of Tourism Research, 30(1): 94-108.

Hollinshead, Keith

1996 "Marketing and metaphysical realism: the disidentification Aboriginal life and traditions through tourism." pp 308-375, in Richard Butler and Thomas Hinch (eds.), Tourism and Indigenous Peoples. London: International Thomson Business Press.

Howard, Alan

1990 "Cultural Paradigms, History, and the Search for Identity in Oceania." pp259- 279, in Jocelyn Linnekin and Lin Poyer (eds.), Cultural Identity and Ethnicity in the Pacific. Honolulu: University of Hawaii Press.

Hughes, George

2002 "Environmental indicators." Annals of Tourism Research, 29(2): 457-477.

Hurles, Matthew, Jayne Nicholson, Elena Bosch, Colin Renfrew, Bryan C. Sykes and Mark A. Jobling

2002 "Y Chromosomal Evidence for the Origins of Oceanic-Speaking Peoples." Genetics, 160: 289-303.

Hunter, Colin

1995 "Key Concepts for tourism and the environment." pp 52-92, in Colin Hunter, and Howard Green (eds.), Tourism and the Environment: A sustainable relationship? London: Routledge.

2002 "Sustainable Tourism and the Touristic Ecological Footprint." Environment, Development and Sustainability, 4: 7-20. 
Hunter, Colin and Howard Green

1995 "The environmental impacts of tourism." pp 10-51, in Colin Hunter, and Howard Green (eds.), Tourism and the Environment: A sustainable relationship? London: Routledge.

Hviding, Edvard

2003 "Between Knowledges: Pacific Studies and Academic Disciplines."

The Contemporary Pacific, 15(1): 43-73.

Ihimaera, Witi

1998 "Introduction." Whiti Ihimaera (ed.), Growing Up Maori. Auckland: Tandem Press.

2002 Whale Rider. Movie: 105 min. Colour. Cast: Keisha Castle-Hughes, Cliff Curtis, Grant Roa, Rawiri Paratene and Vicky Haughton. Director: Niki Caro. Studio: Odeon Films. Producers: Tim Sanders, John Narnett. MPAA Rating: PG-13 for brief language and a momentary drug reference.

Tribute.ca Trailer clip: http://www.tribute.ca/movie spec/6888.htm

James, Allison, Jenny Hockey and Andrew Dawson

1997 "Introduction: The road from Santa Fe." pp 1-15, in Alison James, Jenny Hockey and Andrew Dawson (eds.), After Writing Culture: Epistemology and Praxis in Contemporary Anthropology. London: Routledge.

James, Kerry

2003 "Is There a Tongan Middle Class?: Hierarchy and Protest in Contemporary Tonga." The Contemporary Pacific, 15(2): 309-336.

Jasanoff, Sheila

1999 "Back to Basics in Environmental Politics."

Politics and the Life Sciences, 18(2): 227-9.

Jeannotte, M. Sharon

2002 Buying In or Dropping Out: The Public Policy Implications of Social Cohesion Research. Canadian Heritage presentation, September 20, 2002, Carleton University.

Joseph, Christina A.

2001 "Mediated Resistance: Tourism and the Host Community." Annals of Tourism Research, 28(4): 998-1009.

Josephides, Lisette

1997 "Representing the anthropologist's predicament." pp 16-33, in Allison James, Jenny Hockey and Andrew Dawson (eds.), After Writing Culture: Epistemology and Praxis in Contemporary Anthropology. London: Routledge. 
Karp, Ivan

1991 "Other Cultures in Museum Perspective." pp 373-385, in Ivan Karp and Steven D. Lavine (eds.), Exhibiting Cultures: the poetics and politics of Museum Display. Washington: Smithsonian Institution Press.

Keesing, Roger M.

1987 "Anthropology as Interpretive Quest." Current Anthropology, 28(2): 161-176.

Keller, Kenneth $\mathrm{H}$.

1996 "Unpacking the Environment." World Policy Journal, 13: 11-23.

King, Gary and Christopher J.L. Murray

2001 "Rethinking Human Security." Political Science Quarterly, 116(4): 585-610.

Krippendorf, Jost

1999 [1984] The Holiday Makers: Understanding the impact of leisure and travel. Oxford: Butterworth-Heinemann.

Krystek, Lee

1997 The Chilling Tale of Easter Island, The Unmuseum - Easter Island. http://www.unmuseum.org/easteri.htm

Latukefu, Sione

1992 "The History of the Tongan Constitution." Human Rights and Democracy Movement Convention. http://planet-tonga.com/HRDMT/Articles/Convention 92/Sione Latukefu.shtml

Lawson, Stephanie

1996 Tradition versus democracy in the South Pacific: Fiji, Tonga and Western Samoa. Cambridge University Press.

Leacock, Eleanor

1980 "Montagnais Women and the Jesuit Program for Colonization." pp 25-42, in Eleanor E. Leacock and Mona Etienne (eds.), Women and Colonization:

Anthropological Perspectives. New York: Praeger.

Levitas, Ruth

1998 The Inclusive Society? Social Exclusion and New Labour.

London: MacMillan Press.

Li, Tania Murray

2002 "Engaging Simplifications: Community Based Resource Management, Market Processes and State Agendas in Upland Southeast Asia." World Development, 30(2): 265-283. 
Limb, Melanie and Claire Dwyer (eds)

2001 Qualitative Methodologies for Geographers: Issues and debates.

London: Arnold.

Linnekin, Jocelyn

1990 "The Politics of Culture in the Pacific." pp149-174, in Jocelyn Linnekin and Lin Poyer (eds.), Cultural Identity and Ethnicity in the Pacific.

Honolulu: University of Hawaii Press.

1997 "Consuming Cultures: Tourism and the Commoditization of Cultural Identity in the Island Pacific." pp 215-250, in Michel Picard and Robert E. Wood (eds.), Tourism, Ethnicity, and the State in Asian and Pacific Societies.

Honolulu: University of Hawai' i Press.

Lise, Wietze and Richard S.J. Tol

2002 "Impact of Climate on Tourist Demand." Climate Change, 55: 429-449.

Lonely Planet

2004 Lonely Planet World Guide - Destinations.

http://www.lonelyplanet.com/destinations/loc-aus.htm

MacCannell, Dean

1989 [1976] The Tourist. New York: Schocken Books.

1992 Empty meeting grounds: The tourist papers. London: Routledge.

MacDonald, Sharon

1997 “A people's Story: Heritage, identity and authenticity." pp 155-175, in Chris Rojek and John Urry (eds.), Touring Cultures: Transformations of Travel and Theory. London: Routledge.

Marcus, George E.

1988 "Parody and the Parodic in Polynesian Cultural History." Cultural Anthropology, 3(1): 68-76.

Marcus, George E. and Fred R. Myers

1995 "The Traffic in Art and Culture: An Introduction." pp 1-51, in George E. Marcus and Fred R. Myers (eds.), The Traffic in Culture: Refiguring Art and Anthropology. University of California Press.

Marks, Kathy

2004 "Pitcairn trial hears a litany of child sex abuse." Oct. 3, 2004

"Island chief raped me when I was 11, Pitcairn trial told." Sept. 30, 2004

"Half of Pitcairn Island's adult male population goes on trial." Sept. 26, 2004

The New Zealand Herald. World News. 
Matthew, Richard A.

1998 "A Clean, Secure Future." Forum for Applied Research and Public Policy, 13(4): 115-19.

Matisoo-Smith, E and J.H. Robins

2004 "Origins and dispersals of Pacific peoples: Evidence from mtDNA phylogenies of the Pacific Rat." The National Academy of Sciences USA. 101(24):9167-9172. online: www.pnas.org

Matisoo-Smith, E., R. M. Roberts, G.J. Irwin, J. S. Allen, D. Penny, and D. M. Lambert 1998 "Patterns of prehistoric human mobility in Polynesia indicated by mtDNA from the Pacific rat." The National Academy of Sciences USA. 95:15145-15150. online: www.pnas.org

McBride, Stephen

2000 "Towards Permanent Insecurity: The Social Impact of Unemployment." Journal of Canadian Studies, 34(2): 13-30.

McCall, Grant

1994 [1980] Rapanui: Tradition and Survival on Easter Island. $2^{\text {nd }}$ edition. Honolulu: University of Hawaii Press.

McElroy, Jerome L. and Klaus de Albuquerque

2002 "Problems for Managing Sustainable Tourism in Small Islands." pp 15-47, in Yorghos Apostolopoulos and Dennis J. Gayle (eds.), Island Tourism and Sustainable Development: Caribbean, Pacific, and Mediterranean Experiences. Westport, Connecticut: Praeger.

McMurtry, John

2001 "The Life-Ground, the Civil Commons and the Corporate Male Gang." Canadian Journal of Development Studies, 22, special issue.

Mill, John Stuart and Harriet Taylor Mill

1970 [1832, 1851, 1869] Essays on Sex Equality. Edited by Alice S. Rossi. University of Chicago Press.

Mills, Sara

1991 Discourses of Difference: an analysis of women's travel writing and colonialism. London: Routledge.

Milne, Simon and Irena Ateljevic

2001 "Tourism, economic development and the global-local nexus: theory embracing complexity." Tourism Geographies, 3(4): 369-393.

Moss, Pamela (ed.)

2002 Feminist Geography in Practice: Research and Methods. Oxford: Blackwell. 
Mosse, David

2001 "Social Research in Rural Development Projects." pp. 159-181, in David N. Gellner and Eric Hirsch (eds.), Inside Organizations: Anthropologists at Work. Oxford: Berg.

Naidu, Vijay

2002 "Perspective on Poverty: South Pacific." Economic and Social Commission for Asia and Pacific. Meeting of the Advisory Panel on the ESCAP/UNDP Initiative to Support the Achievement of the Millennium Development Goals in Asia and the Pacific Region. 28 February -1 March 2002. Bangkok.

Neocleous, Mark

2000 “Against Security.” Radical Philosophy, March/April: 7-15.

Norwood, Vera and Janice Monk

1987 The Desert is No Lady: Southwestern Landscapes in Women's Writing and Art. Norwood, Vera and Janice Monk (eds.), Yale University.

OECD - Organisation for Economic Co-operation and Development.

1996 Shaping the $21^{\text {st }}$ Century statement, Introductory Summary - Values and Interests. http://www1.oecd.org/dac/htm/stc/intro.htm

Orange, Claudia

1987 The Treaty of Waitangi. Wellington, New Zealand: Bridget Williams Books Ltd.

Ortner, Sherry B.

2000 [1974] "Is Female to Male as Nature Is to Culture." pp 356-372, in R. Jon McGee and Richard L. Warms (eds.), Anthropological Theory: An Introductory history. Southwest Texas State University, Mayfield Publishing Co.

Osborne, B.

1998 "Constructing Landscapes of Power: The Georges Etienne Cartier Monument, Montreal. Journal of Historical Geography, 24(4): 431-458.

PCC - Polynesian Cultural Center

2004 Purpose and History of the Polynesian Cultural Center, Brigham Young University, Hawaii and the (Mormon) Laie Hawaii Temple. http://www.polynesia.com/purpose/purpose.html

Pearce, Susan

1990 "Objects as meaning; or narrating the past." pp 125-140, in Susan Pearce (ed.), Objects of Knowledge, London: The Athlone Press. 
PGS - NZAID Postgraduate Scholarship program

1986 Report of the BiCultural Commission on the Treaty of Waitangi. Relevant Source document: Alexander Turnbull Library, Richmond-Atkinson Papers, vol. 3, p.97, Acc. 77-253: J. Whiteley to C.W. Richmond, New Plymouth, 17 August 1857. http://www.massey.ac.nz/ plineham/pubs/ch3.doc

Phillips, Ruth B. and Christopher B. Steiner

1999 "Art, Authenticity, and the Baggage of Cultural Encounter." pp 1-19, in Ruth B. Phillips and Christopher B. Steiner (eds.), Unpacking Culture: Art and Commodity in Colonial and Postcolonial Worlds. Berkeley: University of California Press.

Pickrell, John

2004 "Rat DNA Offers Clues to Pacific Colonization, Study says." National Geographic News. June 9, 2004.

http://news.nationalgeographic.com/ search:Rat DNA

Pigram, John J.

1995 "Resource constraints on tourism: Water resources and sustainability." pp 208228, in Richard Butler and Douglas Pearce (eds.), Change in tourism: People, places, processes. London: Routledge.

Pinstrup-Andersen, Per

2001 Achieving Sustainable Food Security For All: Required Policy Action. Paper prepared for Mansholt Lecture, Wageningen University, The Netherlands, November 14, 2001.

PolitInfo

2004 US portal to world politics, human rights and foreign policy from an American perspective. http://us.politinfo.com/Information/ Human Rights/country report 2003 075.html

Porteous, J. Douglas

1981 The Modernization of Easter Island: Western Geographical Series Volume 19. Department of Geography, University of Victoria.

Rahnema, Majid

1992 "Poverty." pp 158-176, in Wolfgang Sachs (ed.), The Development Dictionary: A Guide to Knowledge as Power. London: Zed Books Ltd.

Rajotte, Freda

1980 "Tourism Impact in the Pacific." pp 1-14, in South Pacific Social Sciences Association and the Institute of Pacific Studies, Pacific Tourism: As Islanders see it. Fiji: The Fiji Times and Herald Ltd. 
Ramirez, Ricardo

1999 "Stakeholder analysis and conflict management." Daniel Buckles (ed.), Cultivating Peace: Conflict and Collaboration in Natural resource Management. IDRC/World Bank. http://www.irdc.ca/books/899/205ramir.htm

Rankin, Katherine

2001 "Governing Development: Neoliberalism, Micorcredit, and Rational Economic Woman." Economy and Society, 30(1): 18-37.

Rapport, Nigel

1997 "Edifying anthropology: culture as conversation; representation as conversation." pp 177-193, in Allison James, Jenny Hockey and Andrew Dawson (eds.), After Writing Culture: Epistemology and Praxis in Contemporary Anthropology. London: Routledge.

Redclift, Michael

2001 "Environmental Security and the Recombinant Human: Sustainability in the Twenty-first Century." Environmental Values, 10: 289-299.

Reynolds, Keven and Tim Rose Price

1994 Rapa Nui. Movie: 107 min. Colour. Director: Kevin Reynolds. Screenplay: Tim Rose Price. Stars: George Henare, Sandrine Holt, Jason Scott Lee, Esai Morales, Eru Potaka-Dewes. Studio: Warner Studios. Rating: R. New York Times Trailer clip: http://movies2.nytimes.com/gst/movies/trailer.html?v id=133413

Rivera, Luis N.

1992 [1990] A violent Evangelism: The Political and Religious Conquest of the Americas. Translation Westminister: John Knox Press.

Rocheleau, Diane

2001 "Complex Communities and Relational Webs: Uncertainty, Surprise and Transformation in Machakos." IDS Bulletin, 32(4): 78-86.

Rojek, Chris and John Urry

1997 "Transformations of Travel and Theory." pp 1-22, in Chris Rojek and John Urry (eds.), Touring Cultures: Transformations of Travel and Theory. London: Routledge.

Rosaldo, Renato

1989 Culture \& Truth: The remaking of Social Analysis. Boston: Beacon Press.

Rose, Gillian

1993 "Looking at Landscape: The Uneasy Pleasures of Power." pp 86-112, in Feminism and Geography: The Limits of Geographical Knowledge. University of Minnesota Press. 
Rout, Ettie A. and Hohepa Te Rake

1926. Maori Symbolism. New York: Harcourt.

Routledge, Katherine

1998 [1919] The Mystery of Easter Island. Illinois: Adventures Unlimited Press.

Sachs, Wolfgang

1992 "Environment." pp 26-37, in Wolfgang Sachs (ed.), The Development Dictionary: A Guide to Knowledge as Power. London: Zed Books Ltd.

Sahlins, Marshall D.

1985 "Hierarchy and humanity in Polynesia." pp 195-217, in Anthony Hooper and Judith Huntsman. (eds.), Transformation of Polynesian Culture. Auckland: The Polynesian Society.

Sāmoa - Government of Sāmoa, Department of Lands, Surveys and Environment 1999 First National Communication to the UNFCCC. A PICCAP-GEP funded project. Prepared by Sāmoa's National Climate Change Country Team. Apia, October.

Scheyvens, Regina

2002 "Backpacker Tourism and Third World Development." Annals of Tourism Research, 29(1):144-164.

Sharp, Andrew

1970 [1961] "Polynesian Navigation to Distant Islands." The Polynesian Society, 70(2): 221-226. pp 13-19, republished in Thomas G. Harding and Ben J. Wallace (eds.), Cultures of the Pacific: Selected Readings. New York: The Free Press.

Shiva, Vandana

1992 "Resources." pp 206-218, in Wolfgang Sachs (ed.), The Development Dictionary: A Guide to Knowledge as Power. London: Zed Books Ltd.

Shore, Bradd

1989 "Mana and Tapu." pp 137-173, in Alan Howard and Robert Borofsky (eds.), Developments in Polynesian Ethnology. Honolulu: University of Hawaii Press.

Shweder, Richard A.

1984 "Preview: A Colloquy of Culture Theorists." pp 1-24, in Richard A. Shweder and Robert A. LeVine (eds.), Culture Theory: Essays on Mind, Self, and Emotion. Cambridge University Press.

Smith, Anthony D.

1990 "Towards a Global Culture?" Theory, Culture \& Society, 7: 171-191. 
Smith, Lisa C., Amani E. El Obeid, and Helen H. Jensen

2000 "The geography and causes of food insecurity in developing countries." Agricultural Economics, 22: 199-215.

Smith, Valene L.

1996 "Indigenous tourism: the four Hs." pp 283-307, in Richard Butler and Thomas Hinch (eds.), Tourism and Indigenous Peoples.

London: International Thomson Business Press.

Smith, Valene L. and Maryann Brent

2001 "Introduction." pp 1-14, in Valene L. Smith and Maryann Brent (eds.), Hosts and Guests Revisited: Tourism Issues of the $21^{\text {st }}$ Century.

New York: Cognizant Communication Corporation.

Sönmez, Sevil

2002 "Sustaining Tourism in Islands under Sociopolitical Adversity." pp 161-180, in Yorghos Apostolopoulos and Dennis J. Gayle (eds.), Island Tourism and Sustainable Development: Caribbean, Pacific, and Mediterranean Experiences. Westport, Connecticut: Praeger.

Spiro, Melford E.

1984 "Some Reflections on cultural determinism and relativism with special reference to emotion and reason." pp 323-346, in Richard A. Shweder and Robert A. LeVine (eds.), Culture Theory: Essays on Mind, Self, and Emotion. Cambridge University Press.

Stanley, David

1999 Moon Handbooks Tonga-Samoa. $1^{\text {st }}$ edition. Moon Travel Handbooks. http://www.southpacific.org/tonga.html

Stoler, Anne L.

2000 [1989] "Making Empire Respectable: The Politics of Race and Sexual Morality in Twentieth-Century Colonial Cultures." pp 444-466, in R. Jon McGee and Richard L Warms (eds.), Anthropological Theory: An Introductory history. Southwest Texas State University, Mayfield Publishing Co.

Strain, Ellen

2003 Public Places, Private Journeys: Ethnography, Entertainment, and the Tourist Gaze. New Brunswick: Rutgers University Press.

Suvantola, Jaakko

2002 Tourist's Experience of Place. Chippenham, Wiltshire: Antony Rowe Ltd.

Swain, Ashok

2002 "Environmental Cooperation in South Asia." pp 61-85, in Ken Conca and Geoffrey D. Dabelko (eds.), Environmental Peacemaking. Washington, D.C.: Woodrow Wilson Center Press. 
Swatuk, Larry A.

2002 "Environmental Cooperation for Regional Peace and Security in Southern Africa." pp 120-160, in Ken Conca and Geoffrey D. Dabelko (eds.), Environmental Peacemaking. Washington, D.C.: Woodrow Wilson Center Press.

Takahashi, Akira

1997 "Ethics in Developing Economies of Asia." Business Ethics Quarterly, 7: 33-45.

Taufe'ulungaki, 'Ana Maui

1992 "Women, Politics and Democracy in Tonga." Human Rights and Democracy Movement Convention. http://planet-

tonga.com/HRDMT/Articles/Convention_92/Ana Taufeulungaki.shtml

Taylor-Gooby, Peter

2001 "Sustaining State Welfare in Hard Times: who will foot the bill?" Journal of European Social Policy, 11(2): 133-147.

Teo, Peggy

2002 "Striking a Balance for Sustainable Tourism: Implications of the Discourse on Globalisation." Journal of Sustainable Tourism, 10(6): 459-474.

Terkenli, Theano S.

2002 "Landscapes of tourism: towards a global cultural economy of space?" Tourism Geographies, 4(3): 227-254.

Thaman, Konai Helu

2003 "Decolonizing Pacific Studies: Indigenous Perspectives, Knowledge, and Wisdom in Higher Education." The Contemporary Pacific, 15(1): 1-17.

THE EDGE

2002 "Fotsam and Jetsam: Tuvalu and Greenpeace sue US for global warming." September 20, 2002. The Edge: Environmental News from the Brink, and Initiative of Earth Island Institute.

http://www.earthisland.org/project/newsPage2.cfm?newsID=237\&pageID=177\&s $\underline{\mathrm{ubSite} I \mathrm{D}=44}$

Thomas, Nicholas

1991 Entangled Objects: Exchange, Material Culture, and Colonialism in the Pacific. Cambridge: Harvard University Press. 
TRCNZ - Tourism Research Council, New Zealand Government, Office of Tourism and Sport

2001 A Summary of the report: He Mãtai Tāpoi Māori: A Study of Barriers, Impediments and Opportunities for Māori in Tourism prepared by Te Puni Kökiri and the Office of Tourism and Sport from the original 4 July 2001 report by The StaffordGroup. http://www.maf.gvt.nz/mafnet/publications/ruralbulletin/october2001/0ctober-01-03.htm

2003 Maori Economic Development: Te Ohanga Whanaketanga Maori. NZ Institute of Economic Research (NZIER). www.nzier.org.nz

Tsing, Anna

2000 "Inside the Economy of Appearances." Public Culture, 12(1): 115-144.

Turner, Stephen

2002 "Sovereignty, or the Art of Being Native." Cultural Critique, 51: 74-100.

UN - United Nations

1987 Human Rights: Questions and Answers. New York: United Nations.

1997 Human Rights: a compilation of international instruments. New York: United Nations.

UNESCAP - United Nations Economic and Social Commission for Asia and the Pacific 2000 Ministerial Conference on Environment and Development in Asia and the Pacific 2000, Kitakyushu, Japan 31 August - 5 September 2000.

(a) Review of the state of the environment in Asia and the Pacific. Full Report: http://www.unescap.org/mced2000/pacific/SoE-pacific.htm

(b) Review of implementation of the Programme of Action for Sustainable Development of small island developing states and the regional action programme for environmentally sound and sustainable development, 1996-2000: Pacific Perspective. http://www.unescap.org/mced2000/pacific/review.htm

2001 Regional Action Programme for Environmentally Sound and Sustainable Development 2001-2005. http://www.unescap.org/mced2000/rap2001-2005.pdf

UNIFEM Pacific

2004 "The Squash Industry in Tonga." http://www.unifempacific.com/resources/publications/considerations/squash.htm

Urry, John

1995 Consuming Places. London: Routledge.

2002 [1990] The Tourist Gaze. Second edition. London: Sage Publications. 
Vaiao, Leiataua and Fay Alailima

1994 "Restructuring Samoa's Chiefdom." pp 247-269, in Werner vom Busch, Marjorie Tuainekore Crocombe, Ron Crocombe, Linda Crowl, Tony Deklin, Peter Larmour, and Esther Winimamaori Williams (eds.), New Politics in the South Pacific. Institute of Pacific Studies, University of the South Pacific.

VanDerhaegen, Jean-Christophe

2001 Rapa Nui Syndrome. translated by Jacques Guy, copywrite: David Y. Brookman. http://www.netaxs.com/ trance/linklist.html and http://www.netaxs.com/ trance/jean.html

VanDeveer, Stacy D.

2002 "Environmental Cooperation and Regional Peace: Baltic Politics, Programs, and Prospects." pp 23-60, in Ken Conca and Geoffrey D. Dabelko (eds.),

Environmental Peacemaking. Washington, D.C.: Woodrow Wilson Center Press.

Vertovec, Steven

1997 Social Cohesion and Tolerance. A discussion paper prepared for the Second International Metropolis conference, Copenhagen, September 25-27, 1997.

Visser, Jelle

2000 "From Keynesianism to the Third Way: Labour Relations and Social Policy in Postwar Western Europe." Economic and Industrial Democracy, 21(4): 421-456.

Walker, Ranginui

1990 Ka Whanwhai Tonu Matou: Struggle without end. Auckland: Penguin Books.

Walzer, Michael

2000 “The Civil Society Argument." pp 89-107, in Chantal Mouffe (ed.), Dimensions of radical Democracy: Pluralism, Citizenship and Community. London: Routledge.

Wark, Penny

2004 "When the ultimate taboo isn't." Reprint from the London Times. The Ottawa Citizen, Saturday Observer. October 2, 2004.

Wearing, Stephen and Betsy Wearing

2001 "Conceptualizing the selves of tourism." Leisure Studies, 20:143-159.

Weinthal, Erika

2002 "The Promises and Pitfalls of Environmental Peacemaking in the Aral Sea Basin." pp 86-119, in Ken Conca and Geoffrey D. Dabelko (eds.), Environmental Peacemaking. Washington, D.C.: Woodrow Wilson Center Press. 
Weston, Burns H.

1992 "Human Rights." pp 14-31, in Richard Pierre Claude and Burns H. Weston (eds.), Human Rights in the World Community: Issues and Action. $2^{\text {nd }}$ edition. Philadelphia: University of Pennsylvania Press.

White, Geoffrey M. and Ty Kawika Tengan

2001 "Disappearing Worlds: Anthropology and Cultural Studies in Hawai' $i$ and the Pacific." The Contemporary Pacific, 13(2): 381-416.

Wilbanks, Thomas J. and Robert W. Kates

1999 "Global Change in Local Places: How Scale Matters." Climate Change, 43: 601-628

Wilson, William Julius

1996 "When Work Disappears." Political Science Quarterly, 111: 567-95.

Wolf, Eric R.

1997 [1982] Europe and the People without history.

Berkley: University of California Press.

Wood, Robert E.

1997 "Tourism and the State: Ethnic Options and Constructions of Otherness." pp 1-34, in Michel Picard and Robert E. Wood (eds.), Tourism, Ethnicity, and the State in Asian and Pacific Societies. Honolulu: University of Hawai'i Press.

Yohe, Gary and Richard S.J. Tol

2002 "Indicators for social and economic coping capacity - moving toward a working definition of adaptive capacity." Global Environmental Change, 12: 25-40.

Young, Audrey and NZPA

2004 Power of veto under debate. The New Zealand Herald. News Sept. 31, 2004. http://www.nzherald.co.nz/storyqueryprocess.cfm?kw1=coastline\&kw2=crown\&t hesection=\&period=year\&day $=\&$ month $=\&$ year $=\& o p=a l l \&$ searchorder $=2 \&$ datedr op $=$ no\&start $=1 \&$ requesttimeout $=180$

Zincone, Giovanna, and John Agnew

2000 "The Second Great Transformation: The Politics of Globalisation in the Global North." Space and Polity, 4(1): 5-21.

Zinn, Howard

1990 "The Use and Abuse of History." pp 48-66, in Declarations of Independence: cross-examining American ideology. New York: Harper Collins Publishers.

Zweers, Wim

2000 Participating with Nature: Outline for an Ecologization of our World View.

Utrecht, The Netherlands: International Books. 